ANÁLISE DA DURABILIDADE, RETENÇÃO E TENSÃO EM OVERDENTURES RETIDAS POR IMPLANTES ASSOCIADAS OU NÃO A MINI-IMPLANTES POSTERIORES 



\section{ANÁLISE DA DURABILIDADE, RETENÇÃO E TENSÃO EM OVERDENTURES RETIDAS POR IMPLANTES ASSOCIADAS OU NÃO A MINI-IMPLANTES POSTERIORES}

Tese apresentada à Faculdade de Odontologia de Ribeirão Preto da Universidade de São Paulo para obtenção do título de Doutor em Odontologia pelo Programa de Pós-Graduação em Reabilitação Oral.

Área de Concentração: Reabilitação Oral Orientadora: Prof ${ }^{a}$. Drª . Renata Cristina Silveira Rodrigues Ferracioli

VERSÃO CORRIGIDA

Ribeirão Preto 
Autorizo a reprodução e divulgação do teor total ou parcial deste trabalho, por qualquer meio convencional ou eletrônico, para fins de estudo e pesquisa, desde que citada à fonte.

\section{FICHA CATALOGRÁFICA}

Elaborada pela Biblioteca Central do Campus USP - Ribeirão Preto Alves, Suleima do Vale

Análise da durabilidade, retenção e tensão em overdentures retidas por implantes associadas ou não a mini-implantes posteriores. Ribeirão Preto, 2017.

135 p. : il. ; $30 \mathrm{~cm}$

Tese de Doutorado apresentada à Faculdade de Odontologia de Ribeirão Preto/USP. Área de concentração: Reabilitação Oral.

Versão corrigida da tese. A versão original se encontra disponível na Unidade que aloja o Programa.

Orientadora: Renata Cristina Silveira Rodrigues Ferracioli.

1. Implante dentário 2. Overdenture 3. Força de retenção 4. Attachment 5. Mini-implantes. 
SULEIMA DO VALE ALVES

\section{ANÁLISE DA DURABILIDADE, RETENÇÃO E TENSÃO EM OVERDENTURES RETIDAS POR IMPLANTES ASSOCIADAS OU NÃO A MINI-IMPLANTES POSTERIORES}

Tese apresentada á Faculdade de Odontologia de Ribeirão Preto da Universidade de São Paulo para obtenção do título de Doutor em Odontologia pelo Programa de Pós-Graduação em Reabilitação Oral Área de Concentração: Reabilitação Oral.

Orientadora: Prof ${ }^{-a}$ Dr ${ }^{\text {a }}$. Renata Cristina Silveira Rodrigues Ferracioli

\section{BANCA EXAMINADORA}

$\operatorname{Prof}(\mathrm{a}) \cdot \operatorname{Dr}(\mathrm{a}) \cdot$ :

Instituição:

Julgamento: Assinatura:

$\operatorname{Prof}(\mathrm{a}) \cdot \operatorname{Dr}(\mathrm{a}) \cdot:$

Instituição:

Julgamento: Assinatura:

$\operatorname{Prof}(\mathrm{a}) \cdot \operatorname{Dr}(\mathrm{a}) .:$ Instituição: Julgamento: Assinatura:

A Comissão Julgadora dos trabalhos de defesa da Tese, como parte dos requisitos para obtenção do título de Doutor, em sessão pública realizada na cidade de Ribeirão Preto, em 1 considerou o canditado: 

“'Alguns homens vêem as coísas como são, e dizem 'Por quê?' $\mathcal{E} u$ sonho com as coisas que nuncam foram e digo 'Por que não?' " (Geroge Bernard Shaw) 



\section{Dedicatóría}

Agradeço aos meus pais Décio e Tereza, hoje é um dos dias mais marcantes na minha vída. Hoje, eu cumpro maís uma missão, e tenho muito ou tudo a agradecer a vocês. Vocês se sacrificaram, se dedicaram, abdicaram de tempo e de muitos projetos pessoais para que eu tivesse a oportunidade de estudar e de ter uma boa formação profissional, mas também pessoal. Eu devo tudo que sou a vocês, e se sinto orgulho de mim e do lugar onde cheguei, é porque sei que vocês vieram segurando a minha mão. $\mathcal{E}$ agradeço por me darem a vida e me ensinar a vivê-la com dígnidade e nunca desistír dos obstáculos no caminho. Eu dedico este título a vocês. Obrigada meu pai e minha mãe!

Sem vocês, nada disso sería possivel. Eu os amo!

Ao meu irmão Danilson, e à minha cunhada, Alessandra, por estarem sempre torcendo pelas minhas vitórías. Fico feliz por serem felizes, fico feliz por sempre estarem perto e me ajudar quando preciso, mas com certeza fiquei mais feliz quando chegou a princesa Alice, o melhor sentimento, amor de ser tía.

Agradeço a Deus pela vida! Por sempre me conceder sabedoria nas escothas dos methores caminhos, coragem para acreditar e força para encarar as dificuldades do cotidiano. Agradeço também pelas pessoas que o Senhor colocou em meu caminho, que me inspiram, me ajudam, me desafiam a ser cada dia methor. Foi a minha jornada de tropeços, vitórias e derrotas, que me fez enxergar o verdadeiro significado e da vída. Abençoa-me com boa saúde, paz e alegría. 
Quero agradecer ao meu marido Lucas, por ser esse homem maravithoso e dedicado. Pelos momentos em que chorei e você veio carinhosamente me beijou e me fez sorrir, em que perdir a paciência e você veío com palavras amenas e doces e me acalmou, de alegría que fez questão de dividir comigo, pelos momentos que com muita esperança, pensou junto comigo no nosso futuro. Amor, você não imagina a gratidão imensa que invade o meu coração pela maravilhosa dádiva com que fui abençoada e que você tornou possivel, a nossa filha, o fruto do nosso amor, transformou meu mundo em felicidade perfeita. Obrigada meu amor, meu marido, eu te agradeço por esse presente que é a mais gostosa das concretizações e a plena realização de um sonho - a nossa María Luiza.

Sou grata porque fui abençoada com uma nova família, de pessoas únicas com quem posso compartithar a vida. Obrigada Elza, Vicente, Lorena, Luiz Humberto, Letícia e Scott, e principalmente pelos amores da titia, Henrique e Jack. Obrigada pricipalmente pela compreensão de não conseguir estar presente em alguns momentos, e mesmo assim torcerem para que eu pudesse chegar até aqui. 


\section{Agradecimento Especial}

$\mathcal{A}$ minha orientadora Profa $\mathcal{D r}^{a}$ Renata Cristina Silveira Rodrigues

Ferracioli pela confiança em mím depositada, pela compreensão, consethos e dedicação. Por me ajudar a descobrir o que fazer de methor e, assim, fazê-lo cada vez methor. Me estendeu as mãos mesmo antes de me orientar, acreditou em mim e hoje estou aqui realizando um sonho.

Obrigada por me ensinar as coisas e ter compreensão e paciêncía durante períodos maís complicados. Obrigada por tudo!

Agradeço ao meu co-orientador Profo $^{\circ} \mathcal{D} r^{o}$ Ricardo Faría Ribeiro pelo acolhimento, preocupação e estar sempre disponivel. Professor, a sua ajuda foi fundamental na execução deste trabalho, faz o seus orientados se sentirem capazes e seguir em frente sempre, sem medo dos obstáculos.

À engenheira e amiga Ana Paula Macedo, sua amizade foi essencial nesses anos de convivêncía. Obrigada por ter me ouvido nos momentos de angústía e medo, por ter confíado em mim, pelos elogios e incentivos. Durante toda minha vida, muitas pessoas passaram por mím, día após día. Mas somente algumas dessas pessoas, ficaram para sempre em minha memóría. Essas pessoas são ditas amigas, e as levarei para sempre em meu coração, você é uma delas. Continue sendo essa pessoa cativante e prestativa. Muito obrigada! 



\section{Agradecimentos}

$\mathcal{A}$ Faculdade de Odontología de Ribeirão Preto da Universidade de São Paulo pela oportunidade de poder executar minha pós-graduação.

Ao Departamento de Materiais Dentários e Prótese da FORP-USP, e principalmente ao Laboratórío de Estudos Biomecânicos em Prótese e Implante, por oferecer todos os equipamentos necessários para o desenvolvimento dessa pesquísa e a todos os integrantes.

À Adriana C. Lapría Faría Queiroz, pela convivência, conselhos e prestatividade durante a realização deste trabalho, foi fundamental.

As secretárías do departamento de Materiais Dentários e Próteses Fernanda Talita, Regiane e Deníse, e as secretárías do serviço de pósgraduação pela disponibilidade e atenção.

Aos professores membros da banca examinadora, pela disponíbilidade em avaliar meu trabalho.

$\mathcal{A}$ todos os técnicos de laboratório pela ajuda na execução de trabalhos, principalmente ao Júlio, Sérgio, Fernando, Paulo Sérgio, José de Godoy e $\mathcal{M}$ arcelo, auxílio imprescindivel e sempre de forma atenciosa.

As professoras Profa $\mathcal{D r}^{a}$ María da Glóría Chiarello de Mattos e Profa $\mathcal{D} r^{a}$ Valéría Oliveira Pagnano de Souza pela amizade e auxílio. $\mathcal{A}$ todos os colegas de pós-graduação que de alguma forma participaram de momentos importantes dessa jornada. 
Obrigada a colega Maria Paula Della Vechia, sua parceria e ajuda foi essencial na execução e finalização do trabalho. $\mathcal{E}$ a todos os colegas do Caboratório, Bruna, Lívia, Danilo, Renata, Cristian, Raniel pela convivêncía diáría, amizade e apoio durante estes anos.

Agradeço a amizade, ajuda e compressão das minhas amigas Juliana e Laila, o carisma e companheirismo de vocês são essenciais na minha jornada.

Obrigada a todos os amigos que a pós-graduação me presenteou e que de alguma forma participaram desta fase da minha vida.

$\mathcal{A}$ CAPES pela bolsa concedida durante o doutorado.

$\mathcal{A}$ Singular Implants pela disponibilização de material e incentivo à pesquisa científica.

... a todos que direta ou indiretamente contríbuiram para a realização deste trabalho...conseguindo finalizar essa etapa da minha vida. 



\section{Alves, SV. Análise da Durabilidade, Retenção e Tensão em Overdentures}

Retidas por Implantes Associadas ou não a Mini-Implantes Posteriores. 2017. 135p. Tese (Doutorado em Reabilitação Oral) - Faculdade de Odontologia de Ribeirão Preto, Universidade de São Paulo, Ribeirão Preto, 2017.

O objetivo desse estudo in vitro foi analisar a durabilidade, retenção e tensão gerada nos implantes de overdenture retidas por sistema bola/O'ring ou barra/clipe, associados ou não a mini-implantes na região posterior da mandíbula. Foram utilizados implantes anteriores cone-Morse $(3,75 \times 11 \mathrm{~mm})$ e mini-implantes de corpo único $(2 \times 10 \mathrm{~mm})$ e os grupos divididos em ( $n=12)$ : G2O: overdenture sobre 2 implantes com bola/O'rings; G1B: overdenture sobre 2 implantes com barra/clipe; G4O: overdenture sobre 2 implantes com bola/O'rings e 2 mini-implantes na região posterior; G1B2O: overdenture sobre 2 implantes com barra/clipe e 2 mini-implantes na região posterior. Para avaliação qualitativa das áreas de compressão e/ou tração nos modelos em poliuretano, foi realizado o método de correlação de imagens digitais, com carregamento oclusal $(300 \mathrm{~N})$ e pontual $(250 \mathrm{~N})$ com captura em vista frontal e lateral dos modelos experimentais. Foi realizado ensaio de fadiga acelerada progressiva com cargas de $80 \mathrm{~N}, 140 \mathrm{~N}, 200 \mathrm{~N}, 260 \mathrm{~N}, 320 \mathrm{~N}$ e $380 \mathrm{~N}$, frequência de $5 \mathrm{~Hz}$, totalizando 120.000 ciclos. Para avaliação da retenção os modelos foram submetidos a ensaio de tração previamente a termociclagem (Tempo 1), após $200 \mathrm{~N}$ (Tempo 2) e após $380 \mathrm{~N}$ (Tempo 3) e a força de retenção foi registradas em triplicata e a média obtida em cada tempo. A análise da durabilidade dos componentes retentivos foi realizada após os ensaios de tração nos tempos determinados por microscopia óptica. As imagens da aplicação de carga oclusal, mostraram que as tensões nos grupos 1B e 1B2O foram semelhantes, nos grupos 20 e 40 apresentaram tensões de tração na região anterior, porém no grupo 40 houve melhor distribuição por toda área analisada. $\mathrm{Na}$ aplicação de carga pontual, todos os modelos apresentaram tensões de compressão na região posterior e de tração na anterior, porém com maior intensidade nos modelos 20 e 40 , e menor intensidade nos modelos 1B e 1B2O. Nas análises sobre a retenção dos componentes, não houve diferença significativa $(p<0,05)$ entre os grupos $1 \mathrm{~B}-1 \mathrm{~B} 2 \mathrm{O}$, porém houve diferença significativa entre os grupos $2 \mathrm{O}-4 \mathrm{O}$, notando maior força retentiva no grupo 40 . As comparações entre os grupos, $1 \mathrm{~B}-2 \mathrm{O}$ e $1 \mathrm{~B} 2 \mathrm{O}-4 \mathrm{O}$ houve diferença significativa, sendo que os grupos com sistema barra/clipe obtiveram maior retenção que os grupos com O'rings. Nas imagens microscópicas não houve diferença significativa na estrutura interna dos O'rings, porém houve diferença significativa nos clipes. Conclui-se que a durabilidade, retenção e distribuição de tensão não se altera com a colocação de mini-implantes posteriores em overdentures com sistema retentivo barra/clipe. Com sistema retentivo bola/O'ring a instalação de mini-implantes aumentou a força de retenção e favoreceu a distribuição das tensões, reduzindo a alavanca para posterior.

Palavras chaves: Implante dentário. Overdenture. Força de retenção. Attachment. Miniimplantes. 




\section{Alves, SV. Durability, Retention and Stress Analysis of Implants-retained Overdentures Associated or not to Posterior Mini-Implants. 2017. 135p. Tese (Doutorado em Reabilitação Oral) - Faculdade de Odontologia de Ribeirão Preto, Universidade de São Paulo, Ribeirão Preto, 2017.}

The purpose of this in vitro study was to analyze the durability, retention and strength caused for implants-retained overdentures by ball/O-ring system or bar/clip, associated or not miniimplants in the posterior region of the mandible. Anterior Morse taper connection implants $(3.75 \times 11 \mathrm{~mm})$ and single-body mini-implants $(2 \times 10 \mathrm{~mm})$ were used and the groups divided to ( $n=12)$ : G2O: implants-retained overdentures 2 implants with ball/O-rings ; G1B: implantsretained overdentures 2 bar/clip implants; G4O: implants-retained overdentures 2 implants with ball/O-rings and 2 mini-implants in the posterior region ; G1B2O: implants-retained overdentures 2 implants with bar/clip and 2 mini-implants in the posterior region. For the qualitative evaluation of compression and/or traction areas in polyurethane models, a digital image correlation method (DIC) with occlusal $(300 \mathrm{~N})$ and punctual $(250 \mathrm{~N})$ loading was applied with frontal and lateral views of the experimental models. An accelerated progressive fatigue test with loads of $80 \mathrm{~N}, 140 \mathrm{~N}, 200 \mathrm{~N}, 260 \mathrm{~N}, 320 \mathrm{~N}$ and $380 \mathrm{~N}$, frequency of $5 \mathrm{~Hz}$, completing120,000 cycles. In order to evaluate the retention force, the models were submitted to traction force, previously to thermocycling (Time 1) after $200 \mathrm{~N}$ (Time 2) and posteriorly $380 \mathrm{~N}$ (Time 3), being the retention force recorded in triplicate. The durability analysis, by optic microscopy, of the retentive components was performed after the traction tests at the determined times. The application images of the occlusal load, showed that the stress in groups 1B and 1B2O were similar, in groups 20 and 40 presented stress in the anterior region, but in the 40 group, there was better distribution throughout the analyzed area. In the application of punctual loading, all the models presented compression tensions in the posterior region and traction in the anterior one, but with greater intensity in the $2 \mathrm{O}$ and 40 models, and lower intensity in the $1 \mathrm{~B}$ and $1 \mathrm{~B} 2 \mathrm{O}$ models. In the retention analyzes of the components, there was no significant difference $(p<0.05)$ between groups 1B-1B2O, but there was a significant difference between groups $20-40$, noting a higher retentive force in the $4 \mathrm{O}$ group. The comparisons between the groups, $1 \mathrm{~B}-2 \mathrm{O}$ and $1 \mathrm{~B} 2 \mathrm{O}-4 \mathrm{O}$ showed a significant difference, and the groups with bar/clip systems obtained higher retention than the groups with O-rings. In the microscopic images, there was no significant difference in the Oring's internal structure, but there was a significant difference in the clips' images. It was concluded that the durability, retention and stress distribution do not change with the placement of posterior mini-implants in overdentures with retentive bar/clip system. With retentive system ball/O-ring the installation of mini-implants increased the retention force and favored much the distribution of the stress, thus reducing the forefoot leverage to the posterior part of the prosthesis.

Key words: Dental implant. Overdenture. Retention force. Attachment. Mini implants. 




\section{LISTA DE FIGURAS}

Figura 1. (A) Modelo representativo de mandíbula desdentada; (B) Modelo mestre em

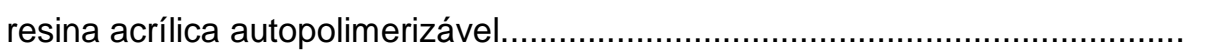

Figura 2. (A) Análogo do implante convencional cone Morse; (B) Mini-implante de corpo único.

Figura 2. (A) Análogo do implante convencional cone Morse; (B) Minitimplante de

Figura 3. (A) Modelo mestre com análogos do implante cone Morse; (B) Modelo mestre com análogos do implante cone Morse e mini-implantes de corpo único.

Figura 4. (A) Encaixamento com cera o 7 do modelo mestre; (B) Vazamento do silicone de duplicação; (C) Molde de silicone de duplicação; (D) Posicionamento dos implantes no molde de silicone........

Figura 5. Modelo inferior em gesso.................................................................... 62

Figura 6. (A, B) Placas articulares com rodetes de cera........................................... 63

Figura 7. (A, B) Modelos superior e inferior posicionados em articulador........................ 64

Figura 8. (A) Prótese inferior incluída em mufla; (B) Mufla na prensa manual colocados num recipiente com água em ebulição para eliminação da cera; (C, D) Dentes artificiais em posição e a base da prótese copiada com silicone laboratorial; (E) Muflas e contra-muflas sob prensa hidráulica de bancada, após colocação da resina de micro-ondas.................................... 65

Figura 9. (A, B) Prótese mandibular e maxilar finalizada.......................................... 66

Figura 10. (A) Mufla e contra-mufla para micro-ondas; (B) Polimerização da resina no micro-ondas.

Figura 11. (A) Resina fotopolimerizável com $2 \mathrm{~mm}$ de espessura adaptada sobre o rebordo do modelo mestre; (B) Resina fotopolimerizável na unidade fotopolimerizadora; (C) Matriz da gengiva artificial após acabamento e polimento; (D) Molde da matriz em silicone Zetalabor; (E) Resina resiliente levada em posição no molde; (F) Gengiva artificial confeccionada com resina resiliente incolor e perfurada com perfurador de dique de borracha................. 68

Figura 12. (A) Attachment bola e O'ring (B) Mini-implante e O'ring............................... 69

Figura 13. (A) Mini-pilar cônico CM; (B) Cilindro do mini-pilar cônico CM Co-Cr; (C) Recorte dos cilindros Co-Cr; (D) Haste metálica com clipe aderido na extremidade e barra em posição.

Figura 14. (A) Conjunto do mini-pilar, cilindro e análogo no paralelômetro, sendo imerso em cera amarela liquefeita; (B) Cilindros encerados; (C) Barra posicionada aos cilindros e unida com cera.

Figura 15. (A) Cápsula calcinável com sprue para fundição; (B) Posicionamento dos conjuntos da barra e cápsula calcinável na base formadora de cadinho; (C) Barra após fundição. 
Figura 16. (A) Posicionamento das cápsulas; (B) Próteses maxilar e mandibular fixadas com godiva, em oclusão.

Figura 17. (A) Captura dos O'rings; (B) Captura do clipe; (C) Prótese com 2 O'rings; (D) Prótese com 4 O'rings; (E) Prótese com 1 clipe; (F) Prótese com 1 clipe e 2 O'rings

Figura 18. (A) Posicionamento do parafuso na prótese superior; (B, C) Verificação dos contatos oclusais com papel carbono; (D) Desgaste seletivo, buscando-se a presença de contatos simultâneos dos dentes posteriores.

Figura 19. (A) Modelos pintados com camada de tinta branca fosca e pontos pretos com tinta preta; (B) Modelos para correlação de imagens.

Figura 20. (A, B) Máquina universal de ensaios e conjunto completo da técnica de CID (câmeras digitais e software).

Figura 21. (A) Calibração das imagens com a placa padrão antes dos carregamentos;

(B) Carregamento pontual na fossa central do $1^{\circ}$ molar inferior direito; (C) Carregamento oclusal com prótese maxilar antagonista...

Figura 22. (A, B) Fixação do anel de PVC à base do modelo de ensaio.......................... 77

Figura 23. Máquina de ciclagem termomecânica......................................................... 78

Figura 24. Dispositivo acrílico colado nas próteses inferiores para ensaio de tração........ 79

Figura 25. Desenho do trapézio isósceles, e a localização dos pontos de perfuração para os modelos com retenção anterior (verde) e retenção anterior e posterior (vermelho).

Figura 26. (A, B) Gancho metálico posicionado no orifício central do dispositivo acrílico.

Figura 27. (A, B) Corrente acoplada ao gancho no modelo inferior e na célula de carga da máquina para realizar o ensaio detração.

Figura 28. (A, B) Confecção de index de silicone para padronização da leitura dos componentes.

Figura 29. (A) Imagem no microscópio óptico da medição do perímetro do O'ring do implante convencional; (B) Imagem da medição do perímetro do O'ring do mini-implante.

Figura 30. Imagem da medida da distância entre as paredes do clipe em três pontos.....

Figura 31. Tensões encontradas na região posterior, com o modelo posicionado lateralmente e carregamento oclusal $(300 \mathrm{~N})$.

Figura 32. Tensões encontradas na região anterior, com o modelo posicionado frontalmente e carregamento oclusal $(300 \mathrm{~N})$.

Figura 33. Tensões encontradas na região posterior, com o modelo posicionado lateralmente e carregamento pontual $(250 \mathrm{~N})$

Figura 34. Tensões encontradas na região anterior, com o modelo posicionado frontalmente e carregamento pontual $(250 \mathrm{~N})$............................................ 90

Figura 35. Modelos com seus componentes e suas respectivas nomenclaturas................ 93 
Figura 36. Análise do perímetro da borracha do O'ring convencional do grupo 20, inicial.

Figura 37. Análise do perímetro da borracha do O'ring convencional do grupo 20 , após $380 \mathrm{~N}$.

Figura 38. Análise do perímetro da borracha do O'ring do mini-implante do grupo 40 , inicial.

Figura 39. Análise do perímetro da borracha do O'ring mini-implante do grupo 40, após $380 \mathrm{~N}$.

Figura 40. Análise do perímetro da borracha do O'ring convencional do grupo 40, inicial.

Figura 41. Análise do perímetro da borracha do O'ring convencional do grupo 40, após $380 \mathrm{~N}$.

Figura 42. Análise da distância entre as paredes em 3 pontos do clipe no grupo 1B, inicial.

Figura 43. Análise da distância entre as paredes em 3 pontos do clipe no grupo 1B, após $380 \mathrm{~N}$.

Figura 44. Análise da distância entre as paredes em 3 pontos do clipe no grupo 1B2O, inicial.

Figura 45. Análise da distância entre as paredes em 3 pontos do clipe no grupo 1B2O, após $380 \mathrm{~N}$.

Figura 46. Análise do perímetro da borracha do O'ring mini-implante do grupo 1B2O, inicial.

Figura 47. Análise do perímetro da borracha do O’ring mini-implante do grupo 1B2O, após $380 \mathrm{~N}$. 

LISTA DE TABELAS E ORGANOGRAMAS 



\section{LISTA DE TABELAS}

Tabela 1. Medidas de posição central e de dispersão da força de retenção $(\mathrm{N})$ em relação aos grupos e aos tempos.

Tabela 2. Modelo linear de efeitos mistos. Comparação da resistência a tração $(N)$ entre os grupos.

Tabela 3. Comparação da resistência a tração entre os tempos no mesmo grupo.

Tabela 4. Medidas de posição central e de dispersão do perímetro do O'ring $(\mathrm{mm})$ e distância entre as paredes do clipe $(\mathrm{mm})$ em relação aos grupos e aos tempos.

Tabela 5. Comparações do perímetro da borracha dos O'rings $(\mathrm{mm})$ e distância entre as paredes do clipe $(\mathrm{mm})$ de cada grupo entre os tempos.

Tabela 6. Comparações do perímetro das borrachas $(\mathrm{mm})$ e da distância entre as paredes do clipe $(\mathrm{mm})$ entre os grupos nos tempos.

\section{LISTA DE ORGANOGRAMAS}

Organograma 1. Delineamento experimental proposto 




\section{SUMÁRIO}

\section{RESUMO}

\section{ABSTRACT}

LISTA DE FIGURAS

LISTA DE TABELAS E ORGANOGRAMAS

1. INTRODUÇÃO E REVISÃO DE LITERATURA 37

2. PROPOSIÇÃO

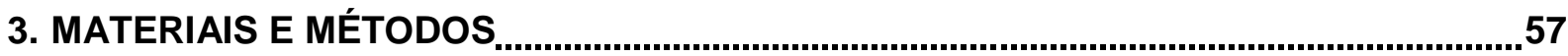

3.1 Obtenção dos modelos mestre e de trabalho........................................................... 57

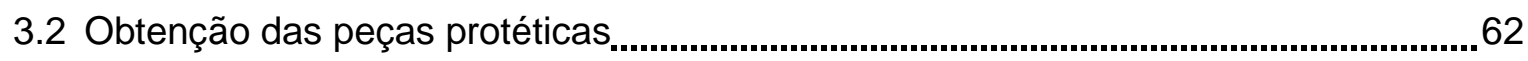

3.2.1 Confecção das Próteses Totais superior e inferior............................................62

3.2.2 Preparo de matriz para confecção de gengiva artificial...................................62

3.2.3 Posicionamento dos componentes protéticos sobre os modelos mestre.......68

3.2.4 Captura dos retentores ....................................................................................... 71

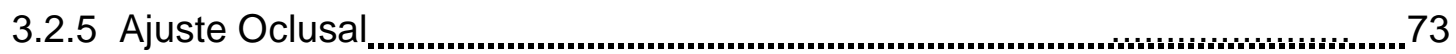

3.3 Obtenção dos modelos para Correlação de Imagens Digitais ..................................... 74

3.3.1 Análise por Correlação de Imagens Digitais .................................................... 75

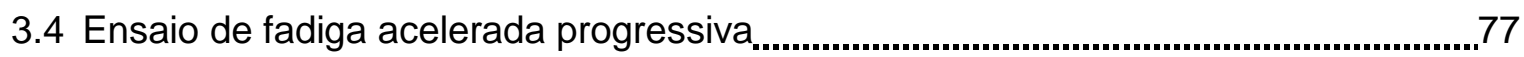

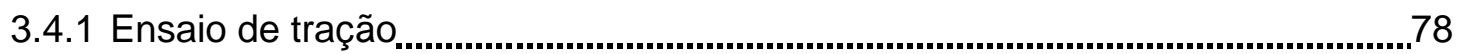

3.4.1.1 Análise estatística dos ensaios de tração............................................81

3.4.2 Análise por microscopia ótica dos componentes protéticos .............................81

3.4.2.1 Análise estatística da microscopia óptica dos componentes protéticos........84

4. RESULTADOS .85

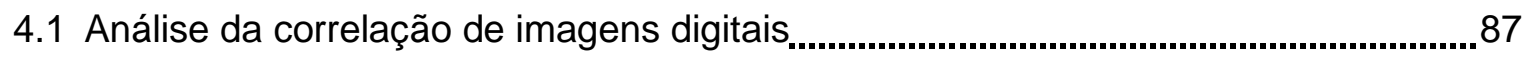

4.2 Ensaio de fadiga acelerada progressiva ...................................................................90

4.3 Análise da microscopia óptica .................................................................................. 93

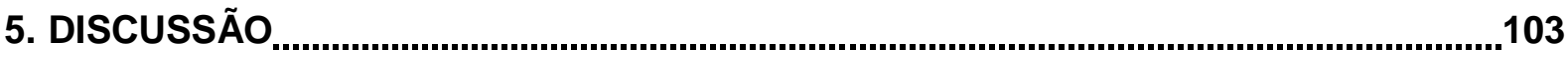

6. CONCLUSÃO

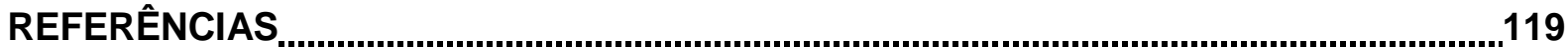

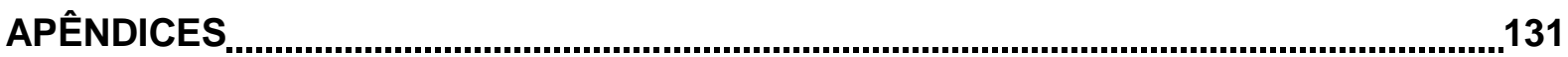



1. INTRODUÇÃO E REVISÃO DE LITERATURA 



\section{INTRODUÇÃO E REVISÃO DE LITERATURA}

A tentativa de substituição do elemento dental, por algum tipo de material, vem desde a antiguidade. A perda de todos os elementos dentais, afeta diretamente a qualidade de vida de um indivíduo, já que ocasiona alterações funcionais e psicossociais. Para um paciente edêntulo total, as próteses totais mucossuportadas, foram por muito tempo, a única opção de tratamento protético (Allen, McMilan, 2003). No entanto, segundo Feine et al. (2002), este tipo de tratamento possui limitações para alguns casos clínicos, principalmente na reabilitação mandibular, como falta de retenção e estabilidade, desconforto, insegurança na alimentação, diminuição da autoestima.

À vista disso, o mercado evoluiu muito com a introdução de novos materiais e técnicas, com o propósito de melhorar a qualidade de vida dos indivíduos desdentados. Consequentemente, o grande sucesso na Odontologia foi introduzido nas últimas décadas do séc. XX por Per-Ingvar Branermark e outros pesquisadores (1969 e 1983 apud Menani, 2009), através da inserção dos implantes dentários no mercado, com intuito de restabelecer pacientes totalmente desdentados, com próteses totais que eram fixadas sobre implantes osseointegrados, chamadas de protocolos. A confirmação se deu com o pesquisador Adell et al. (1981), em um estudo de 15 anos, no qual foram instalados 2768 implantes em 371 pacientes, e que $89 \%$ das próteses maxilares e $100 \%$ das próteses mandibulares continuaram estáveis.

Entretanto, Weinberg (1993) já havia relatado em seu estudo, que o comportamento biomecânico do implante é completamente diferente do dente natural. A resiliência do implante e tecido ósseo é bem menor comparada com a interface entre dente e osso, devido à existência de ligamento periodontal. Glantz, Nilder, 2000; Sahin, Cehreli, Yalçin, 2002; de Souza Batista et al., 2017, ressaltaram alguns princípios, características e realizaram análises biomecânicas que podem interferir na distribuição das forças aplicadas em próteses implanto-suportadas e dento-suportadas, como tipo de implante, pilar e parafuso de fixação utilizado, relacionamento entre os componentes, as forças intrínsecas, se há necessidade de união em próteses múltiplas, passividade e as interferências na transmissão de forças, cargas axiais e oblíquas. Segundo os autores, quando não se estabelece 
distribuição da carga oclusal adequadamente, pode ocorrer fratura ou deformação, devido à sobrecarga mecânica que excedeu o limiar fisiológico do osso.

Sabendo que implantes de titânio são rígidos e retidos diretamente ao tecido ósseo e, tendem a transmitir e distribuir maiores tensões ao osso adjacente, se as forças excederem o limite fisiológico, podem levar a micro fraturas ósseas que podem cicatrizar com tecido conjuntivo não mineralizado. Assim, é desejável otimizar a distribuição de tensão através da confecção correta das próteses e, também analisar a posição e tamanho dos implantes no osso suporte (Beumer, Lewis ,1990).

van Steenberghe (1989), Barbier e Schepers (1997), relataram que a força de oclusão é transmitida ao osso através do implante durante os movimentos excursivos da mastigação. Como o contato entre implantes e o osso alveolar não apresentam praticamente nenhum movimento pela falta de ligamento periodontal, grande parte do estresse se concentra na crista alveolar. Consequentemente, tal concentração excessiva de estresse irá resultar na osteoclasia (reabsorção óssea) podendo levar a falhas da prótese e implante. Ao planejar um tratamento, têm de haver criteriosa avaliação dos pontos de contato entre as próteses ou prótese/dentes, assim como o correto posicionamento do implante, a fim de distribuir adequadamente a carga gerada nos maxilares (Payant, Williams, Zwemer, 1994).

Assim, Kayumi et al. (2015), investigaram a influência das forças oclusais (força contrátil dos músculos mastigatórios) exercidas durante o ajuste oclusal na distribuição das tensões. Utilizaram modelos tridimensionais de elementos finitos da mandíbula, com presença de dentes anteriores, ausência de pré-molares e molares, substituídos por implantes e avaliou a força nas articulações temporomandibulares (ATM) na máxima intercuspidação habitual. Analisaram o ajuste oclusal com forças de $40 \mathrm{~N}$ (mordida leve), $200 \mathrm{~N}$ (mordida dura) e $400 \mathrm{~N}$ (mordida máxima). Concluíram que, por dentes possuírem ligamento periodontal e implantes não, caracterizando resiliência totalmente diferentes no tecido ósseo nos movimentos oclusais, fazer ajustes com mínima força oclusal, pode causar sobrecarga aos implantes. Para evitar essas concentrações nos implantes posteriores, o ajuste oclusal deve ser realizado com a máxima força de oclusão.

Considerando a insatisfação do paciente e as dificuldades da reabilitação mandibular de desdentados totais com próteses totais mucossuportadas convencionais mandibulares, houve maior interesse na indicação de tratamento de próteses totais overdentures retidas por implantes mandibulares localizados na 
região entre caninos, ou seja, próteses totais removíveis que são retidas aos implantes por sistemas de encaixe (Feine et al., 2002; Thomason et al., 2009, Thomason et al., 2012). Esta modalidade de tratamento é eficaz para pacientes desdentados e, em particular, para aqueles que apresentam persistentes problemas em relação à prótese mandibular convencional (Geertman et al., 1996; Ohkubo et al., 2008; Cardoso et al., 2016). Allen e McMillan (2003) realizaram um estudo longitudinal, avaliando o impacto do tratamento com implantes em 103 pacientes, que apresentavam problemas com suas próteses convencionais. Após comparação dos grupos em escala de satisfação, o grupo que recebeu implantes para reter suas próteses relataram melhora significativa na qualidade de vida, permitindo recuperar elementos perdidos e função mastigatória.

Os estudos longitudinais de Naert et al., 1991; Batenburg et al., 1998 e Behneke A, Behneke N, d'Hoedt, 2002, relatam altas taxas de sucesso dos implantes interforaminais utilizados para apoiar próteses overdentures. A maioria dos pacientes que sofre com a instabilidade da prótese, especialmente em prótese mandibular, se beneficia significativamente até mesmo com uma pequena retenção (Ichikawa et al., 1996; Liddelow, Henry, 2010).

Müller et al. (2012), avaliaram 80 pacientes, divididos em quatro grupos: 1overdentures, 2- fixas implanto-suportadas, 3- próteses convencionais 4- pacientes dentados (grupo controle). A junção de próteses totais aos implantes orais parece ter efeitos positivos sobre a espessura do músculo masseter, força máxima de mordida e eficiência de mastigação, trazendo benefícios funcionais, estruturais e psicossociais. A melhora na qualidade de vida com a utilização de próteses overdenture sobre implantes, também foi relata no estudo randomizado com ensaio cruzado, de Karbach et al. (2015), no qual avaliaram 30 pacientes edêntulos, designados a utilizar overdenture sobre dois ou quatro implantes. Concluíram, que os pacientes que utilizaram overdenture retidas por implantes obtiveram melhora na qualidade de vida, comparados aqueles com próteses convencionais, apresentando vantagem estatisticamente significativa no uso de quatro implantes.

Segundo de Kok et al. (2011), a escolha de uma prótese fixa ou removível depende do número, tamanho e comprimento de implantes, da qualidade do osso e também desejo do paciente, pois os dois tipos de próteses apresentaram ser um 
tratamento eficaz e semelhantes perante a satisfação e qualidade de vida dos 20 pacientes analisados no seu estudo, avaliados durante doze meses.

Overdentures implanto-suportadas se tornaram adequada opção de tratamento, além de melhorar a estabilidade e a retenção de próteses totais, são minimamente invasivas e apresentam baixos custos comparados às próteses do tipo protocolo (Rutkunas, Mizutani, Takahashi, 2007; Hong et al., 2012; Chen et al., 2013). Em revisão de literatura, feita por Batenburg, et al. (1998), observaram nos relatos científicos, que a utilização de dois implantes para suportar uma prótese total é suficiente para a maioria das aplicações. Além disso, a utilização de um número mínimo de implantes adequado para o apoio e retenção da prótese também é um benefício econômico para o paciente (Ochiai et al., 2004).

Um estudo randomizado, realizado por Kronstrom et al. (2017) sobre satisfação e resultados clínicos em 36 pacientes, submetidos a colocação de 1 ou 2 implantes inseridos na região anterior da mandíbula e, carregados imediatamente após cirurgia, foram avaliados durante 5 anos. Concluíram não haver diferenças significativas entre os grupos em relação a taxa de sobrevivência dos implantes e perda óssea peri-implantar, e os escores de satisfação dos pacientes aumentaram significativamente quando comparados com os valores basais, em ambos os grupos e sem diferenças significativas.

Há variações no planejamento com overdentures. Pode-se observar propostas de utilização de 1, 2, 3 ou mais implantes, esplintados (barra/clipe, barra/clipe com bola/O'ring nas extremidades) ou isolados (bola O'ring, telescópicos e magnéticos), dependendo do método de fixação que a prótese overdenture será apoiada aos implantes subjacentes (Naert et al., 1991; Kenney, Richards, 1998; Celik, Uludag, 2007; Prakash, D`Souza, AdhiKari, 2009; Barão et al., 2009; Harder et al., 2011).

Considerando vários estudos clínicos e revisões literárias (Gotfredsen, Holm, 2000; Dudic, Mericske-Stern, 2002; Wright et al., 2002; Celik, Uludag, 2007; Alsabeeha, Payne, Swain, 2009; Cune et al., 2010; Mumcu, Bilhan, Geckili, 2012) os tipos de componentes retentivos comumente utilizados são as barras ou attachment bola, cada um com diferentes características biomecânicas.

No estudo, com dez anos de acompanhamento, de Naert et al. (2004), avaliaram o índice de biofilme, de sangramento, alteração no nível de inserção, valores de Periotest e nível ósseo marginal de 26 pacientes com overdentures 
mandibulares retidas por magnetos, O'rings ou barra sobre dois implantes. Os autores não observaram diferença significativa entre os grupos e concluíram que overdentures mandibulares sobre dois implantes tem um excelente prognóstico, independentemente do tipo de retentor.

Celik e Uludag (2014), avaliaram o efeito do número de implantes (2 ou 4) e diferentes mecanismos de retenção (ERA, barra/clipe, barra com bola nas extremidades e barra com fixações rígidas extracoronais - Easy Slot) para overdenture. Foram utilizados modelos fotoelásticos de mandíbulas edêntulas, com aplicação de carga (133 N) na fossa central do primeiro molar direito e gravadas fotograficamente. Concluíram que o número de implantes não teve efeito significativo sobre os valores de tensões em torno dos implantes e, em relação aos sistemas de fixação, o sistema Easy Slot apresentou maiores tensões, seguido por barra com bola nas extremidades e barra/clipe e o menor estresse foi encontrado no sistema ERA.

Lachmann et al. (2007) realizaram, durante sete anos, avaliações clínicas, microbiológicas e imunológicas dos tecidos peri-implantares. Dez pacientes receberam overdentures mandibulares retidas por barra ou O'rings e, mostraram como resultados não haver diferenças entre os parâmetros testados. Concluíram que overdentures retidas por barra ou O'rings foram satisfatórias em todas avaliações por longo período de uso, em pacientes com boa higiene.

Em relação à distribuição de tensões geradas em torno dos implantes e tecido ósseo adjacente, Dashti et al. (2013), compararam dois sistemas de retenção (barra/clipe e bola/O'ring) para overdenture, retidas por 2 implantes. Foram avaliadas as tensões resultantes de carga vertical, geradas no rebordo residual posterior mandibular. Concluíram que o sistema bola/O'ring apresentou menor estresse ao rebordo mandibular posterior comparado ao sistema barra/clipe. Entretanto, comparando a força de retenção de três sistemas (bola/O'ring, barra/clipe, Locator), os pesquisadores Shastry et al. (2016) concluíram que o sistema Locator apresentou a menor retenção entre os sistemas e a barra/clipe a maior força média retentiva no final do estudo.

Os estudos sugerem que é extremamente importante evitar a carga excessiva devido aos efeitos deletérios, tais como, a perda da osseointegração e, consequentemente, a perda de implante dentário. Por esta razão, a escolha do 
mecanismo de retenção pode ser crítica na indução de tensão e lesão dos tecidos peri-implantares e de suporte (Schall, 1991; Wiskott, Belser, 1999; Gotfredsen, Holm, 2000; Rodrigues et al., 2009; Tiossi, 2010).

Bilhan, Mumcu, Arat (2011) realizaram um estudo, com 51 pacientes, que avaliavam a influência de tipos de retentores de overdentures mandibulares na perda óssea marginal, perante avaliações clínicas e radiográficas. Este estudo foi conduzido durante 3 anos, após colocação da prótese retidas com bola/O'rings ou barra/clipe. Os resultados não apresentaram diferença entre estes retentores, na perda óssea marginal dos implantes. Concluíram que sexo, idade e diâmetro dos implantes não influenciaram a perda óssea, mas o comprimento do implante tem papel importante na manutenção óssea. O tipo de retentor não influencia na perda óssea marginal, mas a presença de cantiléver a aumenta.

Segundo Chen et al. (2015), ainda que próteses overdentures retidas por implantes permita que o paciente apresente forças oclusais mais elevadas do que com próteses totais convencionais, há de considerar que a extensão distal destas próteses pode prever remodelação óssea localizada. Com isso, os autores, utilizaram tomografias computadorizadas e próteses totais de pacientes, para confecção de modelos em 3D por elementos finitos, nos quais foram posicionados implantes virtuais nas regiões estabelecidas (overdenture sobre 2 ou 4 implantes entre caninos) e seus tecidos adjacentes, utilizando aplicação de carga oclusal de 63 $\mathrm{N}$, e compararam com tratamento clínico, que foi realizado de forma independente, realizando tomografias computadorizadas iniciais e após 1 ano de inserção da overdenture de pacientes reabilitados com os três tipos de próteses, quantificando as alterações ósseas. Correlacionando os resultados, as regiões que apresentaram maior pressão hidrostática da mucosa nos modelos de elemento finito, foram observadas maiores alterações ósseas nas tomografias. Concluíram que houve sim melhora na estabilidade e maior força mastigatória com overdenture, porém as regiões posteriores (extensão distal da prótese) que apresentaram ter maior pressão hidrostática na mucosa, apontaram maior reabsorção óssea pelas tomografias, sugerindo que, há necessidade de planejamentos que melhore os resultados em longo prazo.

A extensão distal é um fator crucial para o sucesso de próteses removíveis, por isso, foram realizados alguns estudos (Ben-Ur, Aviv, Maharshak, 1991, Amodio et al., 2003; Ohkubo et al., 2008) com intuito de avaliar as ocorrências biomecânicas 
ocasionadas na rotação posterior de prótese parcial removível (PPR). Os autores relataram que a extensão distal de uma prótese parcial removível Classe I ou II de Kennedy, apresenta alguns desafios, como confeccionar próteses corretamente adaptadas para evitar tensões geradas ao suporte ósseo e tecidual, já que a estabilidade e retenção são limitadas devido ao movimento de rotação durante a mastigação, com ocorrência de alavanca. O processo de rotação posterior da PPR Classe I de Kennedy é o mesmo mecanismo biomecânico que ocorre em próteses overdentures, porém a prótese está anexada a implantes anteriores, e não a dentes naturais, podendo ocorrer reabsorção óssea em várias regiões mandibulares, se não houver adequada distribuição de forças oclusais nos movimentos maxilares (Khuder et al., 2017).

Em um estudo de Gonçalves, Campos e Garcia (2014), que avaliou a satisfação do paciente no uso de implantes distais para retenção de PPR convencionais, concluiram maior satisfação no que diz respeito à retenção, conforto e capacidade de mastigação. Estas vantagens estão relacionadas também com menor número de implantes, menor custo, menor tempo clínico e laboratorial, melhor higienização quando comparado com uma prótese parcial fixa, e por proporcionar melhor distribuição das cargas mastigatórias aos pilares, dentes e implantes, preservação do tecido ósseo ao redor dos implantes e dentes remanescentes, melhor conforto por causa do menor movimento de rotação, podendo também converter, posteriormente, em overdenture completa.

A revisão sistemática de literatura de Freitas et al. (2012) que tinha como objetivo investigar a satisfação do paciente, sobrevivência de implantes e complicações protéticas ou manutenção de PPR Classe I e II associadas com implantes posteriores, mostrou ser uma reabilitação benéfica e de baixo custo, com satisfação dos pacientes e altas taxas de sobrevivência dos implantes nas extensões distais. Essa terapia proporcionou estabilização vertical da prótese removível e limitou o movimento rotacional.

Pensando em evitar forças deletérias e obter melhor distribuição da força oclusal em próteses parciais removíveis, Suzuki et al. (2017), avaliaram clinicamente 10 pacientes com PPR, em estudo randomizado cruzado. Estes pacientes possuíam implantes inseridos com attachment bola na região distal, com objetivo de distribuir o estresse gerado durante a movimentação em movimentos excursivos. Concluíram 
que a extensão distal suportada por implantes e sistema bola/O'ring melhoraram a estabilidade da prótese e a satisfação dos pacientes.

Hegazy, Elshahawi IM e Elmotayam H (2013) realizaram um estudo com prótese parcial removível com o objetivo de analisar tensões induzidas aos implantes, de $4,2 \times 13 \mathrm{~mm}$, colocados na distal mandibular, em regiões de prémolares ou segundos molares. Concluíram que o implante colocado mais distalmente pode ser uma solução satisfatória, apresentando menores concentrações de tensões nos implantes.

Porém, há casos clínicos que apresentam limitações de altura óssea posterior para que seja colocado um implante convencional nesta região. Sobre procedimentos de aumento ósseo nessas regiões e avaliação de sucesso destas técnicas, revisões sistemáticas (Chiapasco, Zaniboni, Boisco, 2006; Rocchietta, Fontana, Simion, 2008) mostram que tratamentos alternativos mais radicais para a reconstrução óssea e inserção de implantes na região posterior, apresentaram ter uma abordagem limitada, por encontrarem qualidades metodológicas falhas e baixo número de tratamentos referidos. Além disto, esses procedimentos são muitas vezes traumáticos e a previsibilidade de sucesso é baixa, com resolução demorada, alto custo e possibilidade de sequelas (Stellingsma, Vissink, Raghebar, 2008).

Foi neste contexto que surgiram os implantes curtos como alternativa de tratamento (Stellingsma, Vissink, Raghebar, 2008; das Neves et al., 2006; Hagi et al., 2004), especialmente em reabilitações na região posterior da mandíbula. Embora a definição de implantes curtos seja ainda controversa (Kotsovilis et al., 2009), geralmente tem sido considerado como tal, quando o comprimento intraósseo não ultrapassa dimensões que variam entre sete a dez milímetros (Hagi et al., 2004; das Neves et al., 2006).

Fatores fisiológicos relacionados com a reabsorção óssea na crista mandibular é motivo de preocupação durante o planejamento de terapias com implantes. Kordatzis, Wright, Meijer (2003) acompanharam a reabsorção óssea no rebordo mandibular posterior por 5 anos e obtiveram-se valores médios de 1,63 mm para próteses convencionais e 0,69 $\mathrm{mm}$ para próteses overdentures, quase $1 \mathrm{~mm}$ menor do que com uso de próteses convencionais. Por conseguinte, o osso é preservado em torno dos implantes osseointegrados, como resultado da estimulação e remodelação, sendo importante para a região mandibular posterior, em que a altura do osso é muitas vezes reduzida. 
Pistilli et al. (2013) avaliaram 20 pacientes com mandíbulas atróficas bilaterais e 20 pacientes com mandíbula com 5 a $7 \mathrm{~mm}$ de altura óssea acima do canal mandibular. Foram colocados implantes de $4 \mathrm{~mm}$ de largura e $6 \mathrm{~mm}$ de comprimento, ou implantes com pelo menos $10 \mathrm{~mm}$ comprimento em osso reconstruído em altura. Após 1 ano do carregamento das próteses, concluíram que os implantes mais curtos obtiveram resultados semelhantes do que os implantes mais longos, podendo ser uma escolha preferível para região posterior da mandíbula, porém necessitam de maior período de investigação para que as recomendações sejam confiáveis.

Observa-se que nos estudos (de Freitas et al., 2012; Hegazy, Elshahawi IM e Elmotayam H, 2013; Suzuki et al., 2017), sobre estabilização posterior, referem às análises em próteses parciais removíveis, utilizando implantes convencionais ou curtos, porém, se o paciente não apresentar estrutura óssea suficiente, a utilização desta técnica fica limitada. Nota-se ainda, que há falta de estudos referindo sobre a estabilização posterior em próteses overdentures, já que estes tipos de próteses apresentam o mesmo princípio de movimento rotacional distal.

Mini-implantes dentários são muitas vezes referidos como mini-implantes dentários (IDC), implantes de diâmetro pequeno (IDS) ou implante de corpo estreito (NBIS), utilizados em regiões de incisivos laterais na maxila e incisivos na mandíbula, com taxas de sucesso de 95 a 100\% (Andersen et al., 2001; Cordaro et al., 2006; Maló e Nobre, 2011). Griffiths e colaboradores (2005) observaram 116 mini-implantes colocados na região anterior da mandíbula, durante 13 meses. Observaram que 113 permaneceram em funcionamento com taxa de sucesso de $97,4 \%$, além dos pacientes relatarem melhora na capacidade de mastigar, na fala, maior conforto e retenção.

Os mini-implantes têm sido utilizados para retenção de overdentures mandibulares, na região anterior, de forma bem-sucedida, como alternativa para casos com rebordo reduzido (Jofré et al., 2010a; Jofré, Cendoya, Munoz, 2010b; Bidra, Almas, 2013, Šćepanović et al., 2015). Devido as taxas de sucesso na utilização de mini-implantes para reter próteses totais convencionais (Bulard, Vance, 2005; Fortin et al., 2006; Bidra, Almas, 2013, Šćepanović et al., 2015; Toth et al., 2017), nota-se relevante obter estudos que analisem a retenção e melhor 
distribuição de tensão em próteses overdentures, na região posterior utilizando miniimplantes, buscando diminuir a alavanca ocasionada pelas próteses removíveis.

São considerados mini-implantes, aqueles implantes que apresentam diâmetro menor que 3 mm e corpo único (Davarpanah et al., 2000; Quek, Tan, Nicholls, 2006; Bidra, Almas, 2013). Devido ao seu desenho, os mini-implantes apresentam algumas vantagens em relação aos convencionais, como: menor espessura óssea necessária para instalação, pois são significativamente mais estreitos (Bulard, Vance, 2005; Toth et al., 2017); incisões e rebatimento de retalho geralmente não são necessários para a instalação, o que favorece o reparo tecidual e minimiza a reabsorção óssea durante a osseointegração (Fortin et al., 2006) e redução dos custos do tratamento (Griffiths, Collins CP, Collins, 2005; Della Vecchia, 2015).

No estudo clínico, realizado por Aunmeungtong et al. (2017), compararam overdentures com implantes convencionais (grupo 3) com overdentures retidas por 2 (grupo 1) ou 4 mini-implantes (grupo 2), em região anterior. Dividido em três grupos, 60 pacientes receberam mini-implantes ou implantes convencionais que foram observados, durante 12 meses, nos parâmetros de satisfação e taxa de sobrevivência. Concluíram que a taxa de sobrevivência de todos os grupos foi de 100\%, porém a reabsorção óssea marginal do grupo 3 foi significantemente maior que nos grupos 1 e 2. Não houve diferença significativa na satisfação dos pacientes entre os grupos 1 e 2, mas houve diferença significativa perante a satisfação dos grupos 1 e 2 comparados ao grupo 3.

Os estudos relacionados a mini-implantes, mesmo apresentando resultados promissores (Bulard, Vance, 2005; Jofré et al., 2010a; Bidra, Almas, 2013; Della Vecchia, 2015; de Souza et al., 2015), mostram limitações quanto ao conhecimento sobre o comportamento biomecânico e sobre indicações de regiões que possam ser utilizados para reter próteses totais, que beneficiaria funcionalmente os pacientes que procuram relação favorável de custo-benefício.

Vários métodos são utilizados para análise de tensão da prótese, dos implantes e de seus tecidos (Assunção et al., 2009). Amodio et al. (2003) apresentaram as bases teóricas da técnica de correlação de pontos digitais para análise de tensões em imagens digitais (CID). Este método de análise dos pontos digitais aplica uma análise numérica das imagens obtidas e do posicionamento dos pontos na superfície a ser analisada, proporcionando uma medida mais objetiva, ou 
seja, é uma técnica óptica que fornece o deslocamento, portanto, a tensão sobre uma região de interesse na superfície analisada (Gustafson, Siegmund, Cripton, 2016).

A CID tem sido tradicionalmente utilizada para estudar a deformação de materiais de engenharia (Sutton, Orteu, Schreier, 2009), mas tem despertado interesse crescente no campo da biomecânica biomédica e experimental, pois permite a caracterização de tecidos biológicos, órgãos e suas interações com dispositivos biomédicos (Palanca, Tozzi, Cristofolini, 2016; Hu et al., 2016).

A CID é uma técnica de medição de campo óptico numérica completa, que oferece a possibilidade de determinar campos complexos de deslocamento e de deformação na superfície de objetos sob qualquer tipo de carga. O princípio da CID baseia-se no rastreio de padrões aleatórios, sobre uma superfície de material sujeita a deformação. Um software adequado reconhece e localiza os padrões correspondentes cobertos pela superfície antes e depois da deformação, utilizando um algoritmo de correlação de imagem. O padrão é gravado usando câmera digital antes e depois da deformação. O campo de deslocamento total na superfície da amostra é então determinado pela correlação de duas imagens subsequentes. $\mathrm{Na}$ CID, um padrão aleatório é aplicado à superfície de um objeto com contraste suficiente que pode ser rastreado de imagem para imagem, comparando imagens na configuração deformada com uma configuração de referência. Para processar e ativar a correlação, as imagens são divididas em pequenos subconjuntos de um número de pixels (Maiti et al., 2016).

As imagens dos estados deformados são comparadas com a referência de modo a corresponder a subconjuntos e rastrear o deslocamento. O grau de correspondência entre subconjuntos é avaliado por uma função de correlação cruzada (Sutton, Orteu, Schreier, 2009; Palanca, Tozzi, Cristofolini, 2016).

De acordo com Tiossi et al. (2014) tanto a fotoelasticidade quanto a CID são métodos capazes de avaliar adequadamente a distribuição das tensões e apresentam resultados semelhantes. Pode-se assim, analisar tensões em volta de implantes conectados à overdentures com diferentes tipos de sistemas de retenção e, para garantir a interpretação correta dos resultados da análise de tensões, a combinação dos modelos experimental e matemático são importantes (Karl et al., 2009). Um estudo de Peixoto et al. (2017), utilizaram a metodologia CID para avaliar 
a distribuição de tensão, em estudo in vitro, de diferentes materiais de revestimento (porcelana e resina) e implantes (curtos e convencionais) em próteses parciais fixas, sob carga oclusal de $250 \mathrm{~N}$. Concluíram que não houve influência do tipo de material de revestimento e os implantes convencionais geram menos concentração de tensão, apesar que a utilização de dois implantes curtos e um convencional também seja possível para diminuir essas concentrações tensionais nos implantes.

A durabilidade dos componentes de implante é fortemente influenciada pela carga cíclica durante os ciclos mastigatórios (Wilding, Lewin, 1994; Richter, 1995). Rached et al. (2011) utilizou a metodologia, em estudo in vitro, para avaliar a resistência de próteses overdenture retidas por bola/O'ring, a esforços dinâmicos e estáticos, reforçadas com materiais metálicos (barra de aço inoxidável e malha de aço) e não metálicos (fibras de vidro, malha de vidro, tranças de polietileno e fibras de poliaramida). Os grupos foram termociclados em 5000 ciclos e depois submetidos a carga cíclica de 100000 , e os grupos que não apresentaram fraturas, foram carregados até ocorrer falhas, concluíram que a fibra de vidro, tranças de polietileno e fibras de poliaramida aumentaram a resistência à flexão da overdenture.

A carga cíclica é um teste de fadiga in vitro que simula o carregamento mecânico presente na cavidade oral em ambiente úmido ou seco, para investigar o efeito da força de degradação de um material dental (Gratton, Aquilino, Stanford, 1995; Binon, McHugh, 1996; Khraisat et al., 2006). Ortegón et al. (2009) avaliou a força de retenção de attachment bola/O'ring em overdenture inseridas sob implantes paralelos e angulados, utilizando carga cíclica de 3500 ciclos, no qual as cargas de retenção dos componentes foram registradas através de ensaio de tração no início e a cada 100 ciclos. Concluíram que houve diminuição na retenção nos grupos com implantes angulados comparando com os implantes paralelos, variando entre $11 \mathrm{~N} \mathrm{e}$ $23 \mathrm{~N}$.

Os estudos relatam que muitos pacientes desdentados mandibulares, apresentam dificuldade com suas próteses mucossuportadas, principalmente em relação a retenção e estabilização (Geertman et al., 1996; Ohkubo et al., 2008; Cardoso et al., 2016). Desta maneira, surgiram as próteses overdentures retidas por implantes, alternativa efetiva na reabilitação oral para pacientes edêntulos, e positiva em relação ao seu custo-benefício, quando comparado a próteses fixas, ou seja, são próteses menos invasivas, podendo apresentar boa retenção com a colocação de 
poucos implantes interforaminais (Naert et al., 1991; Batenburg et al., 1998; Behneke A, Behneke N, d'Hoedt, 2002; Rutkunas, Mizutani, Takahashi, 2007; Hong et al., 2012; Chen et al., 2013; Gonçalves, Campos, Garcia, 2014). O tempo clínico e laboratorial é menor e, um fator muito relevante, é a possibilidade de melhor higienização por serem próteses removíveis.

Sabendo que o implante é um material rígido, retido diretamente ao tecido ósseo, sem ter praticamente nenhum movimento, ao contrário do que ocorre com dente natural através do ligamento periodontal, em movimentos mastigatórios, as tensões geradas são direcionadas, com maior intensidade, aos tecidos adjacentes aos implantes, principalmente em próteses removíveis Classe I e II de Kennedy e overdenture, por apresentar extensão distal e movimento rotacional, consequentemente alavanca em movimento excursivo (Ben-Ur, Aviv, Maharshak,1991; Amodio et al., 2003; Ohkubo et al., 2008; Gonçalves, Campos, Garcia, 2014).

Para amenizar injúrias substanciais ao sistema reabilitador, análises foram realizadas em PPRs, nos quais, estabilizaram a região posterior com implantes curtos. Os resultados mostraram ser efetivos quanto a satisfação, conforto e melhor capacidade de mastigação do paciente, além de ter menor perda óssea com a estimulação local, porém, é um tratamento mais invasivo (Stellingsma, Vissink, Raghebar, 2008; das Neves et al., 2006; Hagi et al., 2004).

Observou-se que na literatura, não encontra estudos com o mesmo propósito em próteses overdenture, já relatado como um tratamento promissor para melhora da qualidade de vida em pacientes desdentados total. E como a população, na maioria da realidade atual, está sempre em busca por tratamentos com boa relação de custo-benefício, nota-se há necessidade no desenvolvimento de técnicas que melhore a qualidade de vida desses pacientes com custos acessíveis. Analisando todos os fatores, observa-se que há necessidade, de estudos biomecânicos, com próteses overdentures retidas por implantes anteriores e estabilizadas posteriormente com implantes menos invasivos e que não eleve o custo operacional. Mini-implantes apresentam boas características frente a esses conceitos, já que estes mostram ter resultados promissores, tanto na ancoragem óssea quanto na retenção de próteses e, só há relatos científicos e análises clínicas, para utilização 
na região anterior, não conhecendo seu mecanismo na região posterior. Portanto, análises biomecânicas são necessárias para comprovar esses benefícios, correlacionando os resultados com técnicas tradicionalmente utilizadas. 
2. PROPOSIÇÃO 



\section{PROPOSIÇÃO}

O objetivo deste estudo foi avaliar a durabilidade, força de retenção e distribuição de tensão em modelos experimentais de overdentures convencionais retidas por barra/clipe e por bola/O'ring associadas ou não a mini-implantes na região posterior da mandíbula. Para realização destas análises foram realizados:

- Ensaio de fadiga acelerada progressiva;

- Ensaio de resistência à tração;

- Análise por microscopia óptica;

- Análise por correlação de imagens digitais. 

3. MATERIAIS E MÉTODOS 



\section{MATERIAIS E MÉTODOS}

Para a realização deste estudo foram utilizados os seguintes grupos $(n=12)$ :

- Grupo 2O. Overdenture sobre 2 implantes com bola/O'ring;

- Grupo 1B. Overdenture sobre 2 implantes com barra/clipe;

- Grupo 40. Overdenture sobre 2 implantes com bola/O'ring e 2 miniimplantes na região posterior;

- Grupo 1B2O. Overdenture sobre 2 implantes com barra/clipe e 2 miniimplantes na região posterior.

Os grupos deste estudo foram divididos de acordo com o delineamento experimental proposto no organograma 1.

Organograma 1 - Delineamento experimental proposto.

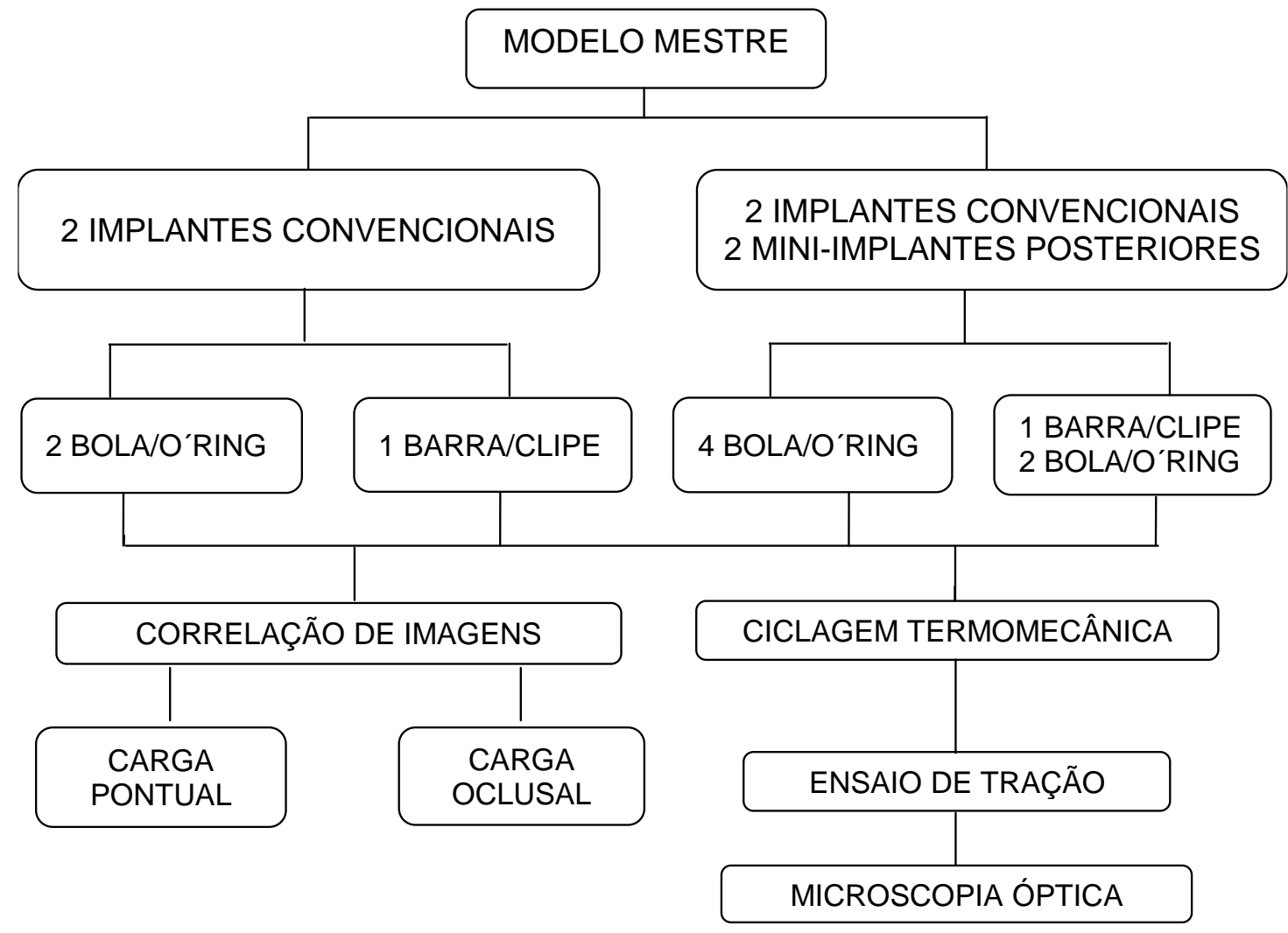

\subsection{Obtenção dos modelos mestre e de trabalho}

Foi utilizado um modelo representativo de mandíbula, o qual foi duplicado com silicone para duplicação (Silicone Master, Talladium do Brasil, Curitiba-PR, Brasil). Mediante o molde, confeccionou-se um modelo mestre inferior em resina acrílica autopolimerizável (JET Clássico, Clássico Indústria Brasileira, Campo Limpo Paulista - SP, Brasil) (Figura 1). 
Figura 1. (A) Modelo representativo de mandíbula desdentada; (B) Modelo mestre em resina acrílica autopolimerizável.
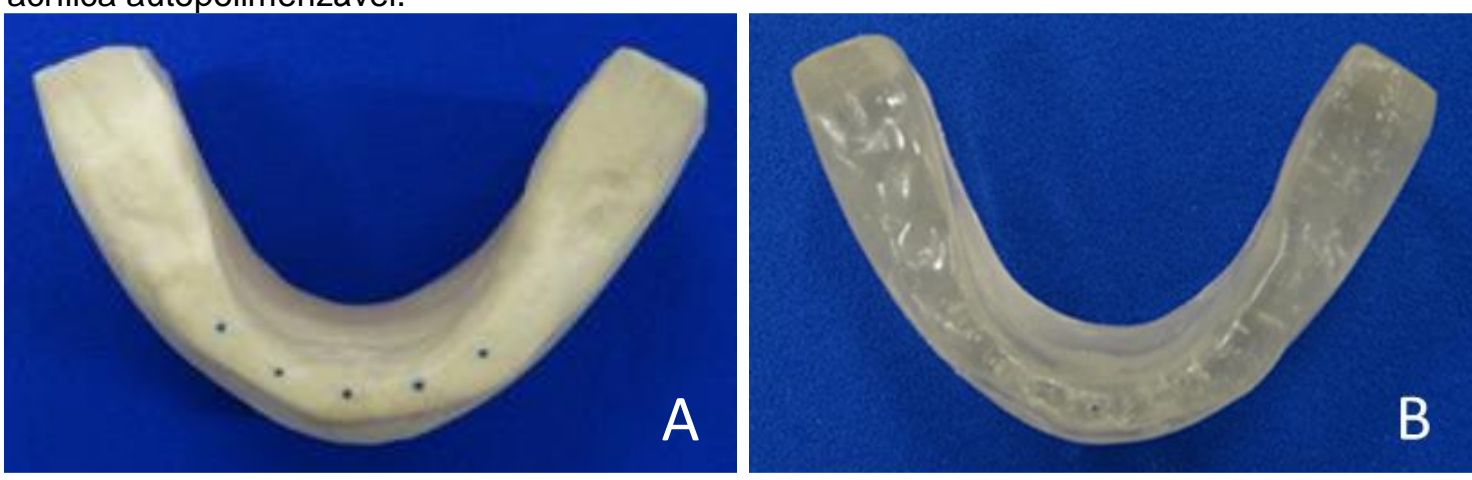

Foram realizadas, duas perfurações no modelo mestre inferior, na região interforaminal (região de caninos) equidistantes $10 \mathrm{~mm}$ da linha média (Yamaguto; Vasconcelos, 2005), com diâmetro e profundidade compatíveis com os análogos do implante convencional cone Morse de 3,75 x $11 \mathrm{~mm}$ (Neodent - JJGC Ind. e Com. de Mat. Dentários S.A., Curitiba - PR, Brasil) a serem posicionados e fixados a 2 $\mathrm{mm}$ infra-ósseo, de acordo com recomendação do fabricante. Foram acrescidas perfurações posteriores para a fixação dos mini-implantes de corpo único 2,0 x 10 mm (Singular Implants - DMR Ind. e Com. de Materiais Odontológicos Ltda., Parnamirim - RN, Brasil) ao nível ósseo, na região do primeiro molar (Figura 2). A perfuração posterior foi de $31 \mathrm{~mm}$ da linha mediana, no qual refere-se a média da distância do incisivo central inferior até a fossa central do primeiro molar inferior (Yamaguto; Vasconcelos, 2005), obtendo posição adequada em relação mésio-distal para a construção da overdenture sobre implante.

Figura 2. (A) Análogo do implante convencional cone Morse; (B) Mini-implante de corpo único.

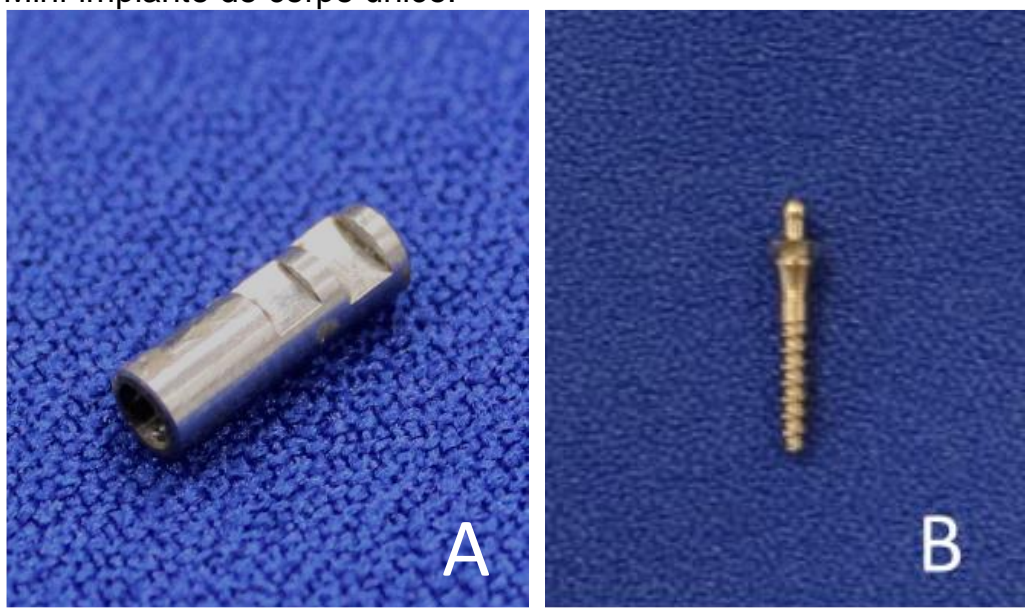


As perfurações foram realizadas em furadeira de bancada com brocas helicoidais de 4,5 $\mathrm{mm}$. Com auxílio de um paralelômetro, os análogos dos implantes e mini-implantes foram posicionados ao seu longo eixo e paralelos em relação à largura mésio-distal. Os análogos dos implantes foram acoplados aos transferentes correspondentes e, fixados dentro das perfurações com cola à base de cianoacrilato (Super Bonder, Loctite Henkel Ltda., São Paulo - SP, Brasil). Para duplicar o modelo mestre, e obter um modelo com apenas os componentes anteriores, rosqueou-se transferentes aos análogos do modelo mestre elaborado anteriormente e este foi duplicado com silicone para duplicação. Foi vedado a abertura onde se encontrava os mini-implantes com cera $n^{0} 7$ no molde de silicone e, os transferentes foram rosqueados a novos análogos, para obter outro modelo mestre inferior em resina acrílica autopolimerizável com análogos anteriores, sem mini-implantes posteriores (Figura 3).

Figura 3. (A) Modelo mestre com análogos do implante cone Morse; (B) Modelo mestre com análogos do implante cone Morse e mini-implantes de corpo único.
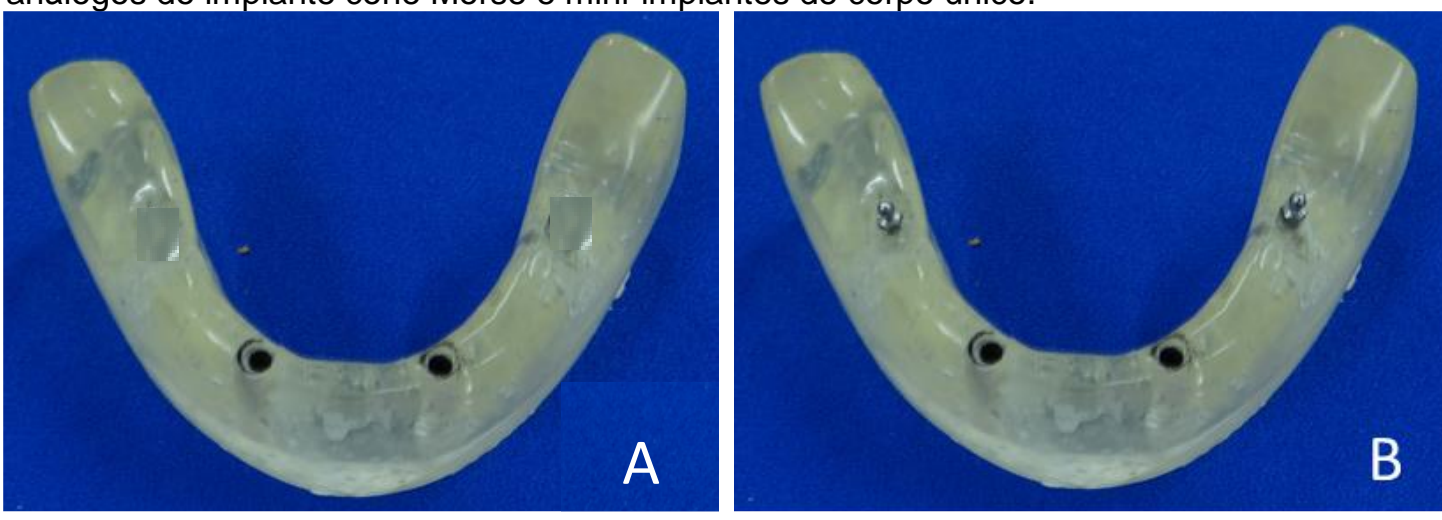

Em seguida, foi realizado o encaixamento dos modelos mestre com cera $n^{\circ}$ 7 (Wilson, Polidental Indústria e Comércio Ltda., Cotia - SP, Brasil) para o vazamento com silicone de duplicação. Os moldes de silicone foram utilizados para o posicionamento dos implantes convencionais e mini-implantes, para confecção dos modelos de trabalho em poliuretano (Axson Brasil In. E Com. Ltda., São Paulo SP, Brasil), utilizados nos ensaios de correlação de imagens digitais (CID) e ciclagem termomecânica (Figura 4). 
Figura 4. (A) Encaixamento com cera o 7 do modelo mestre; (B) Vazamento do silicone de duplicação; (C) Molde de silicone de duplicação; (D) Posicionamento dos implantes no molde de silicone.
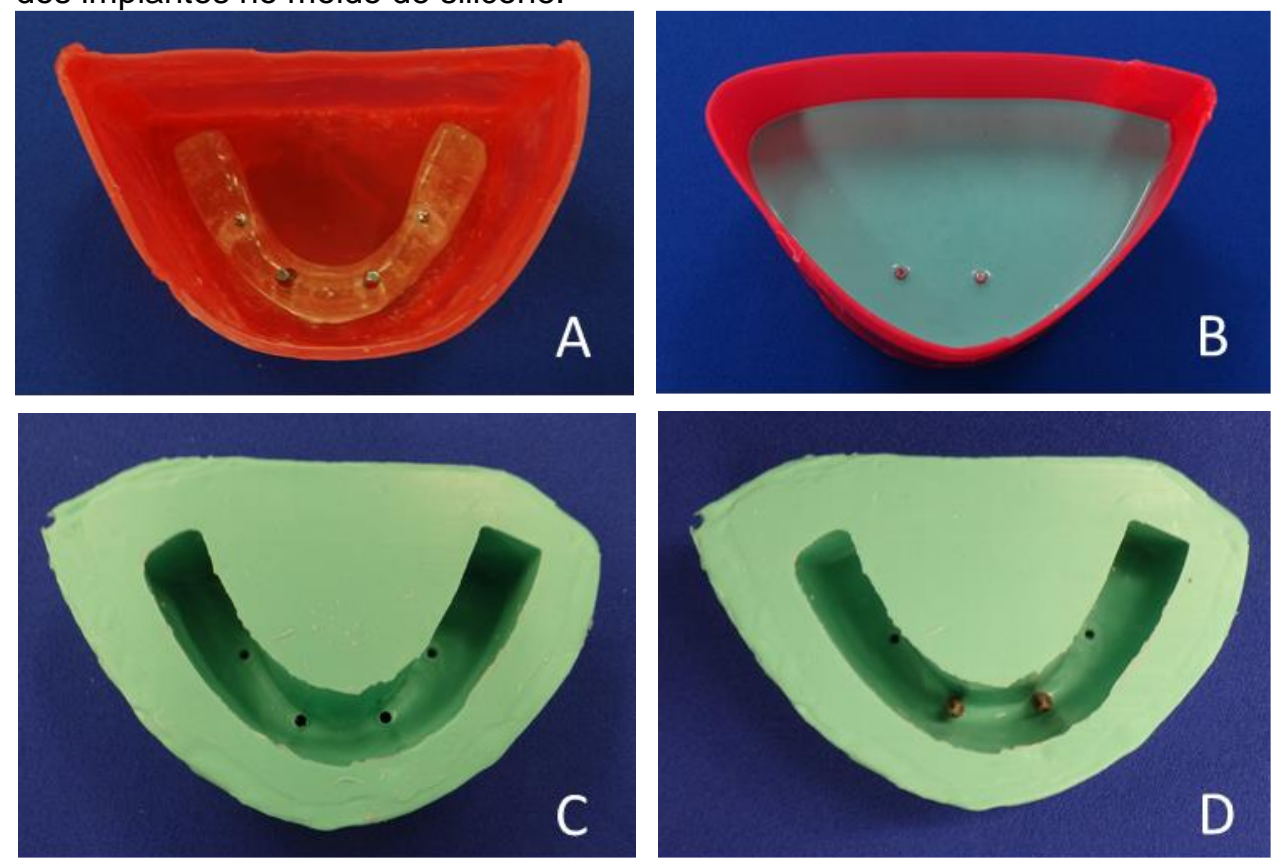

\subsection{Obtenção das peças protéticas}

\subsubsection{Confecção das Próteses Totais superior e inferior}

Para a confecção da prótese total inferior, o modelo mestre foi moldado com alginato tipo II (Dentsply Indústria e Comércio Ltda, Petrópolis - RJ, Brasil). Após a geleificação do material, foi vazado gesso pedra tipo III (Asfer Indústria Química Ltda., São Caetano do Sul - SP, Brasil) para obter o modelo inferior em gesso (Figura 5).

Figura 5. Modelo inferior em gesso.

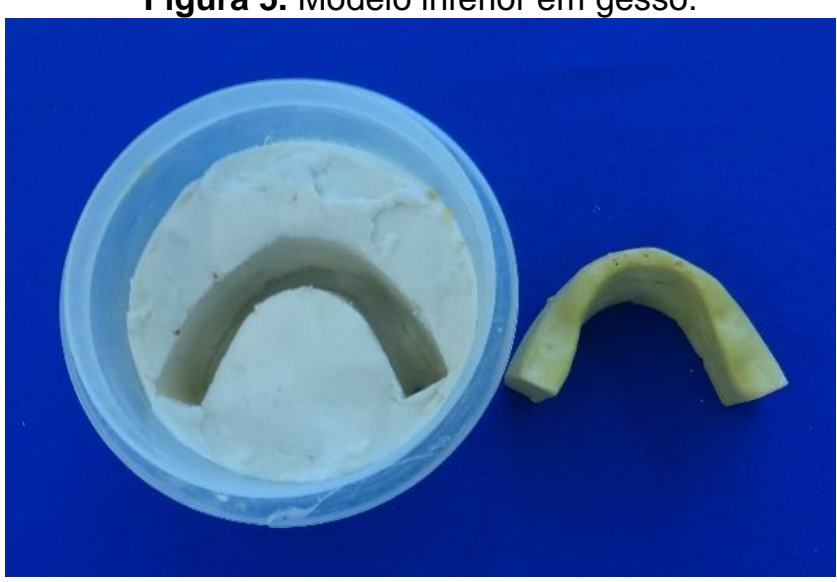


Este modelo foi pincelado com isolante para gesso Cel-lac (S.S. White Artigos Dentários Ltda., Rio de Janeiro - RJ, Brasil), para confeccionar placas articulares em resina acrílica autopolimerizável. Na placa articular superior, foi incluído resina acrílica na região do palato. Foi confeccionado rodete de cera $n^{\circ} 7$ em 6 dobras de $10 \mathrm{~mm}$ de largura no sentido longitudinal da cera e aderido sobre a placa articular com cera aquecida (Figura 6).

Figura 6. (A, B) Placas articulares com rodetes de cera.
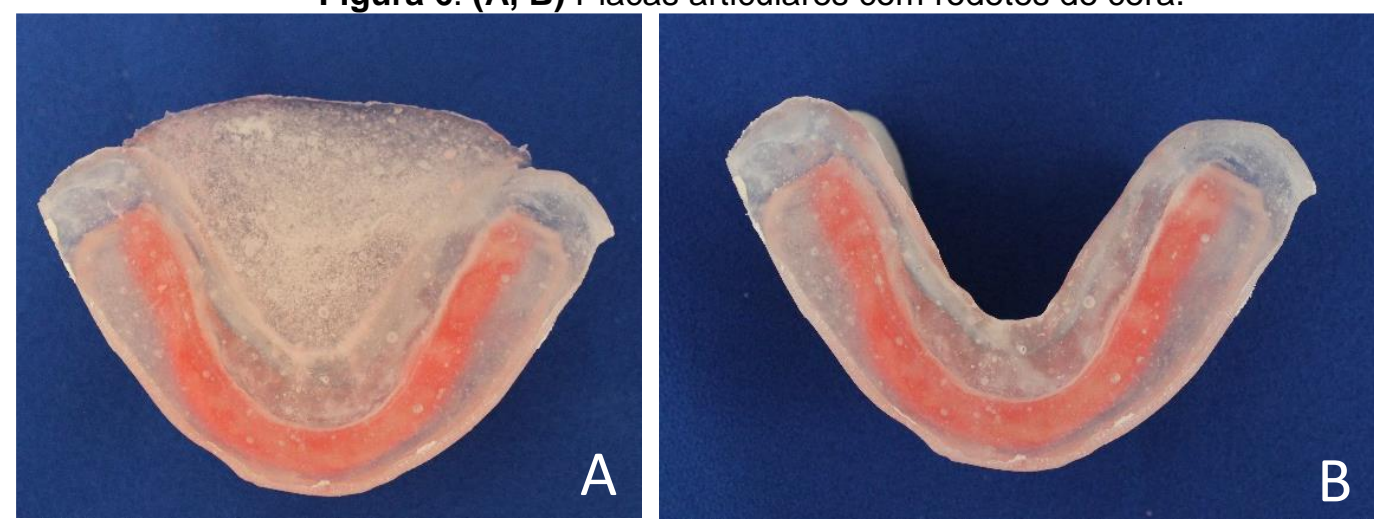

No modelo de gesso inferior, na região vestibular, mediu-se com régua flexível o ponto médio e, marcou-se a linha mediana no rodete de cera.

Para marcar a linha mediana do rodete de cera maxilar, os rodetes das placas articulares superior e inferior foram unidos com grampos, e marcou-se a linha mediana no rodete superior, na mesma direção da linha do rodete inferior. Posteriormente, manipulou-se gesso comum tipo II (Asfer Indústria Química Ltda., São Caetano do Sul - SP, Brasil) e pôs sobre a placa articular para fechar o ramo superior do articulador semi-ajustável Mod 4000 (Bio-Art Equipamentos Odontológicos Ltda., São Carlos - SP, Brasil), de forma que a bolacha metálica entrasse em contato com o gesso. Após a presa do gesso do modelo superior, verteu-se o articulador e prendeu a base do modelo inferior na bolacha metálica com gesso comum tipo II (Figura 7). 
Figura 7. (A, B) Modelos superior e inferior posicionados em articulador.

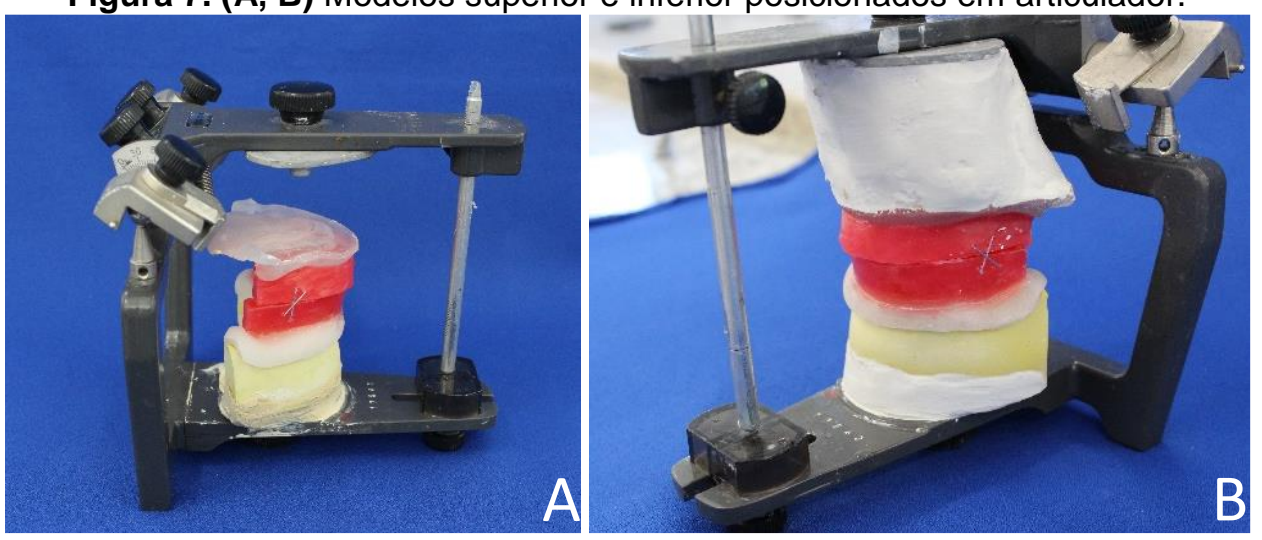

Seguiu-se posteriormente para a montagem dos dentes artificiais superior e inferior, modelos 2D e 30M (Biotone, Dentsply Indústria e Comércio Ltda, Petrópolis - RJ, Brasil), em substituição aos rodetes de orientação, seguindo a técnica indicada e princípios da Prótese Total (Paranhos et al., 2006).

Após a montagem dos dentes, as próteses foram incluídas em muflas para micro-ondas, com gesso pedra tipo III (Asfer Indústria Química Ltda., São Caetano do Sul-SP, Brasil). Após a presa final do gesso, as muflas foram levadas a prensa manual e o conjunto foi colocado num recipiente com água em ebulição durante 10 minutos, para eliminação da cera. Completado o ciclo, as muflas foram deixadas sobre a bancada para serem abertas, após atingir a temperatura ambiente. Removeu-se a placa articular e despejou água quente retirando o restante da cera que ficou aderida nas muflas e contra-muflas. Foram realizadas perfurações com broca esférica na base dos dentes artificiais para melhor fixação destes à base da prótese e, após isolamento da porção de gesso com isolante para gesso (Cel-lac, S.S. White Artigos Dentários Ltda., Rio de Janeiro - RJ, Brasil), a resina de microondas (Vipi Wave, VIPI Indústria e Comércio Exportação e Importação de Produtos odontológicos Ltda., Pirassununga, SP, Brasil) na proporção 3:3, foi vertida sobre os dentes. Os parafusos das muflas foram apertados manualmente e levadas a prensa hidráulica de bancada e submetidas a um ciclo de prensagem gradual até atingir 1000 kgf (Figura 8). 
Figura 8. (A) Prótese inferior incluída em mufla; (B) Mufla na prensa manual colocados num recipiente com água em ebulição para eliminação da cera; (C, D) Dentes artificiais em posição e a base da prótese copiada com silicone laboratorial; (E) Muflas e contra-muflas em prensa hidráulica de bancada, após colocação da resina de micro-ondas.
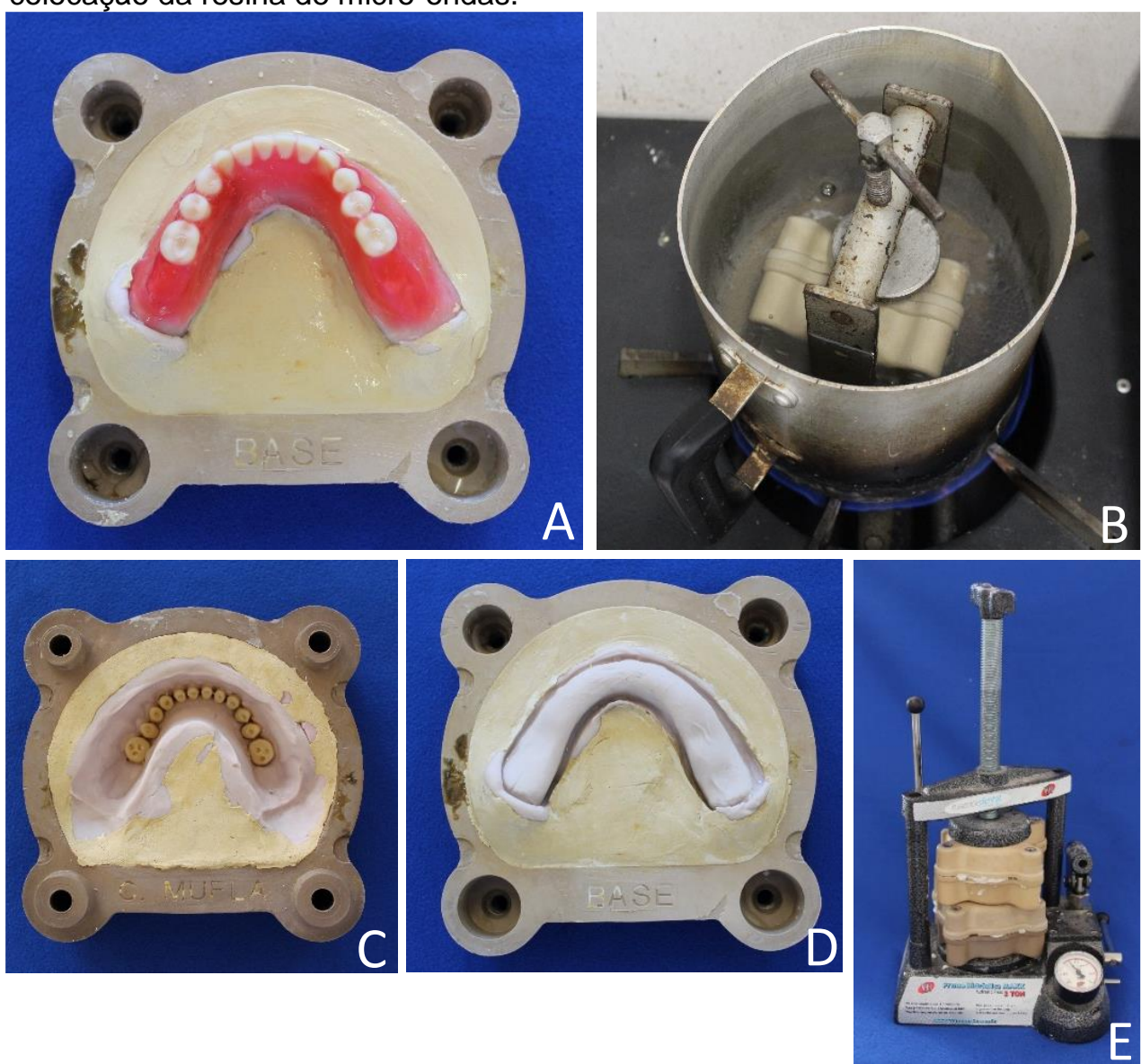

Após estabilizar a prensagem, os modelos foram levados sobre a bancada por 2 horas para descansar e permitir a saturação completa do polímero pelo monômero. Posteriormente, foram imersos em um recipiente com água corrente para hidratação do gesso, por 30 minutos. Levou-se a mufla para o micro-ondas para polimerização da resina, segundo normas do fabricante, primeiramente em posição vertical na potência $10 \%$ por 20 minutos, depois na posição horizontal, na potência $40 \%$ por 5 minutos. Após a finalização do ciclo, a mufla foi deixada sobre a bancada para resfriar antes de abri-la. Após desincluídas, as próteses receberam acabamento por meio de fresas montadas em peça reta e tiras de lixa montadas em mandril, para a eliminação dos excessos de resina acrílica, de forma a tornar as superfícies das próteses arredondadas e livres de irregularidades ou aspereza. O polimento foi realizado com mistura de pedra pomes e água, utilizando-se discos de feltro montados em politriz de bancada (Figura 9).

Figura 9. (A, B) Prótese mandibular e maxilar finalizada. 

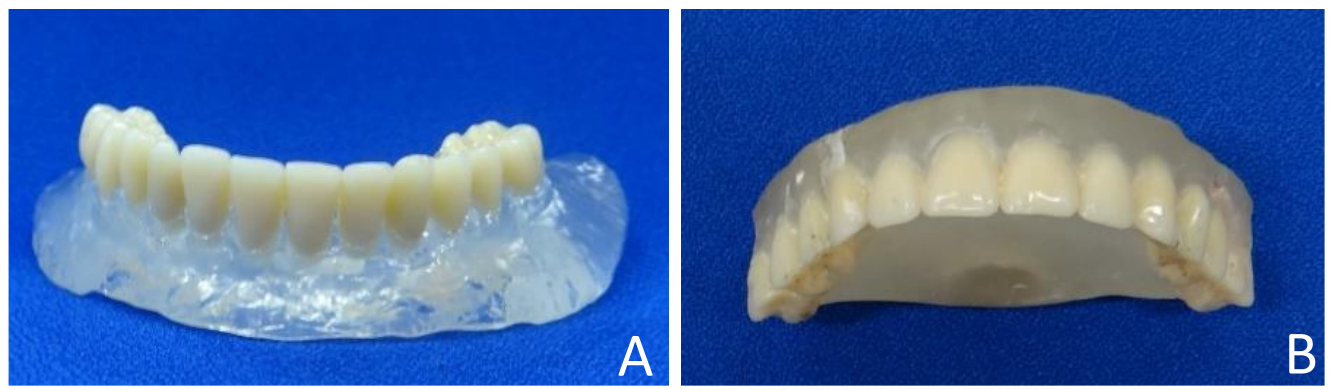

Uma prótese total inferior e uma prótese total superior acabadas e polidas foram utilizadas como matrizes para confeccionar as doze próteses inferiores para overdentures e seis próteses superiores como antagonistas. Foi acomodado silicone laboratorial (Zetalabor, Zhermack S.p.A., Badia Polesine, Rovigo, Itália) sobre os dentes e rebordo, verteu-se gesso pedra tipo III nas mulflas de micro-ondas. Após a presa do gesso, as próteses foram removidas e, colocados os dentes perfurados em suas posições no silicone retido dentro das muflas. Misturou-se e verteu a resina de micro-ondas sobre os dentes, os parafusos das muflas foram apertados e levadas a prensa hidráulica de bancada, repetindo o ciclo anteriormente citado (Figura 10).

Figura 10. (A) Mufla e contra-mufla para micro-ondas; (B) Polimerização da resina no micro-ondas.
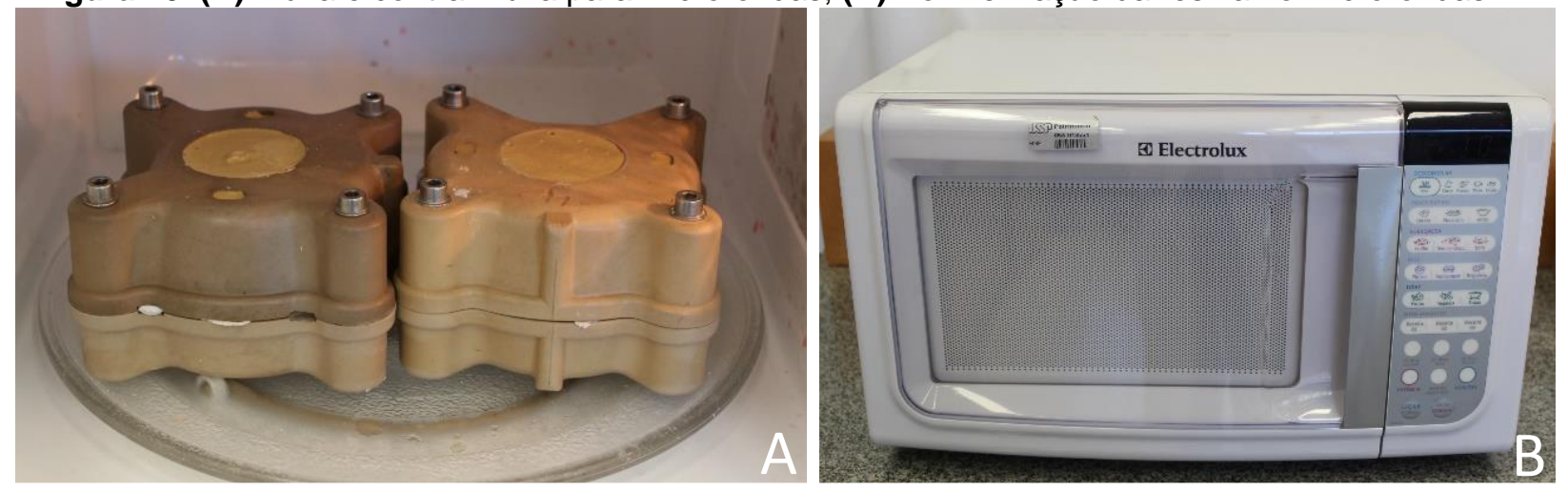

\subsubsection{Confecção de gengiva artificial}

Sobre o modelo mestre, foi confeccionada uma matriz de resina fotopolimerizável (Stern Tek, Sterngold Dental, Attleboro, Estados Unidos). Essa matriz foi utilizada para a posterior confecção da gengiva artificial que ficou sobre os modelos de trabalho.

Uma placa de resina fotopolimerizável, com $2 \mathrm{~mm}$ de espessura, foi adaptada sobre o rebordo do modelo mestre, os excessos foram recortados com Le-cron. De acordo com as recomendações do fabricante, a resina foi levada a unidade fotopolimerizadora EDG-Lux (EDG Equipamentos e Controles Ltda., São 
Carlos - SP, Brasil) por 3 minutos para a fotopolimerização da porção superior e por mais 2 minutos para porção inferior.

Após a fotopolimerização, foi realizado acabamento por meio de fresas montadas em peça reta e tiras de lixa montadas em mandril. O polimento foi realizado com mistura de pedra pomes e água, utilizando-se discos de feltro montados em politriz de bancada. Finalizado o polimento, a matriz foi moldada com silicone laboratorial para confecção de um molde que foi utilizado posteriormente, para a preparação das gengivas artificiais (Figura 11). O molde foi preenchido com resina resiliente incolor (Soft Confort, Dencril Comércio de Plásticos Importação e Exportação Ltda., Pirassununga - SP, Brasil). Após a polimerização do material, a gengiva artificial foi perfurada com perfurador de dique de borracha nas regiões correspondentes aos implantes. 
Figura 11. (A) Resina fotopolimerizável com $2 \mathrm{~mm}$ de espessura adaptada sobre o rebordo do modelo mestre; (B) Resina fotopolimerizável na unidade fotopolimerizadora; (C) Matriz da gengiva artificial após acabamento e polimento; (D) Molde da matriz em silicone Zetalabor; (E) Resina resiliente levada em posição no molde; (F) Gengiva artificial confeccionada com resina resiliente incolor e perfurada com perfurador de dique de borracha.
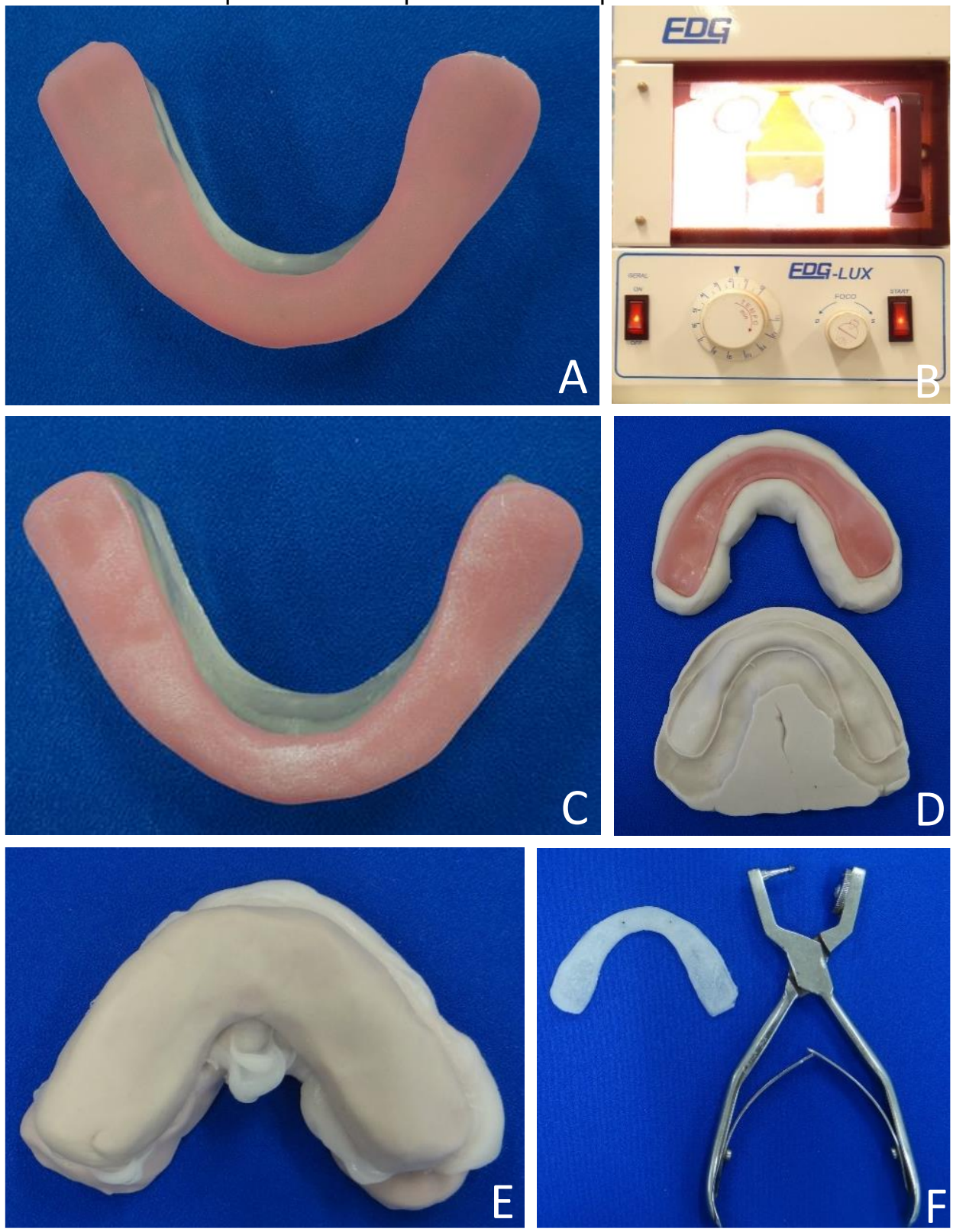

\subsubsection{Posicionamento dos componentes protéticos sobre os modelos mestre}

Para os grupos com attachment bola/O'ring foram utilizados O'ring e attachment bola mini CM (Neodent) de altura $4,5 \mathrm{~mm}$, rosqueados diretamente sobre os implantes, com torque recomendado pelo fabricante (32N). Para os grupos com mini-implantes de corpo único, foi utilizado O'ring (Singular Implantes) (Figura 12). 
Figura 12. (A) Attachment bola e O'ring (B) Miniimplante e O'ring.

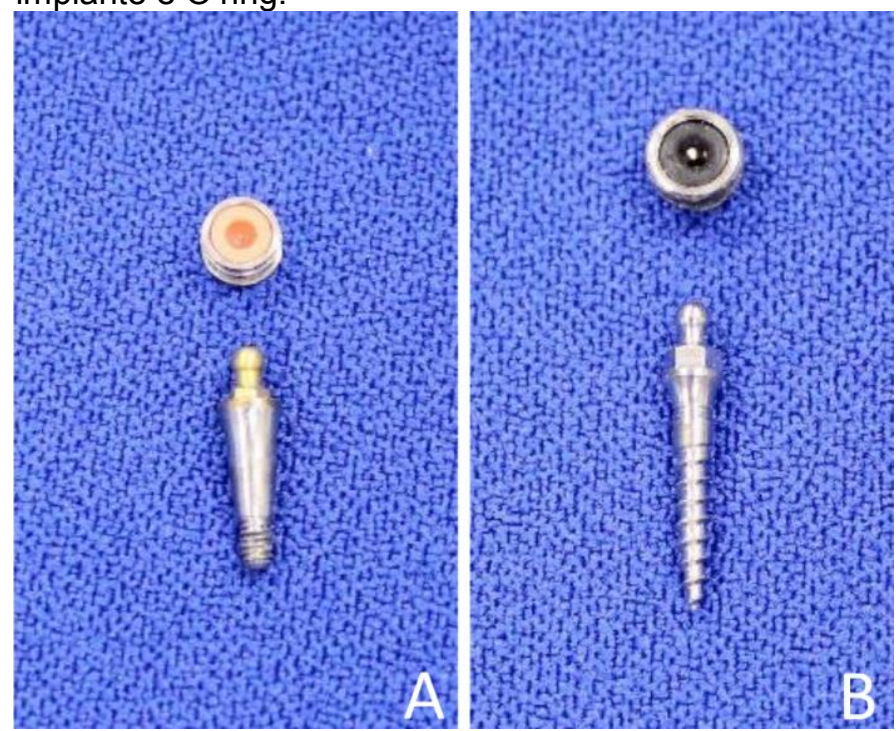

Para os grupos com barra/clipe, aos análogos CM, foram torqueados componentes intermediários mini-pilar cônico com altura 4,5 mm (Neodent), com torque recomendado pelo fabricante $(32 \mathrm{~N})$ e, sobre estes componentes, foram colocados cilindros do mini-pilar cônico com cinta em cobalto-cromo (Neodent). Foi realizado o recorte dos cilindros na primeira marcação das espiras, na porção plástica do cilindro, usando disco de carburundum, deixando todos os cilindros do mesmo tamanho para padronização. As barras foram recortadas no tamanho correspondente à distância entre os cilindros de forma padronizada (Figura 13).

Figura 13. (A) Mini-pilar cônico CM; (B) Cilindro do mini-pilar cônico CM Co-Cr; (C) Recorte dos cilindros Co-Cr; (D) Haste metálica com clipe aderido na extremidade e barra em posição.
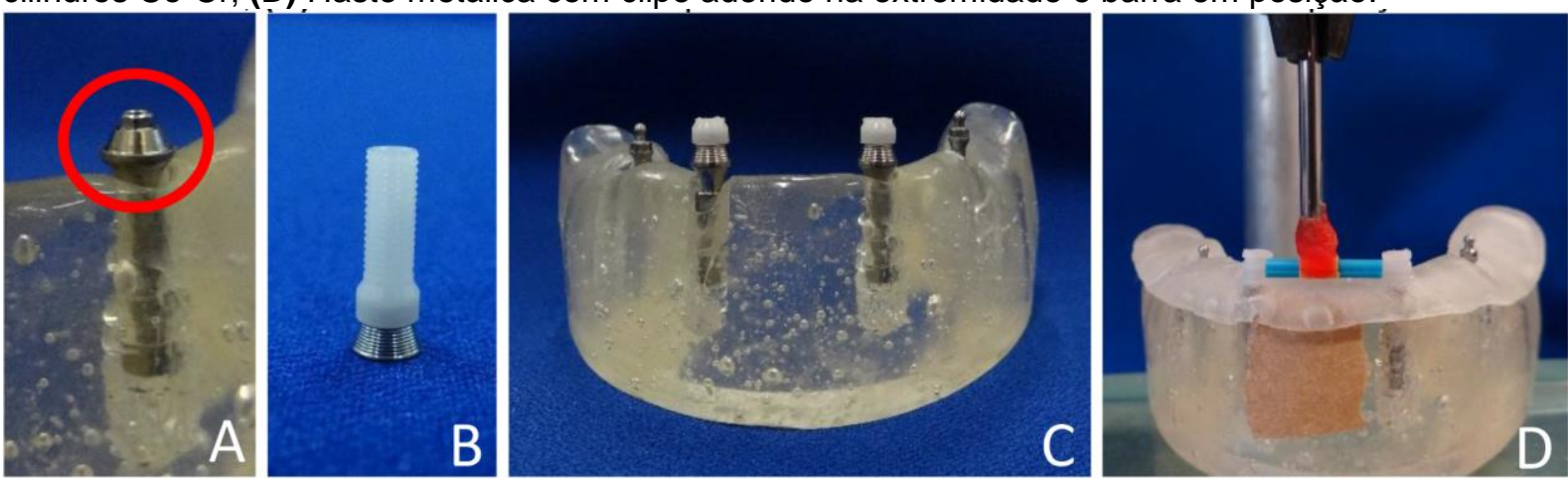

Para o enceramento das barras, o interior de cada cilindro foi preenchido com algodão, para evitar que a cera penetrasse no conduto. O cilindro foi acoplado a um mini-pilar CM correspondente, e o conjunto a um análogo do implante. Colocouse este conjunto no paralelômetro e, o cilindro foi imerso em cera amarela liquefeita, 
até na altura na sua base de Co-Cr. Depois do enceramento, os mini-pilares e cilindros foram posicionados aos análogos do modelo mestre e, com auxílio de um paralelômetro, foi posicionada a barra, do tipo Dolder U (Neodent - JJGC Ind. e Com. de Mat. Dentários S.A., Curitiba - PR, Brasil), cortada anteriormente. Foi posicionada paralela ao plano oclusal entre os cilindros, com auxílio de uma haste metálica, no qual havia um clipe retido com resina Duralay (Reliance Dental, Worth, IL, EUA) na sua extremidade. Esta haste foi acoplada a um paralelômetro para posicionamento da barra entre os cilindros a qual foi unida com cera azul, utilizando gotejadores (Figura 14).

Figura 14. (A) Conjunto do mini-pilar, cilindro e análogo no paralelômetro, sendo imerso em cera amarela liquefeita; (B) Cilindros encerados; (C) Barra posicionada aos cilindros e unida com cera.
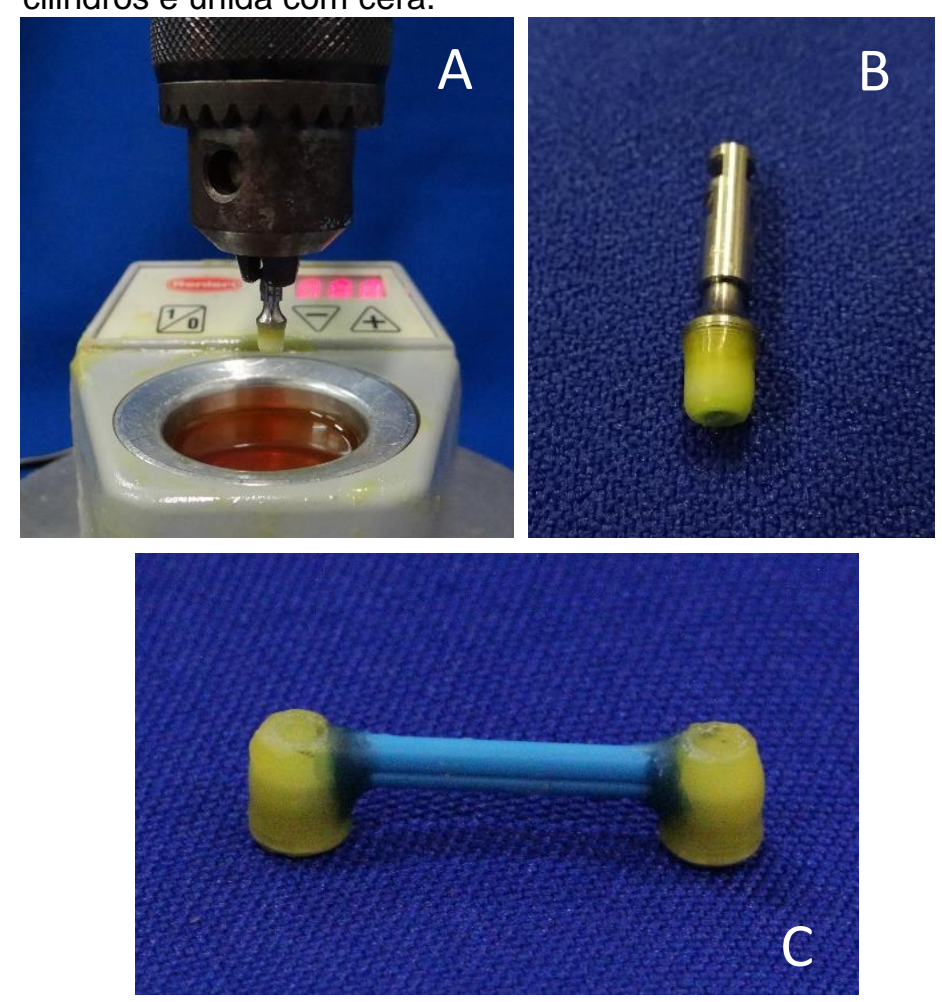

Após o enceramento dos 24 corpos de prova de barra/clipe, as barras foram posicionadas nas bases formadoras de cadinho e também, as 6 cápsulas calcináveis utilizadas para reter os clipes, sendo posteriormente pulverizadas com spray redutor de tensão de superfície (Lubrofilm, Dentaurum, Ispringen, Alemanha) deixando secar a temperatura ambiente. Após adaptados à base do anel de silicone foi vertido o revestimento (MegaVest Press, Eichstätt, Germany). Este revestimento foi manipulado manualmente por 30 segundos, depois levado ao espatulador à vácuo 
por 60 segundos e, manteve-se o vácuo por 30 segundos após espatulação, e com auxílio de um vibrador, o anel foi preenchido com o revestimento. Após adequado resfriamento do revestimento, entre $25-30$ minutos, colocou-se no forno a $850-900^{\circ} \mathrm{C}$ para expansão do revestimento e eliminação da cera, em seguida foi realizada a fundição com chama de gás-oxigênio com liga de cobalto-cromo (Fit Cast Cobalto, Talmax, Curitiba, PR, Brasil) (Figura 15).

As estruturas foram desincluídas e os condutos de alimentação foram seccionados com discos de carburundum e também removeu pequenos nódulos e rebarbas com brocas em alta rotação sob refrigeração constante. Em seguida, foram jateadas com óxido de alumínio (Polidental Indústria e Comércio Ltda., São Paulo, SP, Brasil) de granulação $100 \mu \mathrm{m}$, sob pressão de $80 \mathrm{lib} / \mathrm{pol}^{2}$. As estruturas foram provadas sobre o modelo mestre quanto à passividade pelo método de Sheffield (Eisenman, 1997), caso não houvesse adaptação adequada, foi realizada secção e solda da barra.

Figura 15. (A) Cápsula calcinável com sprue para fundição; (B) Posicionamento dos conjuntos da barra e cápsula calcinável na base formadora de cadinho; (C) Barra após fundição.
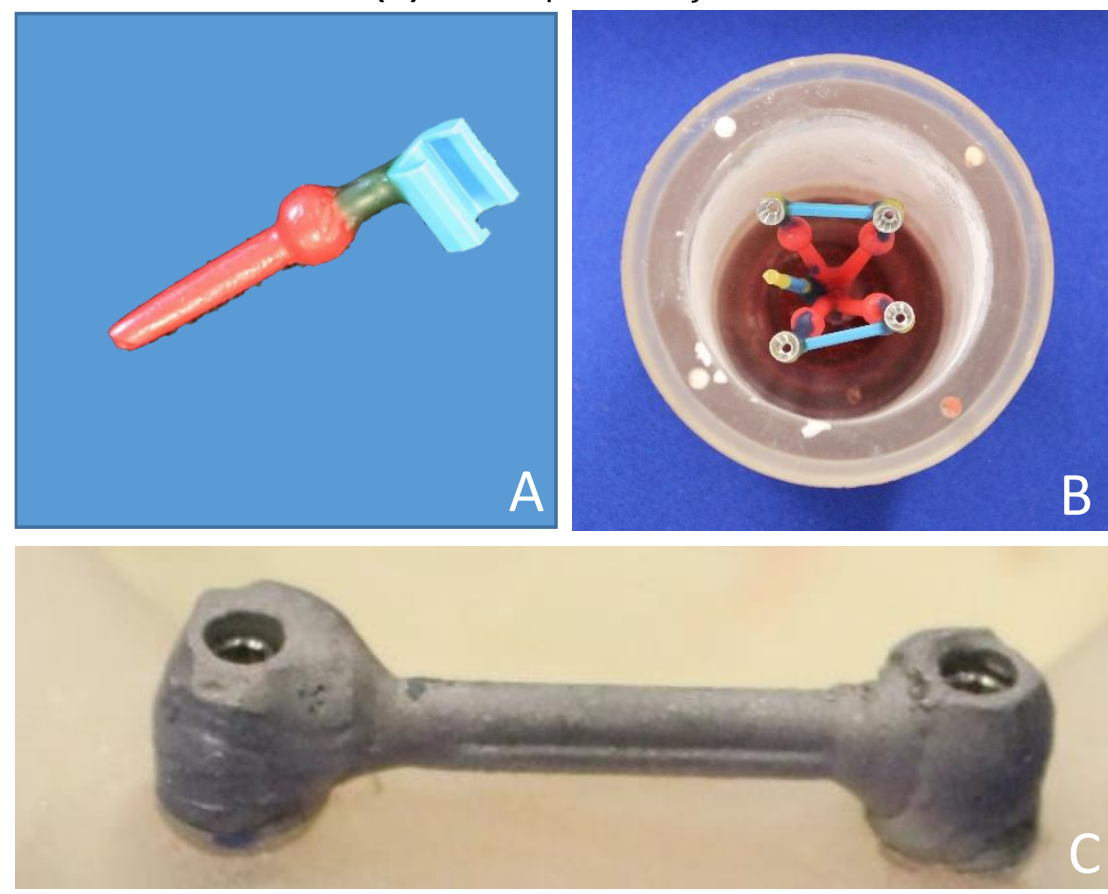

\subsubsection{Captura dos retentores}

A gengiva artificial foi adaptada sobre $o$ modelo $e$ as próteses mandibulares receberam alívio interno, por meio de fresas montadas em peça reta, para posterior captura dos retentores. As próteses maxilar e mandibular foram 
fixadas em oclusão utilizando-se godiva de baixa fusão em bastão (Kerr, Kerr Corporation USA, Orange - Estados Unidos), e posicionadas no delineador. As cápsulas retentoras foram posicionadas sobre os O'rings ou barra. Para verificar o posicionamento das cápsulas, foi utilizada uma ponta de delineador confeccionada na oficina de precisão do Departamento de Materiais Dentários e Prótese. O posicionamento foi considerado correto quando todas as cápsulas tocaram o dispositivo paralelamente (Figura 16).

Figura 16. (A) Posicionamento das cápsulas; (B) Próteses maxilar e mandibular fixadas com godiva, em oclusão.
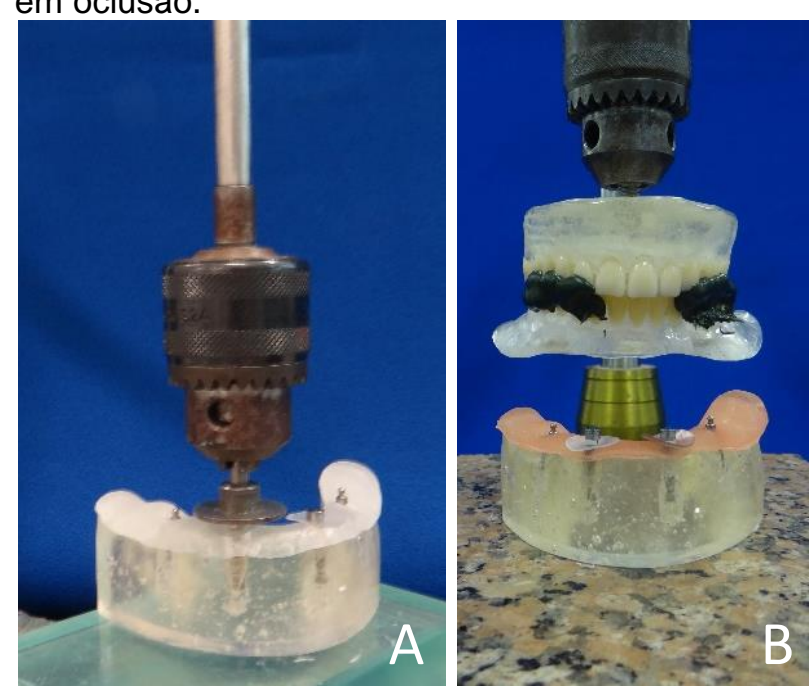

Para 0 procedimento de captura dos retentores propriamente dito, 0 conjunto prótese maxilar e mandibular em oclusão foram posicionados no delineador. Após verificação do posicionamento, o modelo foi fixado na base do delineador com fita dupla face. Resina autopolimerizável na fase plástica foi aplicada sobre as cápsulas, a prótese mandibular foi posicionada sobre as mesmas e aguardou-se a polimerização da resina.

Após a polimerização, o conjunto foi removido do delineador e os espaços entre as cápsulas foram preenchidos com resina acrílica autopolimerizável. O acabamento foi realizado por meio de fresas montadas em peça reta e tiras de lixa montadas em mandril. O polimento foi realizado com mistura de pedra pomes e água, utilizando-se discos de feltro montados em politriz de bancada, tendo cuidado com a borracha ou clipe dentro da cápsula (Figura 17). 
Figura 17. (A) Captura dos O'rings; (B) Captura do clipe; (C) Prótese com 2 O'rings; (D) Prótese com 4 O'rings; (E) Prótese com 1 clipe; (F) Prótese com 1 clipe e 2 O'rings.
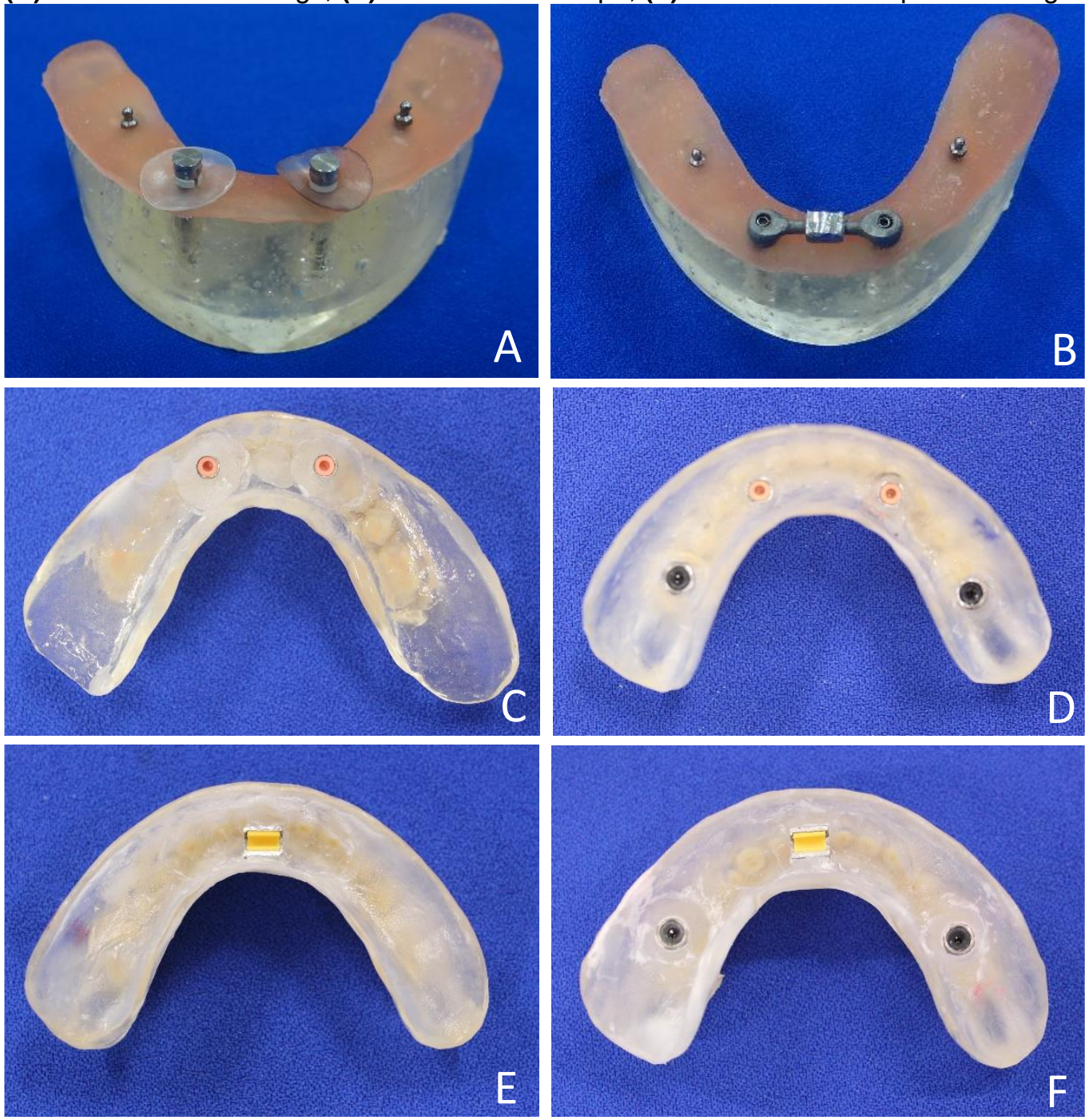

\subsubsection{Ajuste oclusal}

Nas próteses maxilares, foram colocados parafusos com auxílio do delineador, levados em posição para que ficassem perpendiculares ao plano oclusal e fixados com resina acrílica autopolimerizável. Estes parafusos foram utilizados para rosquear os modelos superiores na máquina de fadiga termomecânica e, também na máquina universal de ensaio, quando foi avaliado a tensão superficial, por correlação de imagens digitais.

Para realização do ajuste oclusal, a prótese maxilar foi posicionada no delineador e o modelo inferior, juntamente com a gengiva artificial e overdenture, foi fixado na base do delineador com fita dupla face. Os ajustes oclusais foram feitos com papel carbono (Accu Film II, Parkell in, Farmingdale - NY, Estados Unidos) na posição de máxima intercuspidação, por meio de desgaste seletivo 
buscando-se a presença de contatos simultâneos dos dentes posteriores para promover distribuição equilibrada da carga mastigatória simulada (Figura 18).

Figura 18. (A) Posicionamento do parafuso na prótese superior; (B, C) Verificação dos contatos oclusais com papel carbono; (D) Desgaste seletivo, buscando-se a presença de contatos simultâneos dos dentes posteriores.
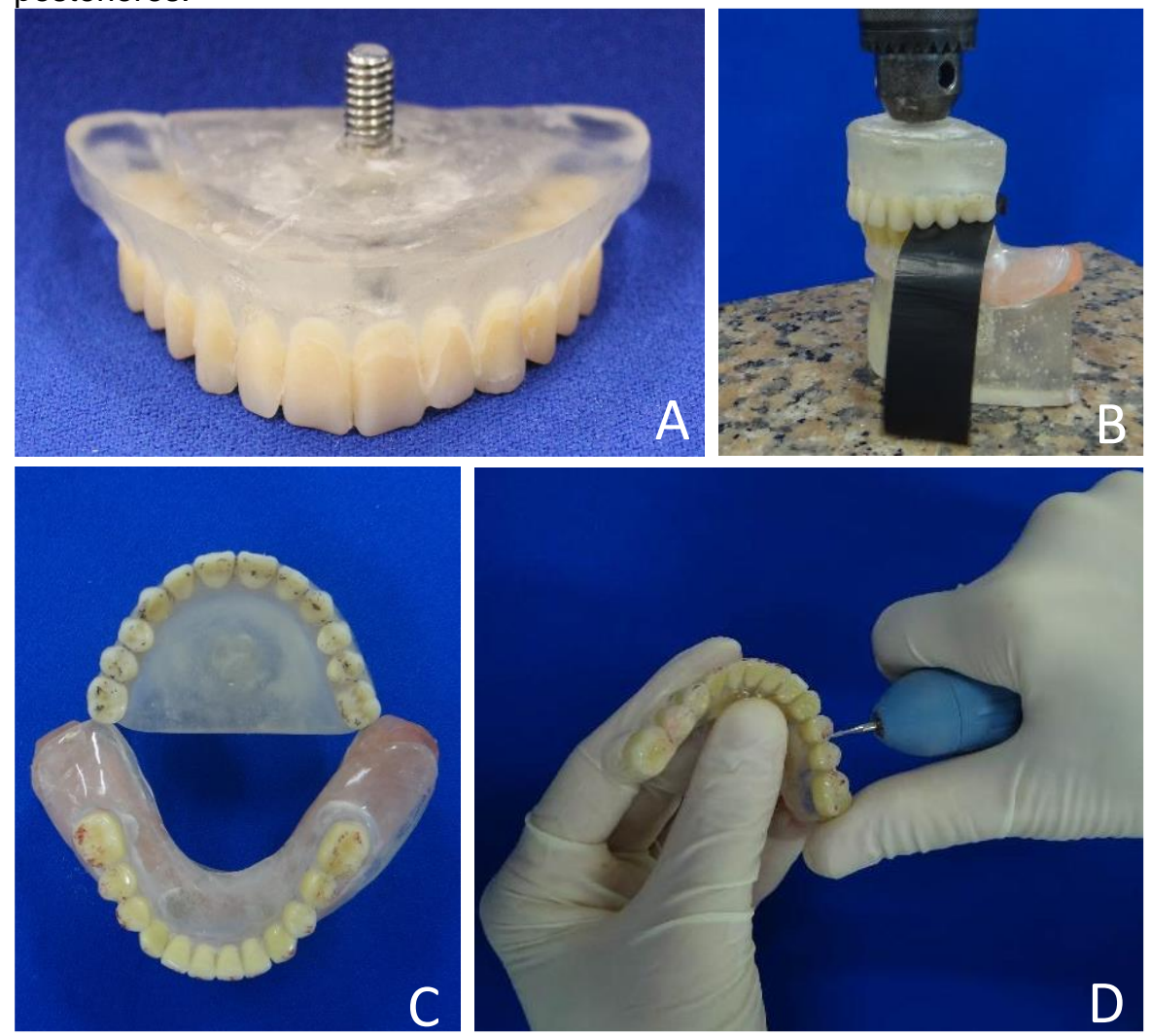

\subsection{Obtenção dos modelos para Correlação de Imagens Digitais}

Para obtenção dos seis modelos de poliuretano (F 160 Resina/Endurecedor - Axson Brasil In. E Com. Ltda., São Paulo - SP, Brasil) foram utilizados os moldes de silicone que reproduziam a posição exata dos implantes convencionais e mini-implantes dos modelos mestre. O poliuretano foi dosado seguindo as recomendações do fabricante, por meio de uma balança de precisão, com a dosagem de $23 \mathrm{~g}$ de resina F160 e $23 \mathrm{~g}$ de endurecedor para a obtenção de cada modelo. O poliuretano foi manipulado por 1 minuto para que a mistura ficasse homogênea. Posteriormente, o poliuretano foi vertido no interior do molde e aguardou-se o período de 60 minutos para a completa polimerização do material.

A superfície do modelo a ser analisada foi pintada com fina camada de tinta spray branca fosca (ColorGin, Sherwin-Williams do Brasil, Taboão da Serra - 
SP, Brasil), com pequenos pontos pretos também realizados com tinta spray que foram utilizados pelo sistema de correlação de imagens para facilitar o rastreamento de seu deslocamento e realizar corretamente os cálculos das tensões geradas na superfície do modelo (Li et al., 2009; Tiossi et al., 2011) (Figura 19).

Figura 19. (A) Modelos pintados com camada de tinta branca fosca e pontos pretos com tinta preta; (B) Modelos para correlação de imagens.
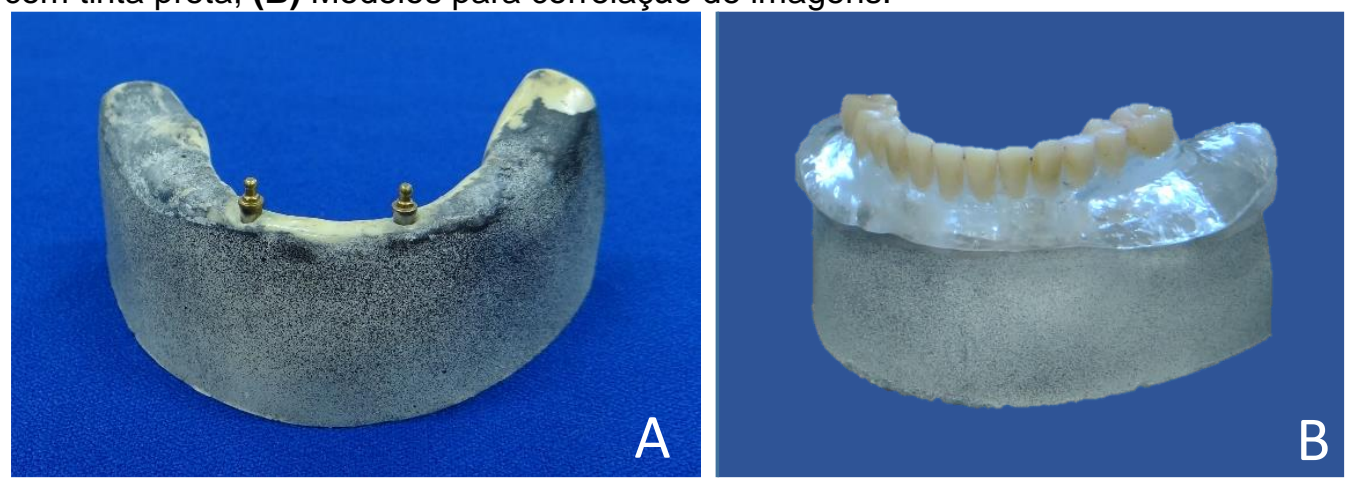

\subsubsection{Análise por Correlação de Imagens Digitais}

O conjunto completo da técnica de correlação de imagens digitais (StrainMaster, LaVision Inc., Goettingen, Alemanha) inclui duas câmeras digitais CCD (Charged-coupled device) (Imager Intense, LaVision Inc.) com resolução de 1039 x 1395 pixels para captura das imagens da superfície do modelo sob carregamento e um software (DaVis 8.1.2 LaVision Inc.) para análise das imagens e cálculo das tensões (Figura 20).

Figura 20. (A, B) Máquina universal de ensaios e conjunto completo da técnica de CID (câmeras digitais e software).
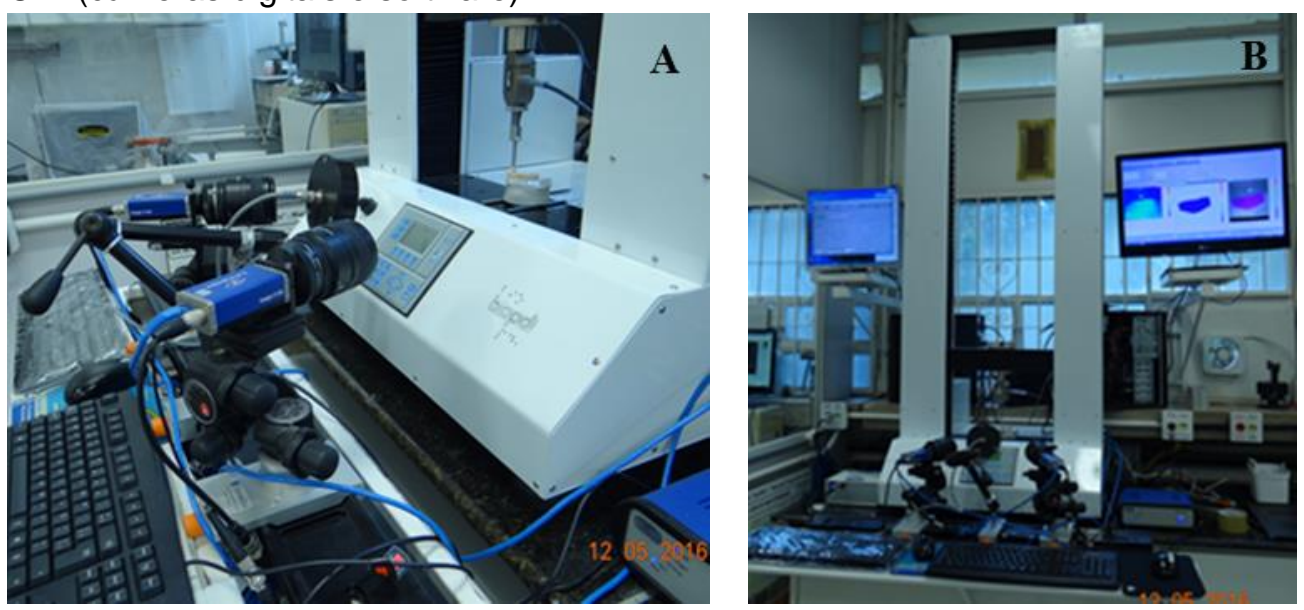

Para a análise por correlação de imagens digitais foram realizados dois tipos de carregamentos: pontual e oclusal. Nos carregamentos pontuais foi 
utilizada uma ponta de aplicação de carga pontual posicionada na fossa central do $1^{\circ}$ molar inferior direito, com carga de $250 \mathrm{~N}$ e velocidade de ensaio $0,5 \mathrm{~mm} / \mathrm{min}$. Nos carregamentos oclusais a prótese maxilar antagonista foi utilizada, e a carga aplicada foi de $300 \mathrm{~N}$ também com velocidade de ensaio $0,5 \mathrm{~mm} / \mathrm{min}$. As aplicações de carga foram realizadas na máquina universal de ensaios (Biopdi Indústria Comércio, Importação e Exportação de Equipamentos Médicos e Odontológicos Ltda., São Carlos - SP, Brasil).

O modelo foi apoiado em dois pontos para que sua base não ficasse em contato com a base na máquina universal de ensaios, evitando que houvesse possíveis alterações nas análises das tensões. A face vestibular do modelo foi posicionada em frente às câmeras digitais e, previamente a cada carregamento, foi realizada calibração das imagens com uma placa padrão fornecida pelo fabricante do equipamento (LaVision Inc) (Figura 21).

Figura 21. (A) Calibração das imagens com a placa padrão antes dos carregamentos; (B) Carregamento pontual na fossa central do $1^{\circ}$ molar inferior direito; (C) Carregamento oclusal com prótese maxilar antagonista.
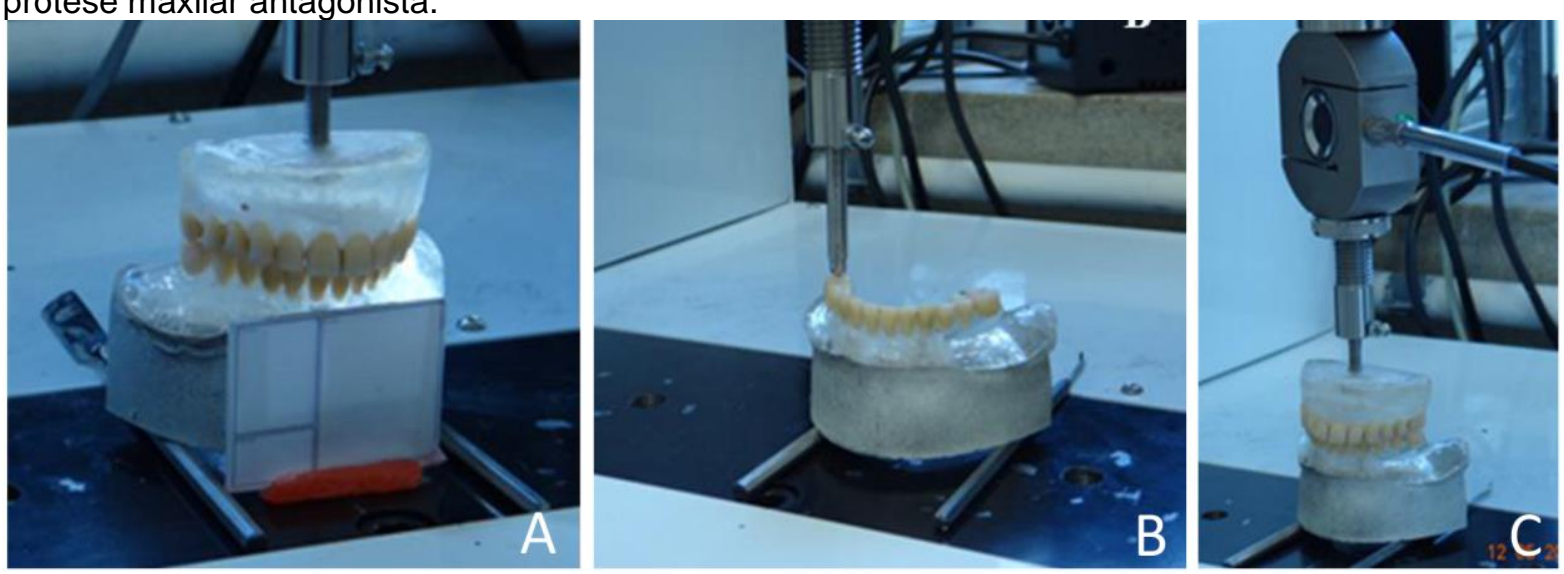

Para medir as tensões geradas na superfície do modelo após, foram obtidas imagens da superfície pintada na frequência de $1,00 \mathrm{~Hz}$ até que as cargas de $250 \mathrm{~N}$ e $300 \mathrm{~N}$ fossem atingidas. As tensões superficiais horizontais $\left(\mathcal{E}_{\mathrm{xx}}\right)$ as quais incluem tensões de compressão e tração foram calculadas a partir dos deslocamentos dos pontos pretos pelo software de correlação de imagens digitais (Davis 8.0, LaVision). Todos os grupos foram analisados pelo sistema de correlação de imagens digitais qualitativamente.

A análise qualitativa das imagens foi realizada baseando-se na escala de cores, na qual os valores positivos (do amarelo ao vermelho) referem-se às tensões de tração e os valores negativos (do verde ao azul) às tensões de compressão. É 
possível encontrar áreas em que há coexistência de tensões de tração e compressão. Ainda existe uma zona em que estas tensões tendem a se equilibrar (branco), que corresponde a tensões de magnitude em torno de zero.

\subsection{Ensaio de fadiga acelerada progressiva}

Seis pares de próteses foram posicionados, por vez, na máquina para ciclagem termomecânica (BIOPDI, São Carlos, SP, Brasil). As bases dos modelos de ensaio foram unidas a anéis de PVC de 3/4" com resina acrílica autopolimerizável (VipiFlash, Vipi), para serem adequadamente posicionados nos casulos da máquina de ciclagem termomecânica (Figura 22).

Figura 22. (A, B) Fixação do anel de PVC à base do modelo de ensaio.
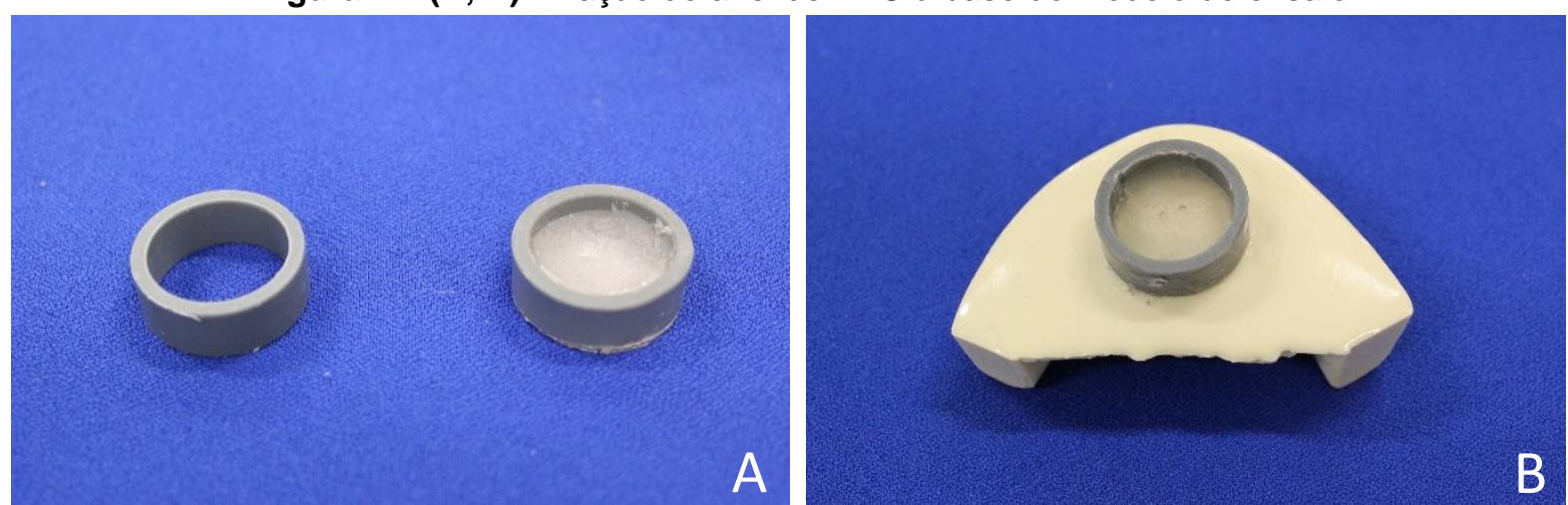

Foi utilizado um carregamento isométrico com frequência de $5 \mathrm{~Hz}$, realizando 20000 ciclos em cada estágio, em um total máximo de 120.000 ciclos. As cargas de compressão pneumática estabelecidas foram de $80 \mathrm{~N}, 140 \mathrm{~N}, 200 \mathrm{~N}, 260 \mathrm{~N}, 320 \mathrm{~N}$ e $380 \mathrm{~N}$ por grupo de modo subsequente. Durante a ciclagem mecânica, os grupos foram submetidos à ciclagem térmica, nos quais ficavam imersos em água com variação de temperatura entre $5^{\circ} \mathrm{C}$ e $55^{\circ} \mathrm{C}$, e tempo de imersão de 40 segundos.

A ciclagem foi realizada iniciando com valores de cargas da força de mordida sobre próteses removíveis (<150 N) (Koc, Dogan, Bek, 2010; Miyaura et al., 2000; Ferrario et al., 2004) chegando a valores maiores que as relatadas na literatura (DeLong, Douglas, 1983; Rekow, Thompson, 2005), para posterior análise da retenção e integridade dos componentes. Observando a taxa de sobrevivência das amostras em todo conjunto (Figura 23). 
Figura 23. Máquina de ciclagem termomecânica.

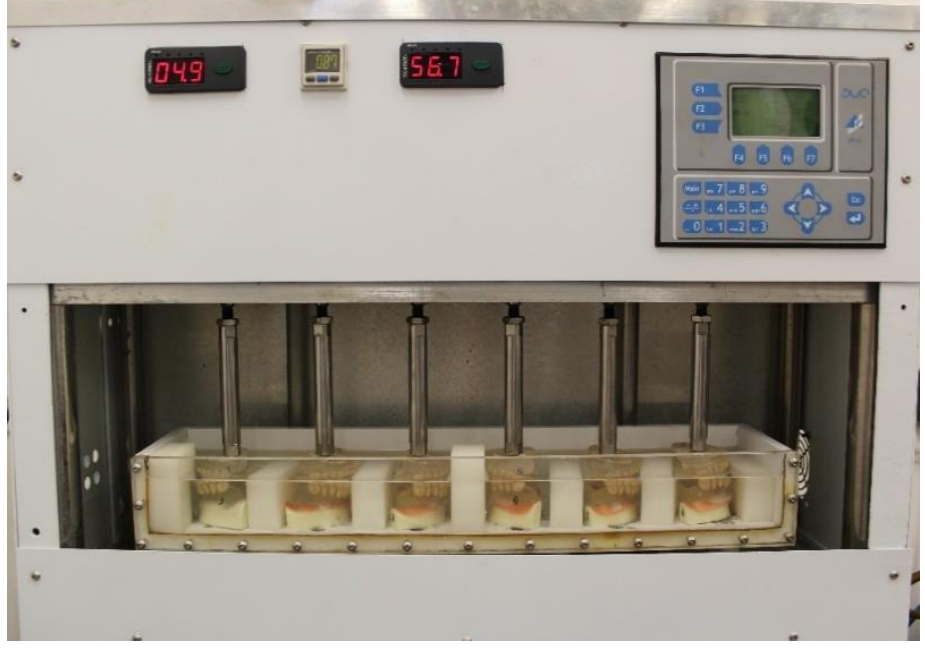

\subsubsection{Ensaio de tração}

As leituras da força de retenção foram realizadas por ensaio de tração em máquina de ensaios universal (Biopdi Indústria Comércio, Importação e Exportação de Equipamentos Médicos e Odontológicos Ltda., São Carlos - SP, Brasil), previamente a ciclagem termomecânica, após carga $200 \mathrm{~N}$ e novamente após carga $380 N$. As leituras foram realizadas em triplicata. Para realizar a tração das próteses, um dispositivo em acrílico, no formato triangular, foi fixado na prótese, no espaço do assoalho bucal com resina acrílica autopolimerizável (Figura 24). 
Figura 24. Dispositivo acrílico colado nas próteses inferiores para ensaio de tração.

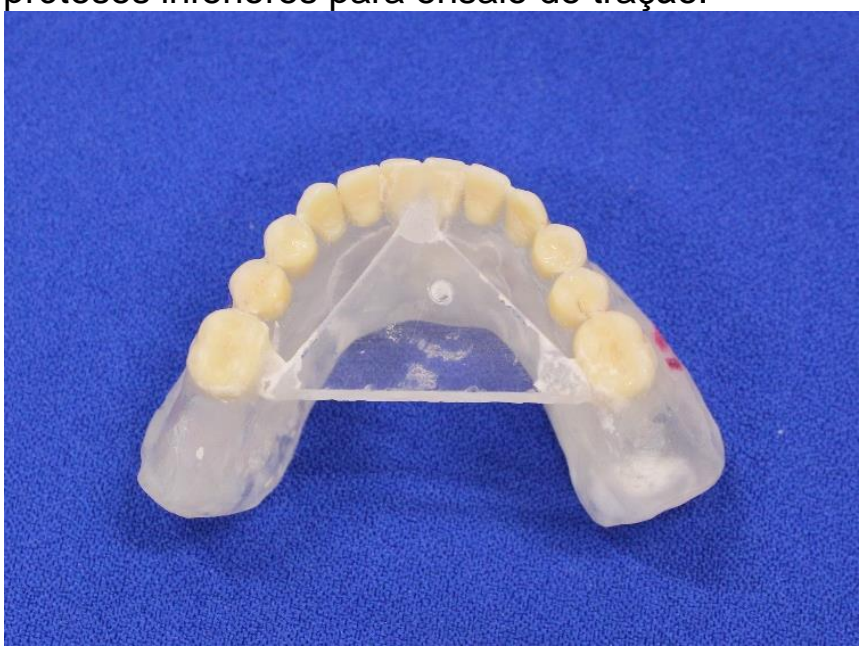

Para que todos os dispositivos em acrílico fossem retidos às próteses inferiores, na mesma angulação e altura, foi utilizada uma ponta de delineador confeccionada na oficina de precisão do Departamento de Materiais Dentários e Prótese. Nesta ponta, o dispositivo acrílico era retido com cera $\mathrm{n}$ 7 e levado de encontro a placa de vidro, para obter paralelismo do mesmo. Logo após, era colocado o modelo inferior em posição e novamente a ponta era levada de encontro a prótese inferior, logo abaixo da parte lingual dos dentes de estoque. $\mathrm{O}$ dispositivo foi colado à prótese com resina acrílica autopolimerizável e aguardou a polimerização total da resina.

Para os modelos mandibulares com retenção anterior, a perfuração foi realizada no ponto central da linha média entre os implantes. Para os modelos mandibulares com retenção anterior e posterior, foi realizada a perfuração no ponto neutro do trapézio, formado pelos quatro implantes (Provenza, 1986), essas perfurações foram realizadas para o posicionamento do gancho de retenção (Figura 25). Sendo que: 
Figura 25. Desenho do trapézio isósceles, e a localização dos pontos de perfuração para os modelos com retenção anterior (verde) e retenção anterior e posterior (vermelho).

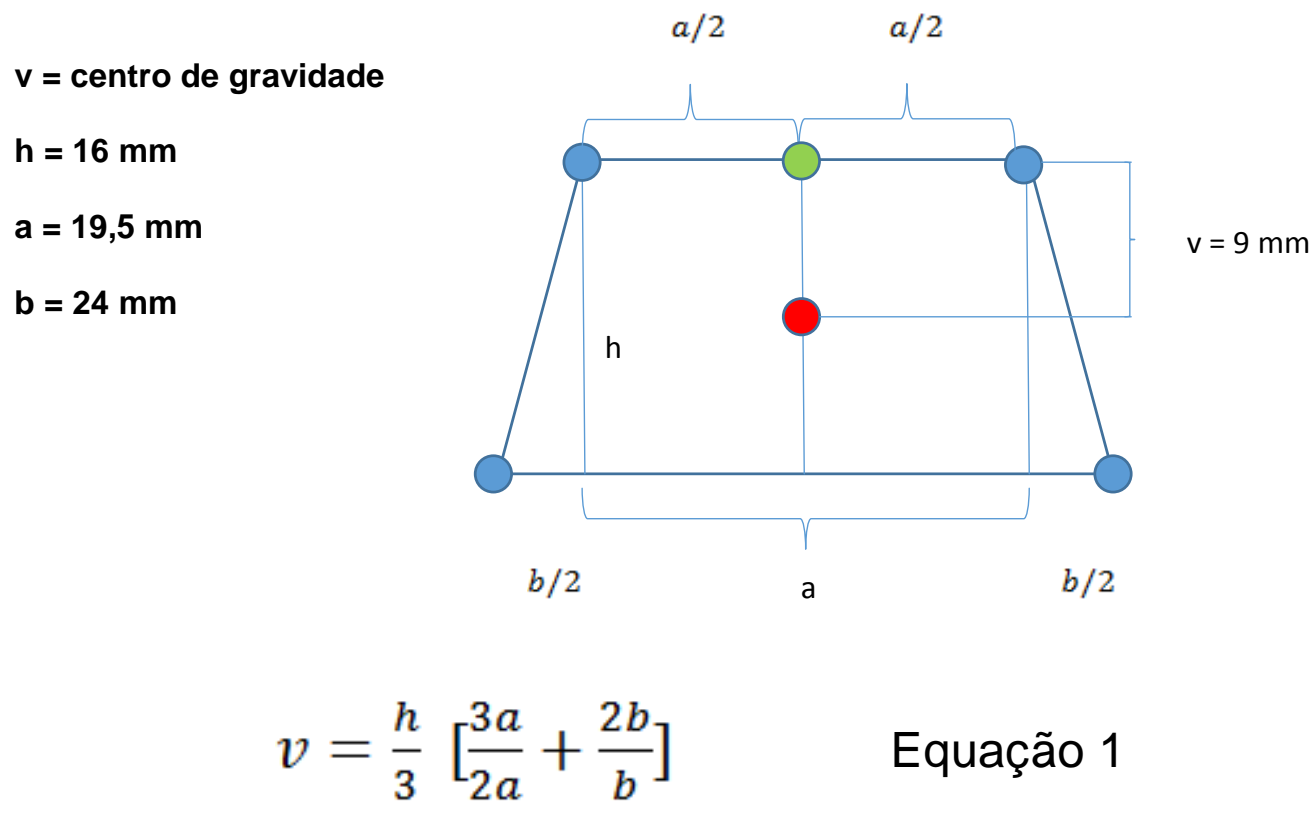

Foi realizada perfuração com peça reta e broca esférica para que fosse rosqueado o gancho metálico. Este procedimento foi realizado em todos os modelos para o posicionamento considerado correto da linha de tracionamento (Figura 26).

Figura 26. (A, B) Gancho metálico posicionado no orifício central do dispositivo acrílico.
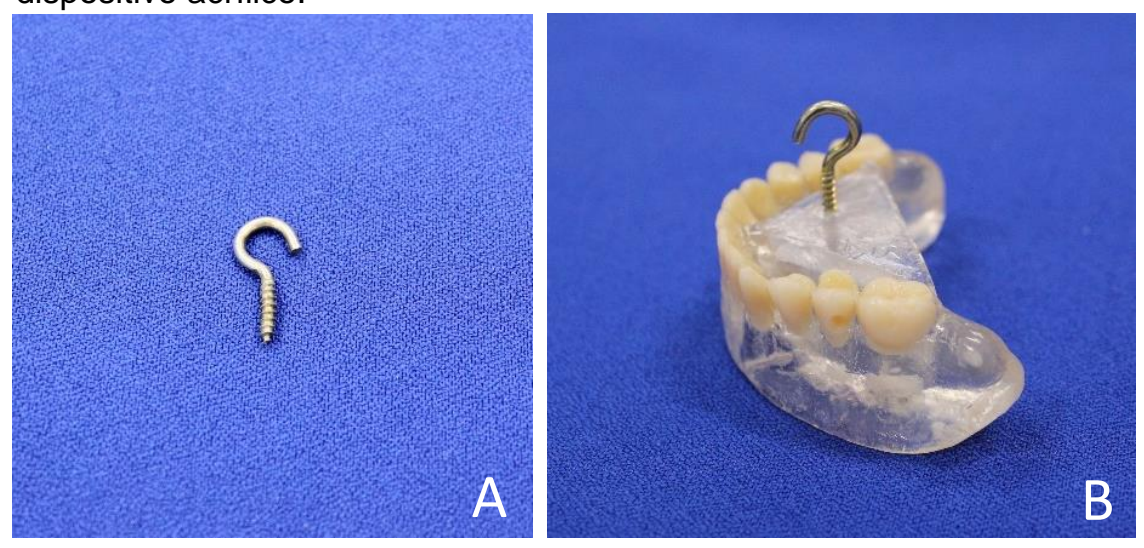

Foi utilizada uma corrente, que passava na argola do gancho metálico e a outra extremidade passava na ponta da célula de carga de $100 \mathrm{Kgf}$ da máquina de ensaio. O tracionamento foi realizado na velocidade de $10 \mathrm{~mm}$ por minuto até a remoção da overdenture do modelo (Figura 27). 
Figura 27. (A, B) Corrente acoplada ao gancho no modelo inferior e na célula de carga da máquina para realizar 0 ensaio detração.
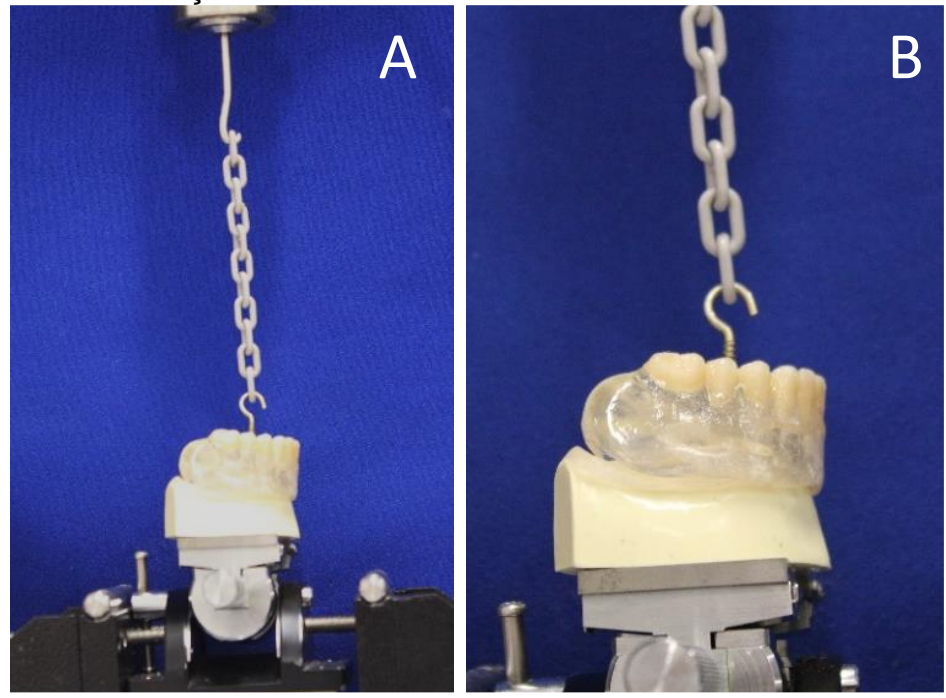

\subsubsection{Análise estatística dos ensaios de tração}

Para análise estatística dos efeitos da ciclagem termomecânica sobre a retenção dos componentes, inicialmente foi realizado análise exploratória de dados através de medidas de posição central e de dispersão. Um modelo de regressão linear de efeitos mistos foi ajustado. Foi considerado como efeito fixo o tempo e os grupos, as medidas repetidas do mesmo corpo de prova foi considerada como efeito aleatório. As comparações entre os grupos em cada tempo e os tempos em cada grupo foram realizadas utilizando contrastes ortogonais. A análise de resíduo foi desempenhada através de gráficos de normalidade e de dispersão entre o resíduo e os valores preditos. O modelo foi implementado no PROC MIXED do programa SAS versão 9.3. Para todas as comparações adotou-se nível de significância de 5\%.

\subsubsection{Análise por microscopia ótica dos componentes protéticos}

Antes e após cada ensaio de tração nas cargas mencionadas acima, foi realizada a análise no microscópio óptico modelo S8AP0 (Leica, Alemanha) das borrachas de cada O'ring e clipe, com magnitude de $20 \mathrm{x}$, para verificar o perímetro circunferencial interno das borrachas e a distância dos bordos dos clipes, observando se houve alterações estruturais nesses componentes ao longo da ciclagem. Foi também realizada análises das imagens das barras e attachments bolas dos sistemas convencional e mini-implante, para verificar se havia danos 
estruturais relevantes, porém não foi observado irregularidades significativas ao longo dos ensaios.

Para padronizar a posição dos modelos, durante análise das imagens capturadas pela câmera CLS 150 x do microscópio óptico, foi confeccionado com index de silicone laboratorial (Zetalabor). Para o modelo inferior, a moldagem copiava a parte inferior, e o tudo PVC apresentava-se como guia para posicionar os outros modelos. Já para a prótese inferior, foi confeccionado um index de silicone copiando os dentes artificiais (Figura 28).

Figura 28. (A, B) Confecção de index de silicone para padronização da leitura dos componentes.
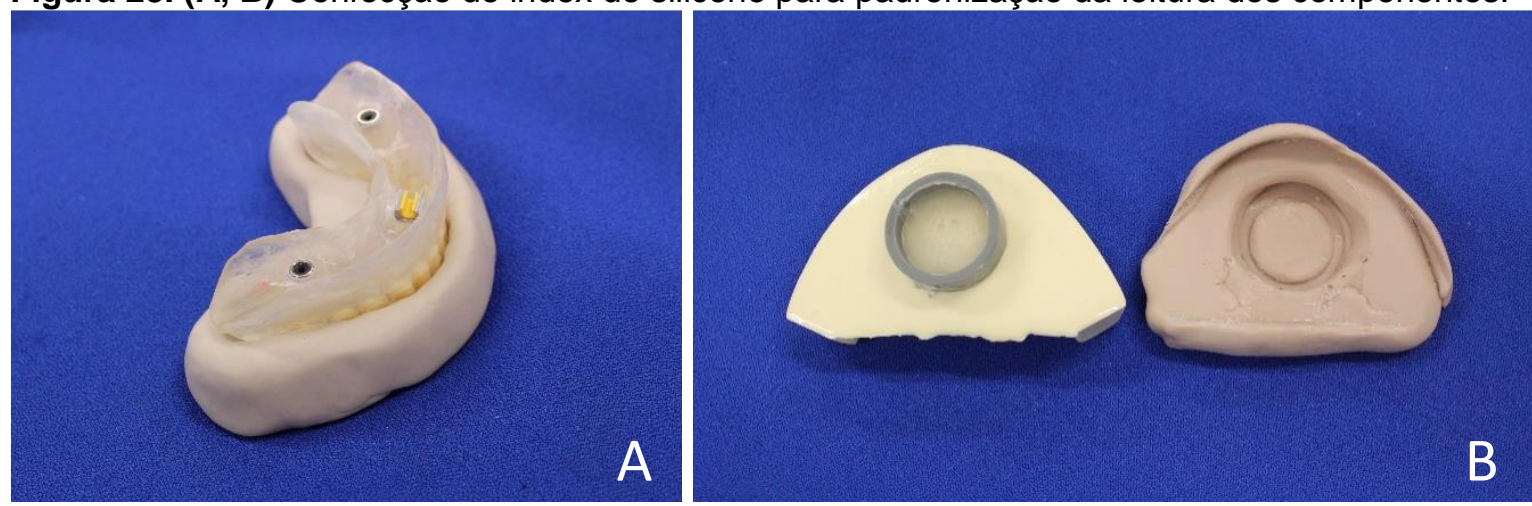

Para análise das imagens realizadas nos O'rings e clipes, utilizou-se um software LAS V4.0 (Leica Application Suite V4/Framework.exe "LAS"), acoplado ao microscópio óptico, as medidas de cada componente protético foram realizadas em triplicata. Em relação aos O'rings, preconizou a medição do perímetro circunferencial interno da borracha (Figura 29). 
Figura 29. (A) Imagem no microscópio óptico da medição do perímetro do O'ring do implante convencional; (B) Imagem da medição do perímetro do O'ring do mini-implante.
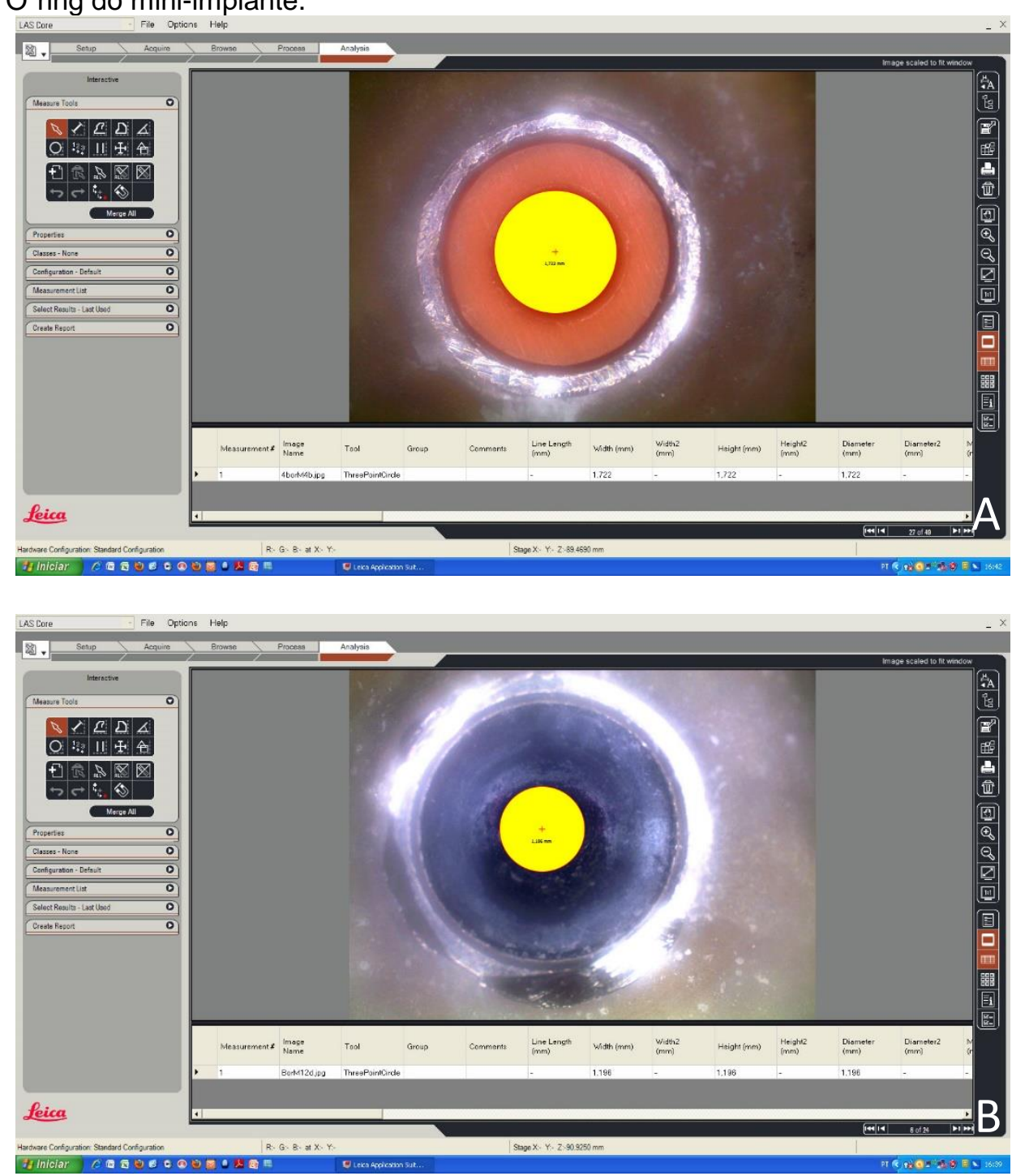

Nos clipes foram medidas as distâncias entre as paredes em 3 pontos, no qual através de um ícone do software, mediu-se $1 \mathrm{~cm}$ aquém das extremidades e uma medida correspondente ao centro do clipe, unindo linhas de um bordo ao outro do clipe. Foi realizada, posteriormente, análise quantitativa dessas alterações (Figura 30). 
Figura 30. Imagem da medida da distância entre as paredes do clipe em três pontos.

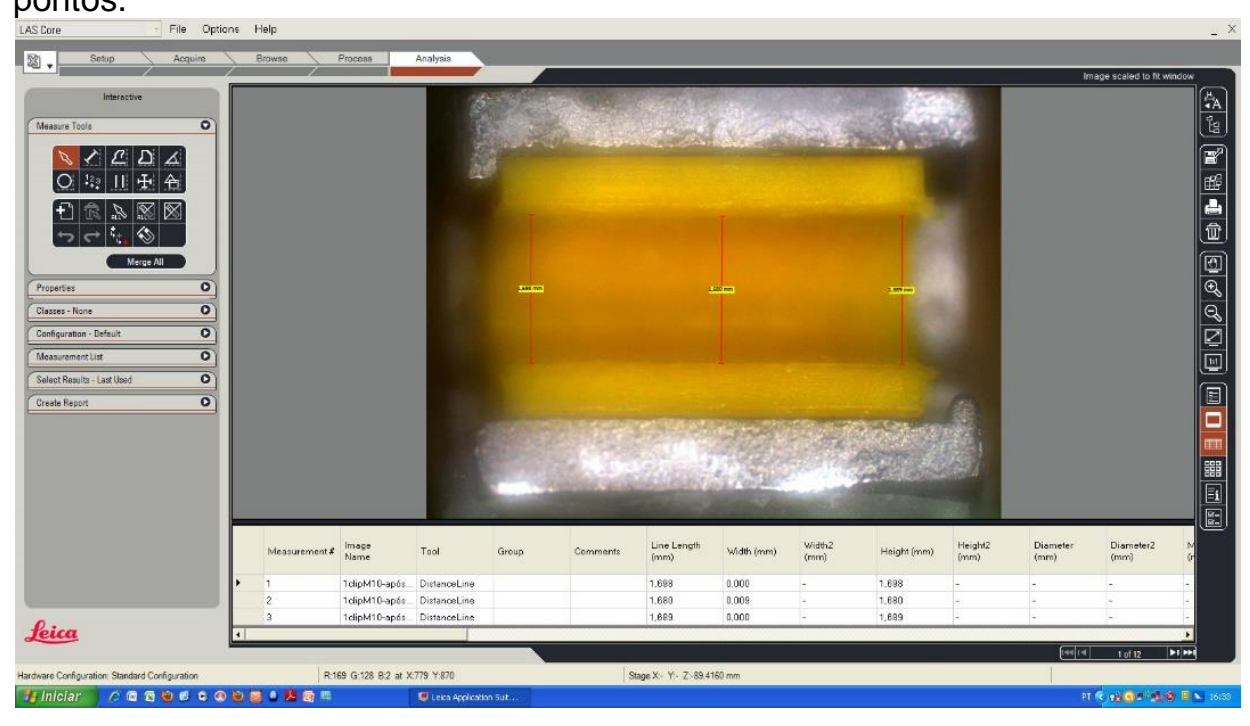

\subsubsection{Análise estatística da microscopia óptica dos componentes protéticos}

Os dados foram descritos através de medidas de posição central e de dispersão. Para verificar o efeito dos grupos e do tempo sobre os componentes de retenção, o método de equação de estimativas generalizadas (GEE) (McCullagh, Nelder, 1989) foi utilizado para estimar os parâmetros do modelo linear generalizado com distribuição Gama e função de ligação identidade. Foi considerado uma estrutura para dados correlacionados uma vez que ouve medidas ao longo do tempo para o mesmo corpo de prova (Zeger, Liang 1986). As comparações foram realizadas através de contrastes. O modelo foi implementado no programa SAS versão 9.2 considerando a PROC GENMOD. Para todas as comparações adotou-se nível de significância de 5\%. 
4. RESULTADOS 



\section{RESULTADOS}

\subsection{Análise da correlação de imagens digitais}

A comparação qualitativa entre os grupos foi realizada, avaliando se houve tensões compressivas (valores negativos na escala verde para azul) ou de tração (valores positivos na escala amarela para vermelha), nas regiões anterior e posterior de cada modelo.

A figura 31 apresenta a vista lateral das tensões resultantes da aplicação de carga oclusal.

Figura 31. Tensões encontradas na região posterior, com o modelo posicionado lateralmente e carregamento oclusal $(300 \mathrm{~N})$.

\section{OCLUSAL LATERAL}

$1 \mathrm{~B}$

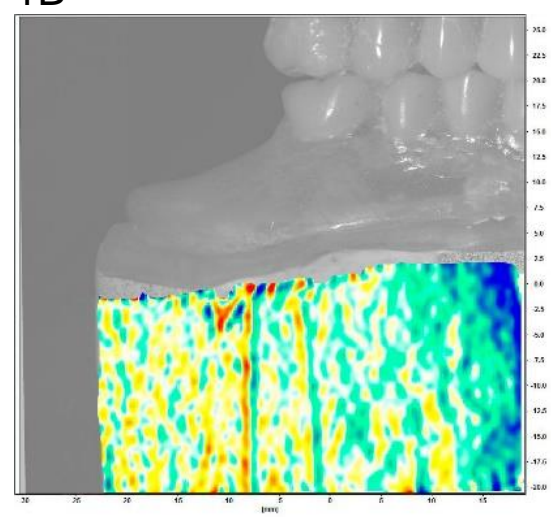

20

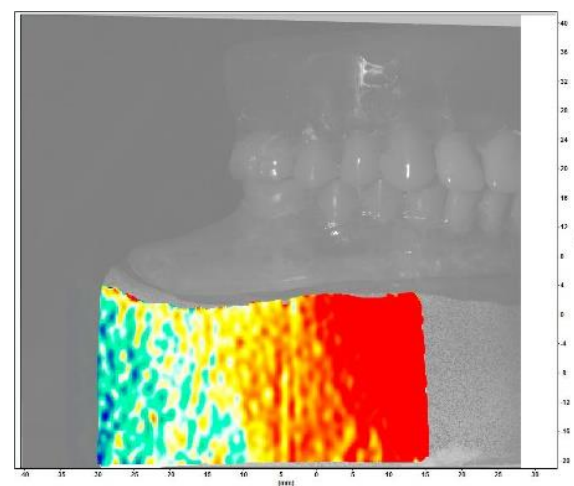

$1 \mathrm{~B} 2 \mathrm{O}$

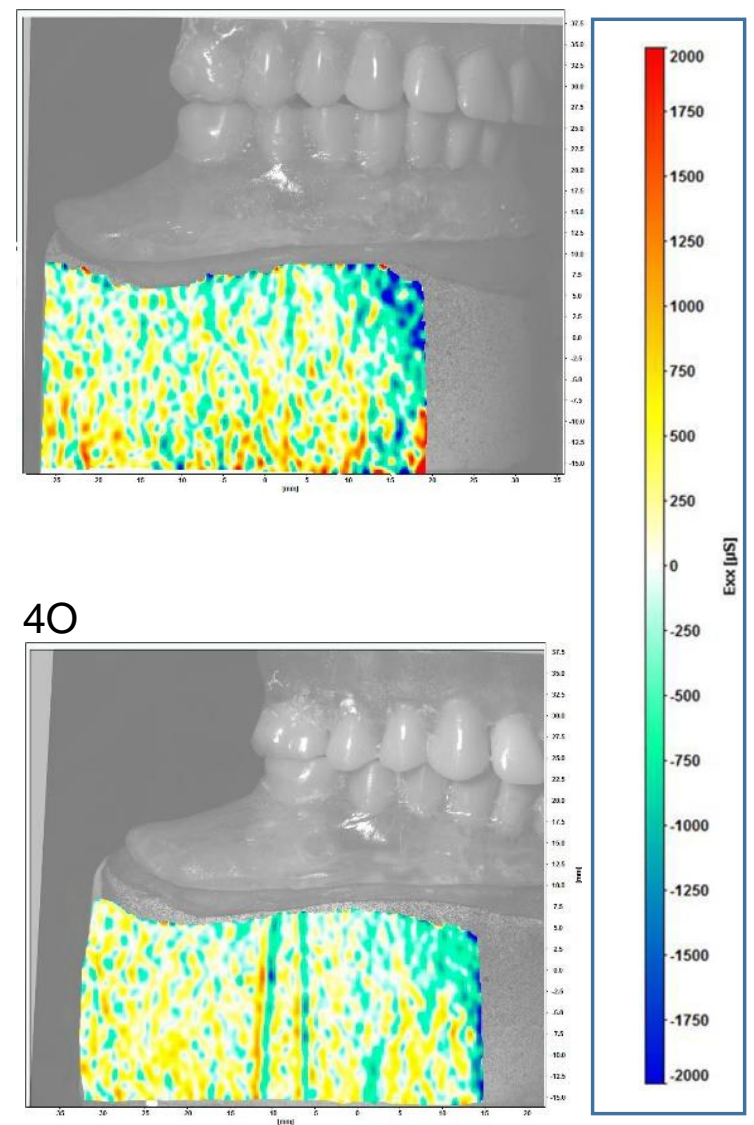

Pode-se verificar qualitativamente na Figura 31, que as tensões nos grupos 1B e 1B2O foram semelhantes, observando região com tensões compressivas na parte mais anterior do modelo e tesões de tração entre áreas neutras na região mais posterior. Em vista disso, pode-se relatar que a distribuição de tensão não se altera 
com a colocação de mini-implantes posteriores em próteses com sistema retentivo barra/clipe.

No grupo 20, observou tensões de tração intensa na região anterior, próximo a região dos caninos. O comportamento no grupo $4 \mathrm{O}$, foi oposto ao $2 \mathrm{O}$, pois não apresentou quase nenhuma tensão de tração, e sim tensões compressivas por toda área analisada e, com menor intensidade. Desta maneira, o mini-implante para este tipo de prótese favoreceu muito a distribuição das tensões.

A figura 32 apresenta a vista frontal da distribuição das tensões resultantes da aplicação de carga oclusal.

Figura 32. Tensões encontradas na região anterior, com o modelo posicionado frontalmente e carregamento oclusal $(300 \mathrm{~N})$.

\section{OCLUSAL FRONTAL}

$1 \mathrm{~B}$

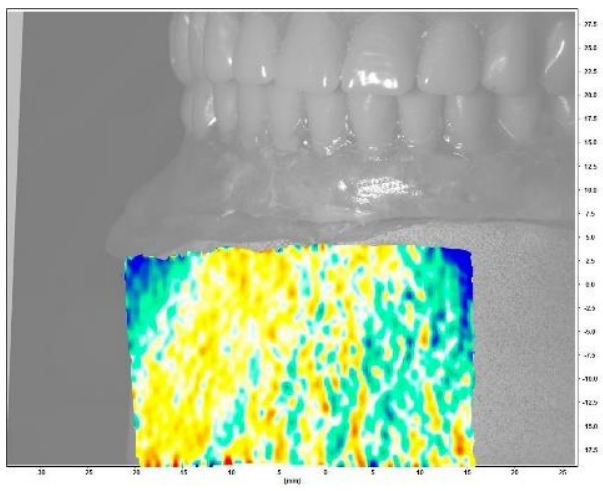

20

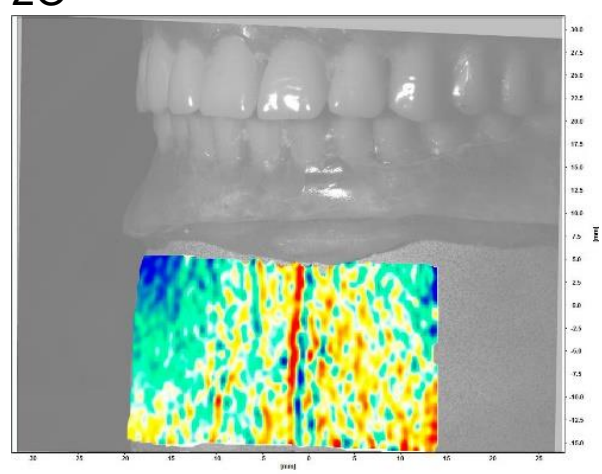

$1 \mathrm{~B} 2 \mathrm{O}$

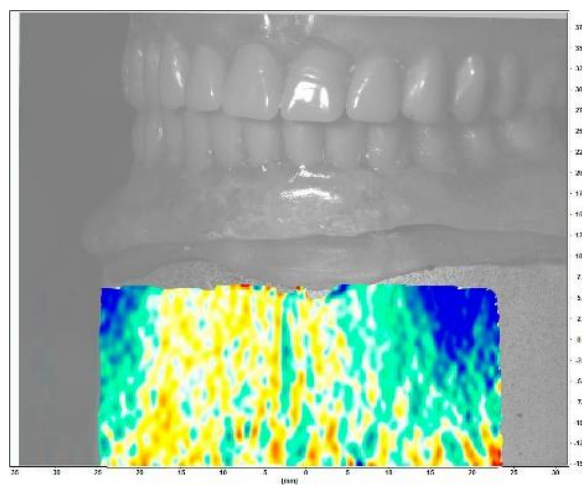

40

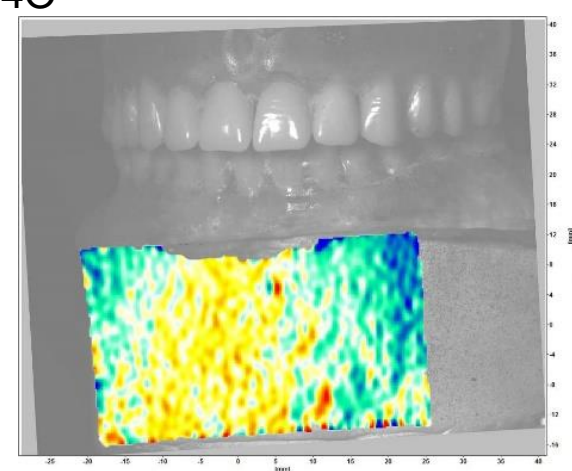

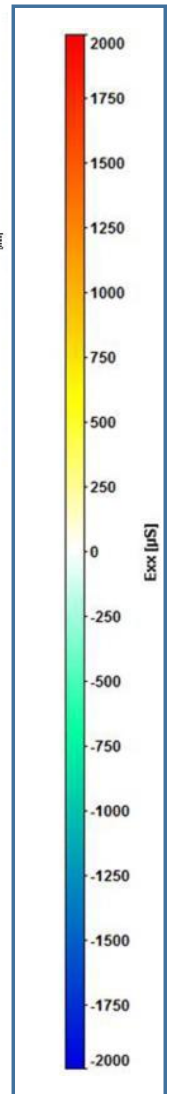

$\mathrm{Na}$ figura 32, notou-se que a distribuição das tensões de todos os modelos foi semelhante, ou seja, as tensões anteriores apresentaram áreas com coexistência de tensões de tração e compressão. Deve atentar-se que o grupo 20, houve tendência a valores positivos maiores, apresentando tensão de tração um pouco mais evidente, confirmando a maior rotação da prótese para posterior. 
A figura 33 apresenta a vista lateral da distribuição das tensões resultantes da aplicação de carga pontual.

Figura 33. Tensões encontradas na região posterior, com o modelo posicionado lateralmente e carregamento pontual $(250 \mathrm{~N})$.

\section{PONTUAL LATERAL}

$1 \mathrm{~B}$

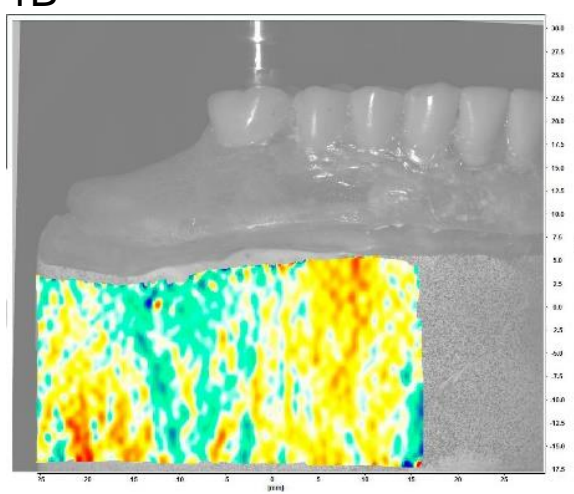

20

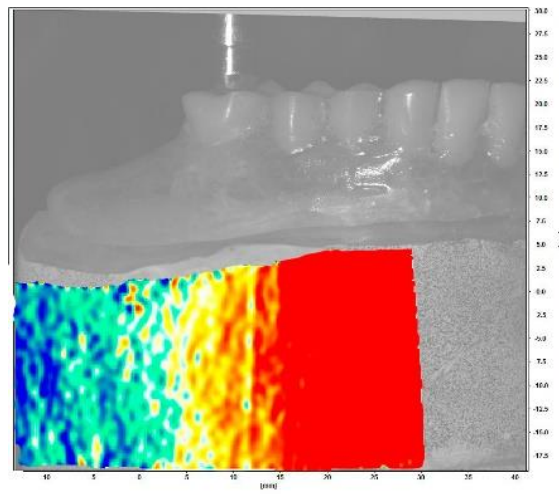

$1 \mathrm{~B} 2 \mathrm{O}$

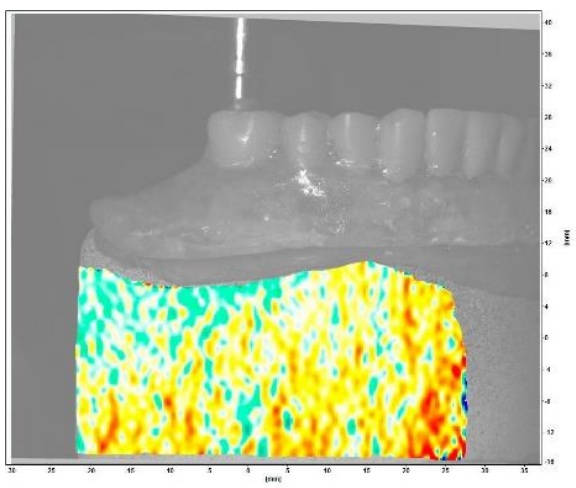

40

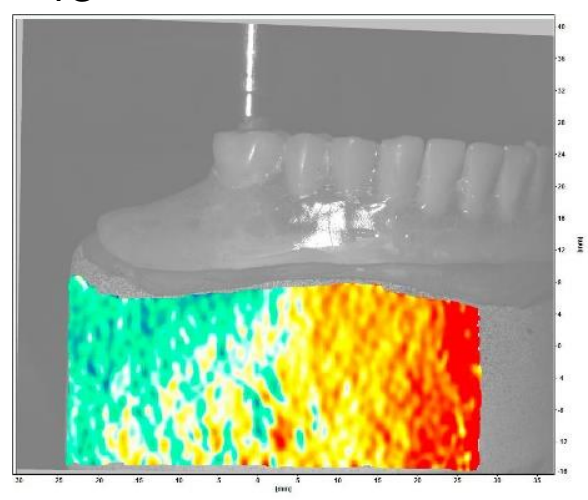

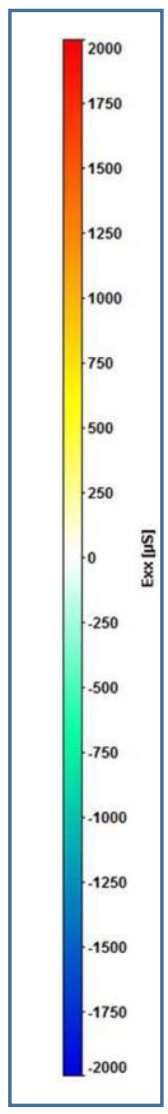

Após analisar as imagens da figura 33, notou-se que todos os modelos apresentaram tensões de compressão na região posterior e tensões de tração na região anterior, sendo mais expressivas nos modelos com O'rings. Porém, com maior intesidade no grupo 20 , relacionando assim, a influência positiva dos miniimplantes posteriores no grupo 4O, ou melhor, eles mantém a prótese mais estável, não ocorrendo força de tração demasiada nos implantes anteriores. Comparando os grupos 1B e 1B2O, a concentração de tensão de tração anterior apresenta ser menos intensa quando há mini-implantes posteriores.

A figura 34 apresenta a vista frontal da distribuição das tensões resultantes da aplicação de carga pontual. 
Figura 34. Tensões encontradas na região anterior, com o modelo posicionado frontalmente e carregamento pontual $(250 \mathrm{~N})$.

\section{PONTUAL FRONTAL}

$1 \mathrm{~B}$

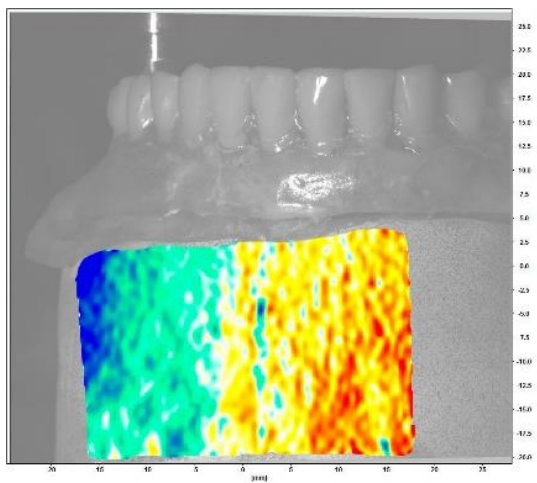

20

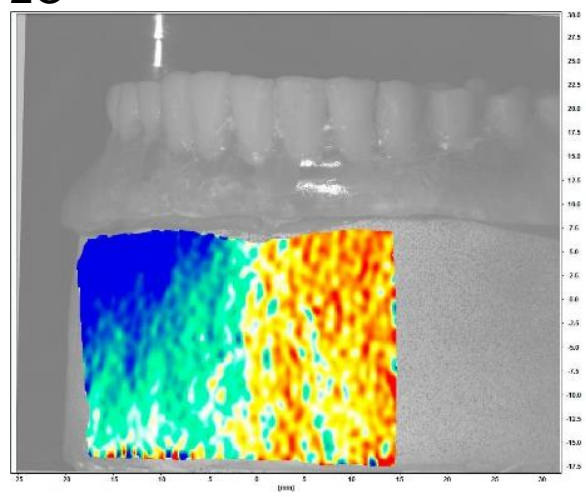

$1 \mathrm{~B} 2 \mathrm{O}$

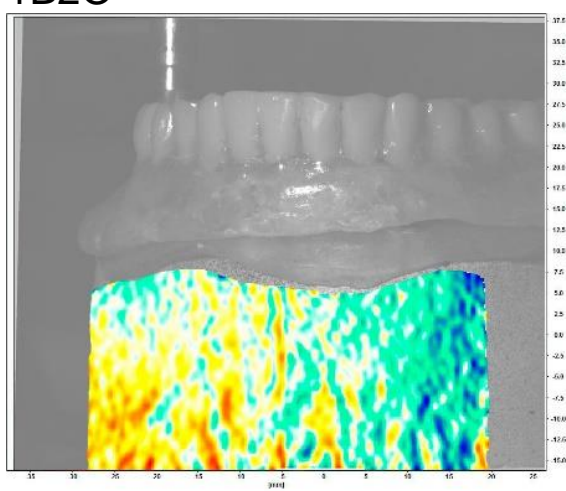

40

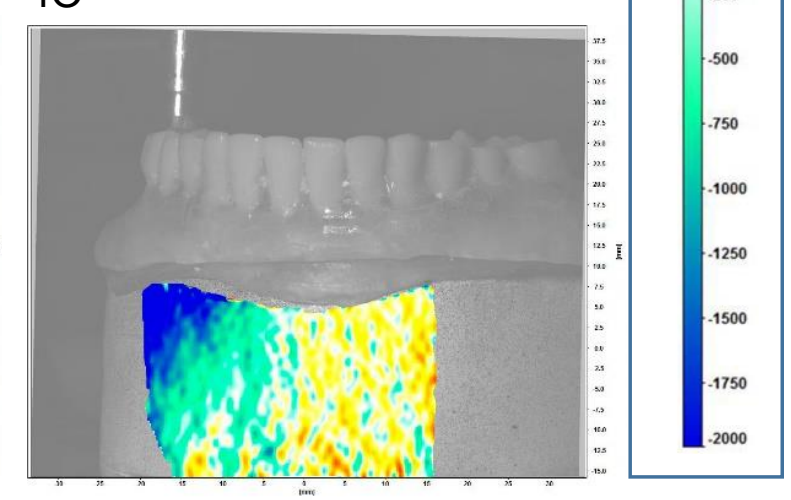

$\mathrm{Na}$ figura 34, observa-se tensões de tração do lado oposto da aplicação da carga pontual nos grupos 1B, 20 e com pouca intensidade no grupo 4O. Já no grupo 1B2O há tensão de compressão devido à diminuição de rotação do clipe somado a parada do movimento com os mini-implantes posteriores. Em relação a tensão de compressão apresentada nos modelos, é bem visível no local que a carga pontual está sendo efetuada. Podendo relatar que nesta situação, os mini-implantes posteriores exerceram diferença positiva na distribuição de tensão.

\subsection{Ensaio de fadiga acelerada progressiva}

As tabelas abaixo apresentam a estatística descritiva e as comparações estatísticas dos grupos e dos tempos de trabalho estabelecidos, seguindo as nomenclaturas mencionadas no capítulo 3: Grupo 1B; Grupo 1B2O; Grupo $2 \mathrm{O}$ e Grupo 4O, para o ensaio de fadiga acelerada progressiva. Todos os corpos de prova resistiram ao ensaio, com exceção de um corpo de prova do grupo 1B, que fraturou 
após a ciclagem termomecânica com carga de 80N. Após observação do modelo, pressupõe que esta fratura ocorreu devido a pouca espessura de resina na região lingual onde se encontrava o clipe, e não por falha devido à carga estabelecida.

A Tabela 1 apresenta os resultados da estatística descritiva com média e desvio padrão, da força de retenção dos componentes protéticos no ensaio de tração. Todos os modelos foram submetidos ao ensaio de ciclagem termomecânica, ao tracionamento e coleta de dados, foram realizados previamente a ciclagem termomecânica (Tempo 1), após 200 N (Tempo 2) e após 380 N (Tempo 3). Para todas as comparações adotou-se nível de significância de 5\%.

Tabela 1. Medidas de posição central e de dispersão da resistência à tração $(\mathrm{N})$ em relação aos grupos e aos tempos.

\begin{tabular}{cccccccccc}
\hline Grupo & Tempo & N. Obs. & Média & $\begin{array}{c}\text { Desvio } \\
\text { Padrão }\end{array}$ & Mediana & Q1 & Q3 & Min & Max \\
\hline \multirow{2}{*}{ 1B } & 1 & 36 & 36,55 & 19,12 & 29,63 & 24,23 & 46,26 & 5,6 & 89,31 \\
& 2 & 36 & 37,87 & 15,03 & 35,71 & 28,35 & 41,07 & 16,18 & 79,85 \\
& 3 & 36 & 33,09 & 10,4 & 33,86 & 24,76 & 40,25 & 14,64 & 54,37 \\
\hline \multirow{2}{*}{$\mathbf{1 B 2 0}$} & 1 & 36 & 40,64 & 9,82 & 39,25 & 32,28 & 48,98 & 25,43 & 60,27 \\
& 2 & 36 & 39,44 & 9,52 & 38,72 & 32,01 & 46,09 & 25,25 & 61,09 \\
& 3 & 36 & 35,38 & 9,29 & 34,88 & 29,93 & 43,27 & 15,25 & 51,07 \\
\hline \multirow{2}{*}{$\mathbf{2 0}$} & 1 & 36 & 17,09 & 5,77 & 15,77 & 12,81 & 20,1 & 7,56 & 31,47 \\
& 2 & 36 & 18,11 & 5,92 & 17,91 & 13,91 & 21,17 & 7,94 & 32,39 \\
& 3 & 36 & 20,4 & 4,28 & 20,59 & 17,29 & 23,89 & 12,3 & 28,76 \\
\hline \multirow{2}{*}{ 40 } & 1 & 36 & 29,86 & 4,13 & 28,67 & 27,28 & 31,13 & 24,02 & 40,61 \\
& 2 & 36 & 28,1 & 2,96 & 28,37 & 26,42 & 30,31 & 21,1 & 32,61 \\
& 3 & 36 & 26,77 & 3,79 & 27,19 & 23,91 & 29,35 & 18,51 & 32,89 \\
\hline
\end{tabular}

Tempo 1. Antes da ciclagem termomecânica

Tempo 2. Após $200 \mathrm{~N}$

Tempo 3. Após $380 \mathrm{~N}$

Nível de significância: $p<0,05$

$\mathrm{Na}$ tabela 2 são apresentados os resultados das comparações da resistência à tração $(\mathrm{N})$ das overdentures dos diferentes grupos nos três tempos analisados. 
Tabela 2. Modelo linear de efeitos mistos. Comparação da resistência a tração (N) entre os grupos.

\begin{tabular}{cccccc}
\hline \multirow{2}{*}{ Tempo } & $\begin{array}{c}\text { Comparação entre } \\
\text { grupos }\end{array}$ & $\begin{array}{c}\text { Estimativa da diferença } \\
\text { entre as médias }\end{array}$ & \multicolumn{2}{c}{ IC 95\% } & \multirow{2}{*}{ P-valor } \\
\cline { 4 - 5 } & $1 \mathrm{~B}-1 \mathrm{~B} 2 \mathrm{O}$ & $-4,0895$ & $\mathbf{L}$ & $\mathbf{L S}$ & \\
\multirow{2}{*}{$\mathbf{1}$} & $1 \mathrm{~B}-2 \mathrm{O}$ & 19,4609 & $-8,3515$ & 0,1724 & 0,06 \\
& $1 \mathrm{~B} 2 \mathrm{O}-4 \mathrm{O}$ & 10,7804 & 15,199 & 23,7229 & $<, 0001$ \\
& $2 \mathrm{O}-4 \mathrm{O}$ & $-12,7701$ & 6,5184 & 15,0423 & $<, 0001$ \\
& $1 \mathrm{~B}-1 \mathrm{~B} 2 \mathrm{O}$ & $-1,4528$ & $-17,0321$ & $-8,5082$ & $<, 0001$ \\
\hline \multirow{2}{*}{$\mathbf{2}$} & $1 \mathrm{~B}-2 \mathrm{O}$ & 19,8704 & $-5,8119$ & 2,9063 & 0,5127 \\
& $1 \mathrm{~B} 2 \mathrm{O}-4 \mathrm{O}$ & 1,3407 & 15,5113 & 24,2295 & $<, 0001$ \\
& $2 \mathrm{O}-4 \mathrm{O}$ & $-9,9825$ & 7,0788 & 15,6027 & $<, 0001$ \\
& $1 \mathrm{~B}-1 \mathrm{~B} 2 \mathrm{O}$ & $-2,1812$ & $-14,2445$ & $-5,7205$ & $<, 0001$ \\
\hline \multirow{2}{*}{$\mathbf{3}$} & $1 \mathrm{~B}-2 \mathrm{O}$ & 12,8031 & $-6,5403$ & 2,1779 & 0,3259 \\
& $1 \mathrm{~B} 2 \mathrm{O}-4 \mathrm{O}$ & 8,6126 & 8,444 & 17,1622 & $<, 0001$ \\
& $2 \mathrm{O}-4 \mathrm{O}$ & $-6,3717$ & 4,3507 & 12,8746 & $<, 0001$ \\
& & & $-10,6337$ & $-2,1097$ & 0,0035 \\
\hline
\end{tabular}

Tempo 1. Antes da ciclagem termomecânica

Tempo 2. Após $200 \mathrm{~N}$

Tempo 3. Após $380 \mathrm{~N}$

Nível de significância: $p<0,05$

A tabela de comparação entre os grupos revela não haver diferença significativa na retenção de seus componentes entre os grupos 1B e 1B2O nos três tempos analisados. Sendo assim, a presença dos mini-implantes na região posterior não aumentou a retenção da prótese.

A análise estatística evidenciou diferenças significativas $(p<0,05)$ comparando os demais grupos. Comparando os grupos 1B e 2O, o grupo 1B apresentou maior retenção nos três tempos analisados. Comparando os grupos 1B2O e 4O, observou-se que o grupo 1B2O apresentou maior força de retenção dos três períodos avaliados. Evidenciando diminuição da retenção nos dois grupos ao longo do aumento da carga cíclica.

Nota-se que os grupos com barra/clipe apresentaram maior retenção quando comparados aos grupos apenas com bola/O'ring.

Comparando a retenção dos grupos dos O'rings, observa-se que o grupo com 4 O'rings apresentou maior força retentiva durante todo o ensaio. Verificando que para o grupo com O'rings, a presença dos mini-implantes posteriores aumentou a capacidade retentiva da prótese. 
Tabela 3. Modelo linear de efeitos mistos. Comparação da resistência a tração (N) entre os tempos no mesmo grupo.

\begin{tabular}{cccccc}
\hline \multirow{2}{*}{$\begin{array}{c}\text { Comparação no } \\
\text { mesmo grupo }\end{array}$} & Tempo & $\begin{array}{c}\text { Estimativa da } \\
\text { diferença entre as } \\
\text { médias }\end{array}$ & \multicolumn{2}{c}{ IC 95\% } & \multirow{2}{*}{ P-valor } \\
\cline { 4 - 5 } & & $-1,434$ & LI & LS & \\
\multirow{2}{*}{$\mathbf{1 B}$} & 1 e 2 & & $-5,7931$ & 2,9251 & 0,5182 \\
& 1 e 3 & 3,3506 & $-1,0085$ & 7,7096 & 0,1316 \\
& 2 e 3 & 4,7846 & 0,3331 & 9,236 & 0,0352 \\
\hline \multirow{2}{*}{$\mathbf{1 B 2 0}$} & 1 e 2 & 1,2027 & $-3,0592$ & 5,4647 & 0,5794 \\
& 1 e 3 & 5,2589 & 0,9969 & 9,5208 & 0,0157 \\
& 2 e 3 & 4,0562 & $-0,2058$ & 8,3181 & 0,0621 \\
\hline \multirow{2}{*}{$\mathbf{2 0}$} & 1 e 2 & $-1,0245$ & $-5,2865$ & 3,2374 & 0,6368 \\
& 1 e 3 & $-3,3073$ & $-7,5692$ & 0,9547 & 0,1279 \\
& 2 e 3 & $-2,2827$ & $-6,5447$ & 1,9792 & 0,293 \\
\hline \multirow{2}{*}{40} & 1 e 2 & 1,7631 & $-2,4989$ & 6,025 & 0,4166 \\
& 1 e 3 & 3,0911 & $-1,1708$ & 7,3531 & 0,1547 \\
& 2 e 3 & 1,3281 & $-2,9339$ & 5,59 & 0,5405 \\
\hline
\end{tabular}

Tempo 1. Antes da ciclagem termomecânica

Tempo 2. Após $200 \mathrm{~N}$

Tempo 3. Após $380 \mathrm{~N}$

Nível de significância: $p<0,05$

$\mathrm{Na}$ análise do comportamento dos componentes do mesmo grupo ao longo do tempo e frente a diferentes cargas, observou não haver diferença significativa na retenção para os grupos com O'rings, mostrando que a ciclagem não afetou a capacidade retentiva destes componentes. Entretanto, no grupo 1B houve diferença significativa quando comparou o grupo nos tempos 2 e 3 , com queda na capacidade retentiva, o mesmo acontecendo para o grupo 1B2O nos tempos 1 e 3 .

\subsection{Análise da microscopia óptica}

Os dados da tabela 4 apresentam a estatística descritiva com média e desvio padrão, do perímetro interno das borrachas dos O'rings e distância entre as paredes dos clipes antes do ensaio (Tempo 1) e após o ensaio de ciclagem (Tempos 2 e 3 ). Para todas as comparações adotou-se nível de significância de $5 \%$.

$\mathrm{Na}$ figura 35, apresenta-se as imagens dos modelos com a posição de seus componentes e nomenclatura adotadas para análises posteriores.

Figura 35. Modelos com seus componentes e suas respectivas nomenclaturas.
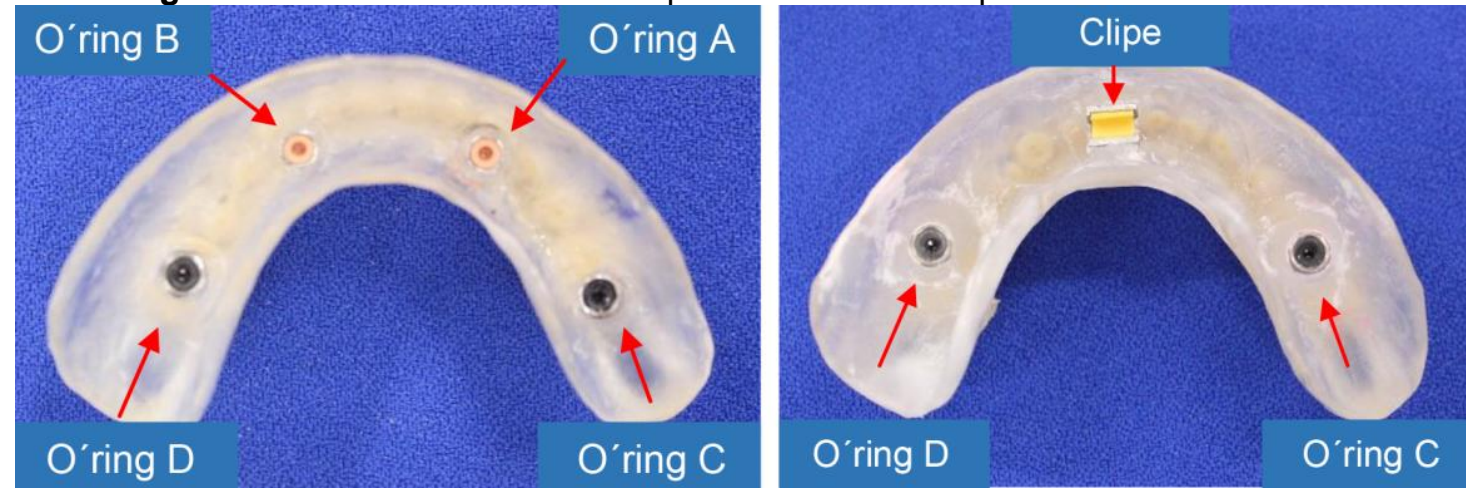
Tabela 4. Medidas de posição central e de dispersão do perímetro do O'ring $(\mathrm{mm})$ e distância entre as paredes do clipe $(\mathrm{mm})$ em relação aos grupos e aos tempos.

\begin{tabular}{|c|c|c|c|c|c|c|c|c|c|c|c|}
\hline Grupo & Componente & Tempo & N Obs & N. & Média & $\begin{array}{l}\text { Desvio } \\
\text { Padrão }\end{array}$ & Mediana & Q1 & Q3 & Min & Max \\
\hline \multirow{3}{*}{ 1B } & \multirow{3}{*}{ clipe } & 1 & 12 & 12 & 1,68 & 0,09 & 1,69 & 1,61 & 1,74 & 1,55 & 1,83 \\
\hline & & 2 & 12 & 11 & 1,74 & 0,09 & 1,73 & 1,67 & 1,83 & 1,62 & 1,86 \\
\hline & & 3 & 12 & 11 & 1,8 & 0,07 & 1,79 & 1,75 & 1,87 & 1,67 & 1,91 \\
\hline \multirow{9}{*}{$1 \mathrm{~B} 2 \mathrm{O}$} & \multirow{3}{*}{ C } & 1 & 12 & 12 & 3,91 & 0,18 & 3,91 & 3,83 & 4,06 & 3,63 & 4,16 \\
\hline & & 2 & 12 & 12 & 3,88 & 0,51 & 3,93 & 3,77 & 4,13 & 2,48 & 4,59 \\
\hline & & 3 & 12 & 12 & 4,13 & 0,81 & 3,96 & 3,77 & 4,09 & 3,48 & 6,58 \\
\hline & \multirow{3}{*}{ D } & 1 & 12 & 12 & 3,89 & 0,18 & 3,84 & 3,79 & 3,92 & 3,7 & 4,33 \\
\hline & & 2 & 12 & 12 & 4,22 & 0,87 & 3,91 & 3,75 & 4,36 & 3,63 & 6,75 \\
\hline & & 3 & 12 & 12 & 3,85 & 0,33 & 3,76 & 3,61 & 4,07 & 3,43 & 4,41 \\
\hline & \multirow{3}{*}{ clipe } & 1 & 12 & 12 & 1,75 & 0,09 & 1,74 & 1,71 & 1,79 & 1,58 & 1,96 \\
\hline & & 2 & 12 & 12 & 1,84 & 0,1 & 1,8 & 1,78 & 1,87 & 1,74 & 2,08 \\
\hline & & 3 & 12 & 12 & 1,93 & 0,11 & 1,91 & 1,82 & 2,02 & 1,81 & 2,1 \\
\hline \multirow{6}{*}{20} & \multirow{3}{*}{ A } & 1 & 12 & 12 & 5,31 & 0,12 & 5,33 & 5,25 & 5,37 & 5,05 & 5,5 \\
\hline & & 2 & 12 & 12 & 5,15 & 0,36 & 5,22 & 5,13 & 5,32 & 4,07 & 5,45 \\
\hline & & 3 & 12 & 12 & 5,22 & 0,18 & 5,23 & 5,12 & 5,31 & 4,9 & 5,5 \\
\hline & \multirow{3}{*}{ B } & 1 & 12 & 12 & 5,29 & 0,09 & 5,27 & 5,22 & 5,34 & 5,22 & 5,54 \\
\hline & & 2 & 12 & 12 & 5,17 & 0,37 & 5,26 & 5,2 & 5,31 & 4,07 & 5,56 \\
\hline & & 3 & 12 & 12 & 5,28 & 0,11 & 5,28 & 5,19 & 5,37 & 5,13 & 5,46 \\
\hline \multirow{12}{*}{40} & \multirow{3}{*}{ A } & 1 & 12 & 12 & 5,28 & 0,11 & 5,31 & 5,25 & 5,35 & 5,03 & 5,38 \\
\hline & & 2 & 12 & 12 & 5,3 & 0,09 & 5,28 & 5,25 & 5,37 & 5,14 & 5,44 \\
\hline & & 3 & 12 & 12 & 5,33 & 0,07 & 5,32 & 5,3 & 5,36 & 5,2 & 5,46 \\
\hline & \multirow{3}{*}{ B } & 1 & 12 & 12 & 5,27 & 0,12 & 5,31 & 5,16 & 5,35 & 5,08 & 5,42 \\
\hline & & 2 & 12 & 12 & 5,25 & 0,11 & 5,24 & 5,17 & 5,32 & 5,06 & 5,42 \\
\hline & & 3 & 12 & 12 & 5,22 & 0,18 & 5,2 & 5,1 & 5,33 & 4,92 & 5,51 \\
\hline & \multirow{3}{*}{ C } & 1 & 12 & 12 & 3,9 & 0,23 & 3,85 & 3,77 & 4,13 & 3,49 & 4,24 \\
\hline & & 2 & 12 & 12 & 4,03 & 0,34 & 3,95 & 3,77 & 4,29 & 3,58 & 4,62 \\
\hline & & 3 & 12 & 12 & 4,1 & 0,31 & 4,03 & 3,86 & 4,22 & 3,75 & 4,8 \\
\hline & \multirow{3}{*}{ D } & 1 & 12 & 12 & 3,98 & 0,2 & 3,94 & 3,8 & 4,1 & 3,75 & 4,33 \\
\hline & & 2 & 12 & 12 & 4,01 & 0,14 & 4 & 3,89 & 4,14 & 3,83 & 4,22 \\
\hline & & 3 & 12 & 12 & 3,98 & 0,19 & 3,98 & 3,84 & 4,14 & 3,67 & 4,27 \\
\hline
\end{tabular}

Tempo 1. Antes da ciclagem termomecânica

Tempo 2. Após $200 \mathrm{~N}$

Tempo 3. Após $380 \mathrm{~N}$

O'rings. A, B, C, D

Nível de significância: $p<0,05$

$\mathrm{Na}$ tabela 5 são apresentados os resultados das comparações dos componentes dos grupos barra/clipe e bola/O'rings, entre os tempos analisados. 
Tabela 5. Comparações do perímetro da borracha dos O'rings $(\mathrm{mm})$ e distância entre as paredes do clipe $(\mathrm{mm})$ de cada grupo entre os tempos.

\begin{tabular}{|c|c|c|c|c|c|c|}
\hline \multirow[t]{2}{*}{ Grupo } & \multirow{2}{*}{$\frac{\text { Tempo }}{1 \text { e } 2}$} & \multirow{2}{*}{$\begin{array}{c}\text { Comparações } \\
\text { clipe }\end{array}$} & \multirow{2}{*}{$\begin{array}{c}\begin{array}{c}\text { Estimativa Dif } \\
\text { Médias }\end{array} \\
-0,094\end{array}$} & \multicolumn{2}{|c|}{ IC 95\% } & \multirow{2}{*}{$\begin{array}{c}\text { P-Valor } \\
0,002\end{array}$} \\
\hline & & & & $-0,152$ & $-0,035$ & \\
\hline & 1 e 3 & clipe & $-0,179$ & $-0,253$ & $-0,105$ & $<, 0001$ \\
\hline & 2 e 3 & clipe & $-0,085$ & $-0,167$ & $-0,004$ & 0,041 \\
\hline & 1 e 2 & C & 0,035 & $-0,270$ & 0,339 & 0,823 \\
\hline \multirow[t]{6}{*}{$1 \mathrm{~B} 20$} & 1 e 3 & $\mathrm{C}$ & $-0,214$ & $-0,633$ & 0,205 & 0,316 \\
\hline & 2 e 3 & $\mathrm{C}$ & $-0,249$ & $-0,740$ & 0,242 & 0,320 \\
\hline & 1 e 2 & $\mathrm{D}$ & $-0,335$ & $-0,826$ & 0,156 & 0,181 \\
\hline & 1 e 3 & $\mathrm{D}$ & 0,042 & $-0,168$ & 0,253 & 0,695 \\
\hline & 2 e 3 & $\mathrm{D}$ & 0,377 & $-0,075$ & 0,829 & 0,102 \\
\hline & 1 e 2 & clipe & $-0,066$ & $-0,103$ & $-0,029$ & 0,001 \\
\hline \multirow[t]{4}{*}{ 1B } & 1 e 3 & clipe & $-0,123$ & $-0,181$ & $-0,064$ & $<, 0001$ \\
\hline & 2 e 3 & clipe & $-0,056$ & $-0,111$ & $-0,001$ & 0,045 \\
\hline & 1 e 2 & $A$ & 0,165 & $-0,018$ & 0,347 & 0,077 \\
\hline & 1 e 3 & $A$ & 0,093 & $-0,034$ & 0,221 & 0,152 \\
\hline \multirow[t]{6}{*}{20} & 2 e 3 & $A$ & $-0,071$ & $-0,266$ & 0,124 & 0,474 \\
\hline & 1 e 2 & $B$ & 0,123 & $-0,089$ & 0,335 & 0,256 \\
\hline & 1 e 3 & B & 0,016 & $-0,041$ & 0,073 & 0,588 \\
\hline & 2 e 3 & B & $-0,107$ & $-0,299$ & 0,085 & 0,275 \\
\hline & 1 e 2 & $A$ & $-0,025$ & $-0,071$ & 0,021 & 0,290 \\
\hline & 1 e 3 & $A$ & $-0,052$ & $-0,105$ & 0,001 & 0,054 \\
\hline \multirow[t]{10}{*}{40} & 2 e 3 & $A$ & $-0,027$ & $-0,050$ & $-0,004$ & 0,020 \\
\hline & 1 e 2 & $B$ & 0,021 & $-0,050$ & 0,091 & 0,571 \\
\hline & 1 e 3 & B & 0,043 & $-0,025$ & 0,110 & 0,216 \\
\hline & 2 e 3 & B & 0,022 & $-0,058$ & 0,102 & 0,589 \\
\hline & 1 e 2 & C & $-0,129$ & $-0,324$ & 0,067 & 0,198 \\
\hline & 1 e 3 & $\mathrm{C}$ & $-0,194$ & $-0,374$ & $-0,013$ & 0,036 \\
\hline & 2 e 3 & C & $-0,065$ & $-0,186$ & 0,057 & 0,295 \\
\hline & 1 e 2 & $\mathrm{D}$ & $-0,038$ & $-0,116$ & 0,040 & 0,337 \\
\hline & 1 e 3 & $D$ & $-0,007$ & $-0,102$ & 0,087 & 0,877 \\
\hline & 2 e 3 & $\mathrm{D}$ & 0,031 & $-0,043$ & 0,105 & 0,417 \\
\hline
\end{tabular}

Tempo 1. Antes da ciclagem termomecânica

Tempo 2. Após $200 \mathrm{~N}$

Tempo 3. Após $380 \mathrm{~N}$

O'rings. A, B, C, D

Nível de significância: $p<0,05$

$\mathrm{Na}$ tabela 5, comparando os componentes do mesmo grupo em tempos diferentes, observa-se não haver diferença significativa na estrutura interna dos O'rings dos mini-implantes, porém houve diferença significativa do clipe no grupo 1B2O, revelando que a colocação de mini-implantes posteriores não auxiliou na manutenção interna dos clipes em qualquer carga cíclica. E no grupo 1B, ocorreu também significativa diferença na deformação do seu clipe, mostrando que o clipe 
sofre deformação estrutural, independente se tem ou não de mini-implantes posteriores e da carga aplicada.

Comparando o perímetro das borrachas nos tempos estabelecidos, observou não haver diferença significativa nem no grupo 20 e nem no grupo 40.

Tabela 6. Comparações do perímetro das borrachas $(\mathrm{mm})$ e da distância entre as paredes do clipe (mm) entre os grupos nos tempos.

\begin{tabular}{lcccccc} 
Comparação & $\begin{array}{c}\text { Grupos } \\
\text { Componentes }\end{array}$ & Tempo & $\begin{array}{c}\text { Estimativa } \\
\text { Dif Médias }\end{array}$ & \multicolumn{2}{c}{ IC 95\% } & P-Valor \\
\hline $\mathbf{2 0}-\mathbf{4 0}$ & $\mathrm{A}$ & 1 & 0,0371 & $-0,0145$ & 0,0887 & 0,1588 \\
$\mathbf{2 0}-\mathbf{4 0}$ & $\mathrm{A}$ & 2 & $-0,1525$ & $-0,3258$ & 0,0208 & 0,0846 \\
$\mathbf{2 0}-\mathbf{4 0}$ & $\mathrm{A}$ & 3 & $-0,1082$ & $-0,2208$ & 0,0045 & 0,0599 \\
$\mathbf{2 0}-\mathbf{4 0}$ & $\mathrm{B}$ & 1 & 0,0274 & $-0,0583$ & 0,1131 & 0,5308 \\
$\mathbf{2 0}-\mathbf{4 0}$ & $\mathrm{B}$ & 2 & $-0,0749$ & $-0,2753$ & 0,1254 & 0,4636 \\
$\mathbf{2 O}-\mathbf{4 0}$ & $\mathrm{B}$ & 3 & 0,0542 & $-0,0562$ & 0,1645 & 0,3359 \\
$\mathbf{1 B}-\mathbf{1 B 2 0}$ & Clipe & 1 & $-0,070$ & $-0,126$ & $-0,015$ & 0,013 \\
$\mathbf{1 B}-\mathbf{1 B 2 0}$ & clipe & 2 & $-0,098$ & $-0,177$ & $-0,018$ & 0,016 \\
$\mathbf{1 B}-\mathbf{1 B 2 0}$ & Clipe & 3 & $-0,127$ & $-0,201$ & $-0,052$ & 0,001 \\
\hline
\end{tabular}

Tempo 1. Antes da ciclagem termomecânica

Tempo 2. Após $200 \mathrm{~N}$

Tempo 3. Após $380 \mathrm{~N}$

O'rings. A, B

Nível de significância: $p<0,05$

$\mathrm{Na}$ tabela 6 , observa-se não haver diferença significante na deformação estrutural entre os componentes anteriores em nenhum dos tempos estabelecidos, quando compara-se os grupos $2 \mathrm{O}$ e $4 \mathrm{O}$.

Analisando os grupos 1B e 1B2O, nota-se haver diferença estatística significativa na distância entre as paredes dos clipes em todos os tempos analisados, mostrando que a presença de mini-implantes posteriores não influência de forma positiva na estrutura interna dos clipes.

As figuras abaixo apresentam as imagens das borrachas e dos clipes antes e após a ciclagem. 
Figura 36. Análise do perímetro da borracha do O'ring convencional do grupo 20 , inicial.

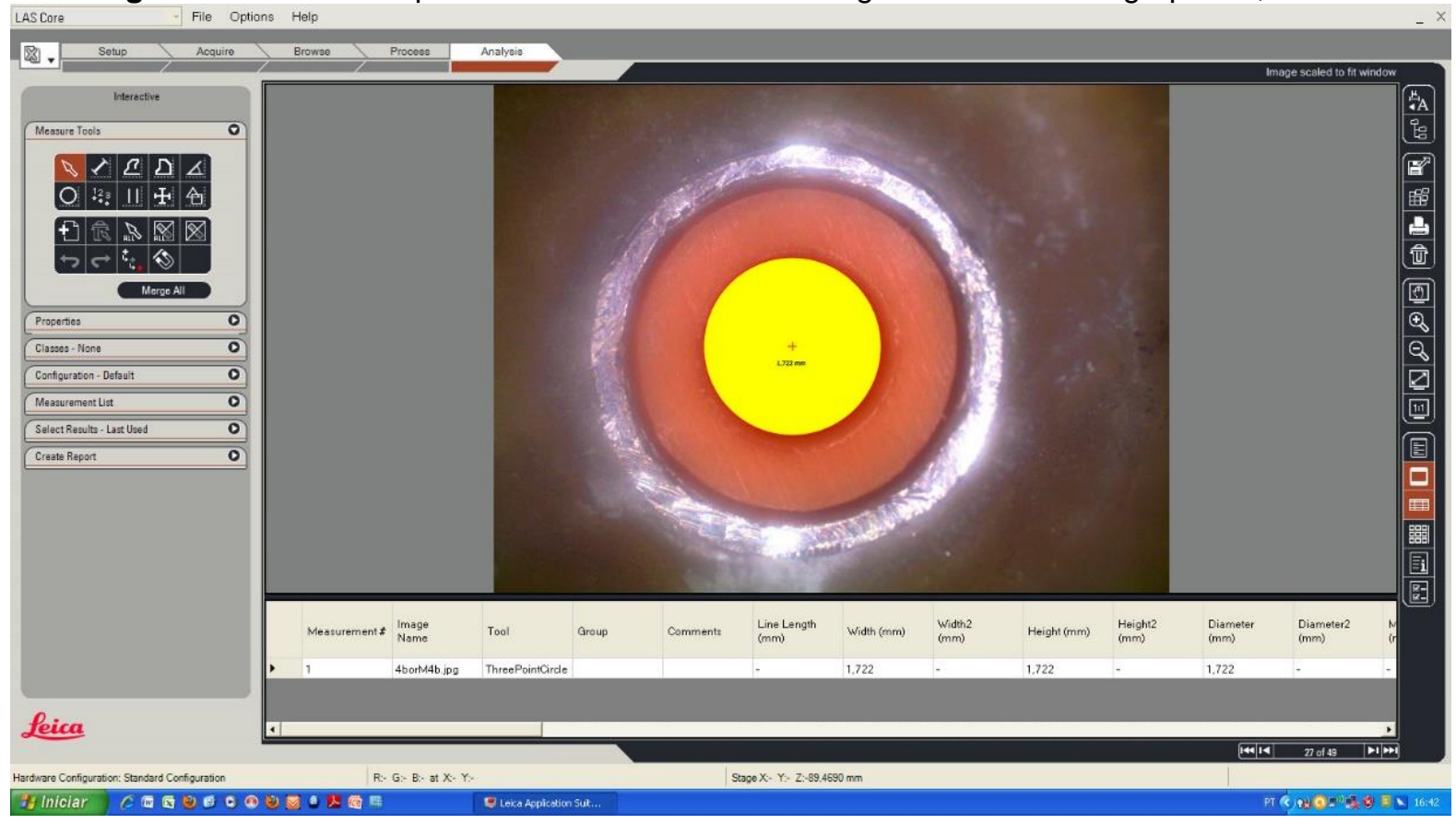

Figura 37. Análise do perímetro da borracha do O'ring convencional do grupo 20, após $380 \mathrm{~N}$.

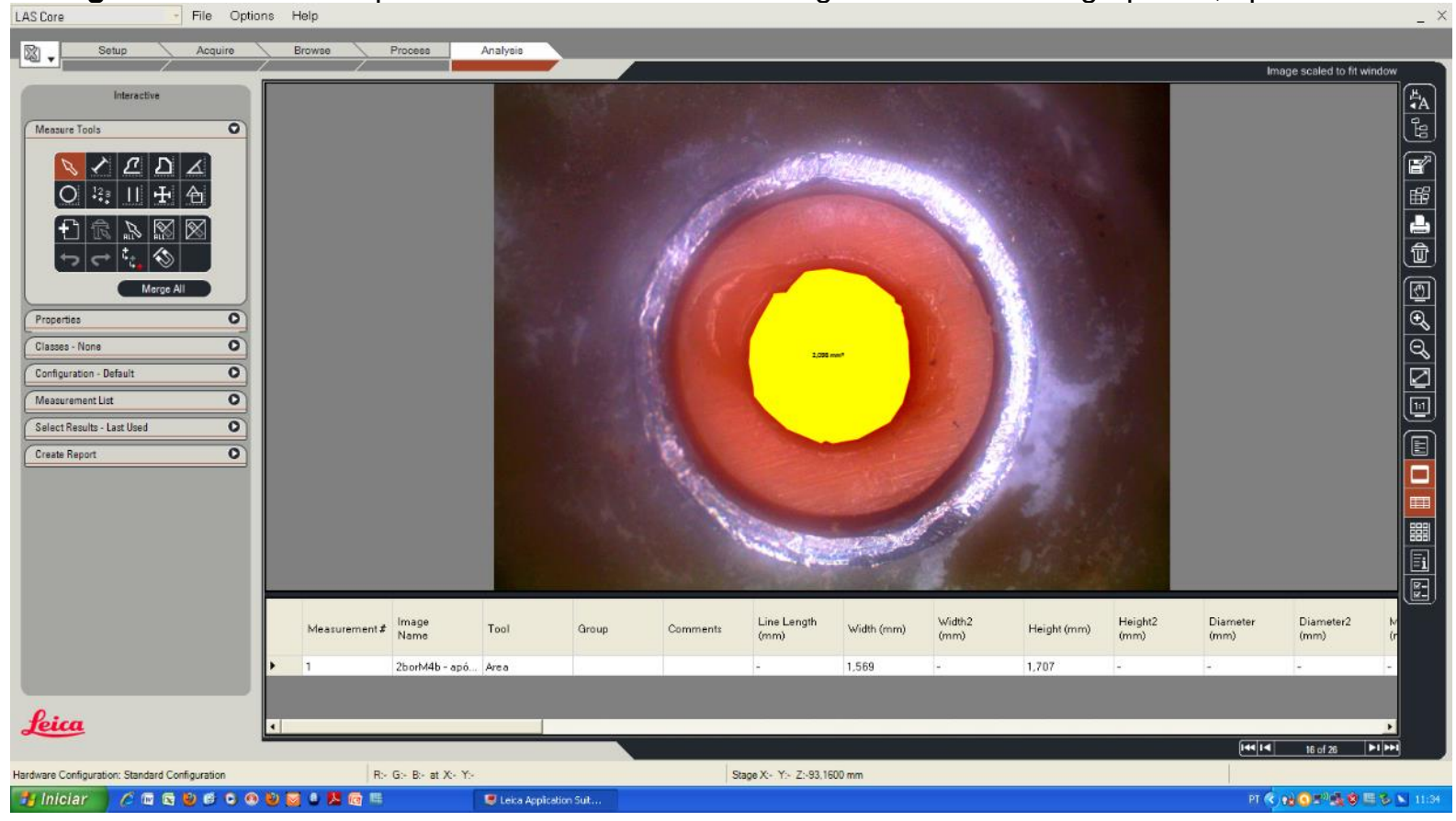


Figura 38. Análise do perímetro da borracha do O’ring do mini-implante do grupo 40, inicial.

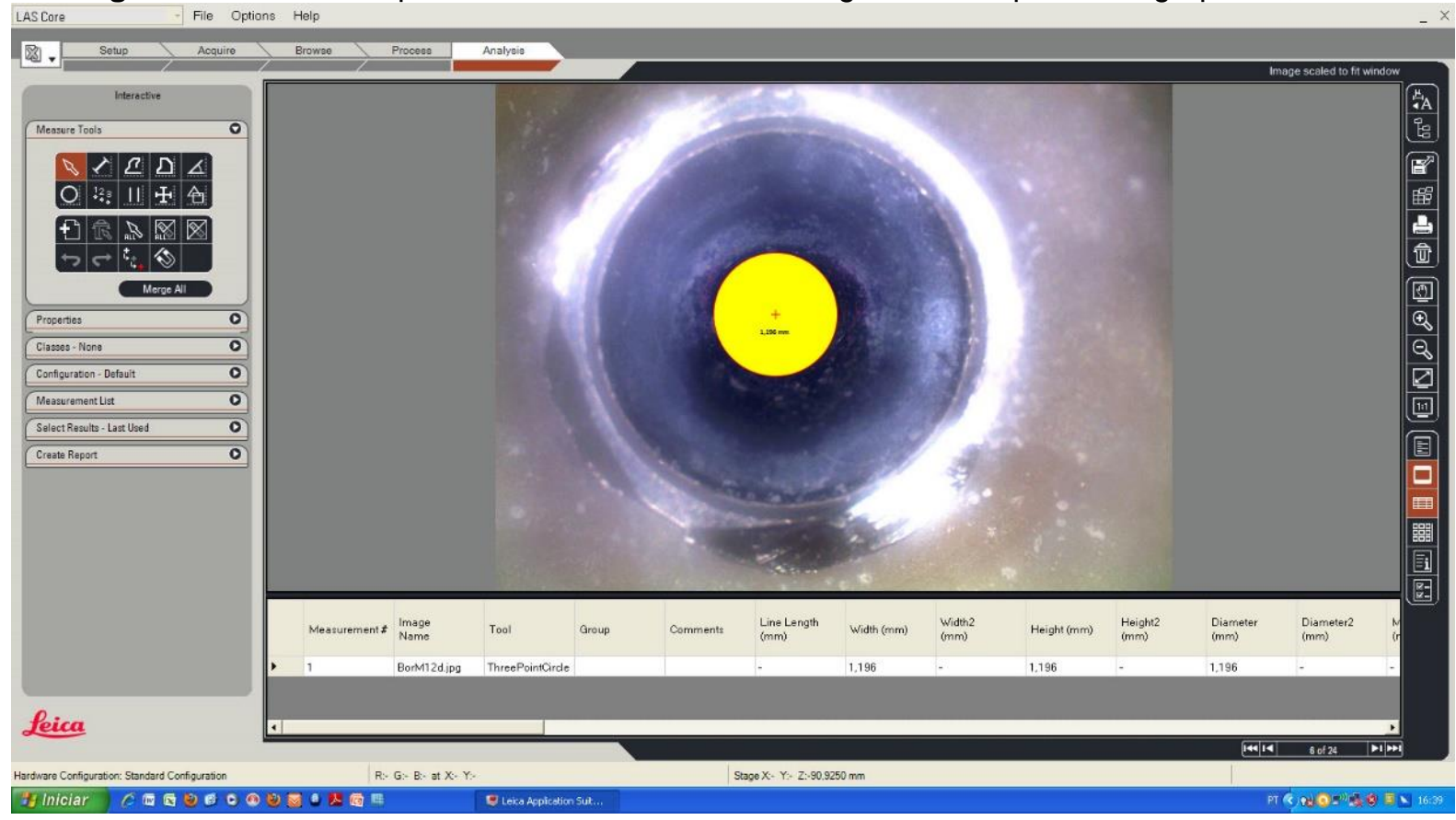

Figura 39. Análise do perímetro da borracha do O’ring mini-implante do grupo 4O, após $380 \mathrm{~N}$.

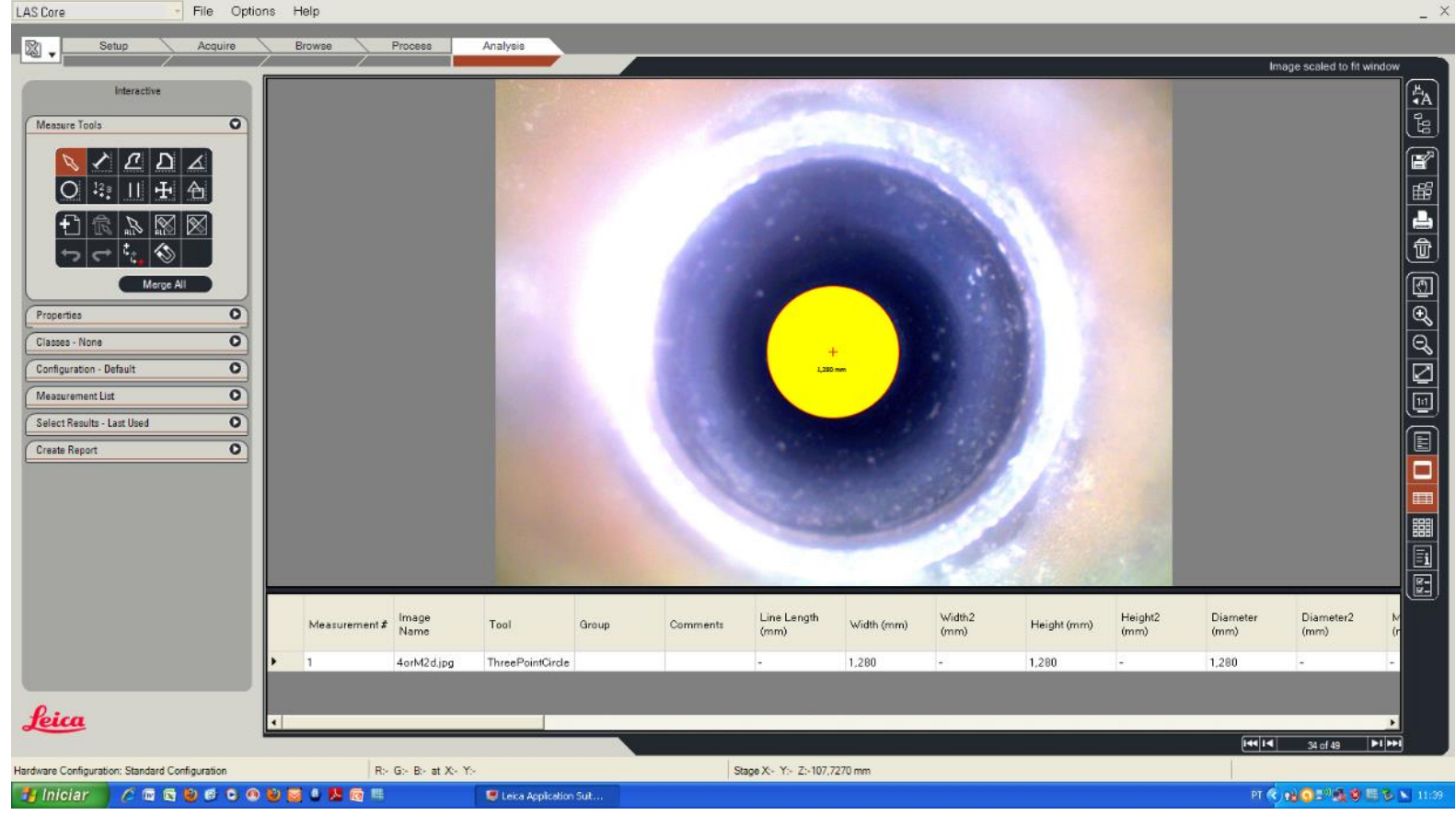


Figura 40. Análise do perímetro da borracha do O'ring convencional do grupo 40 , inicial.

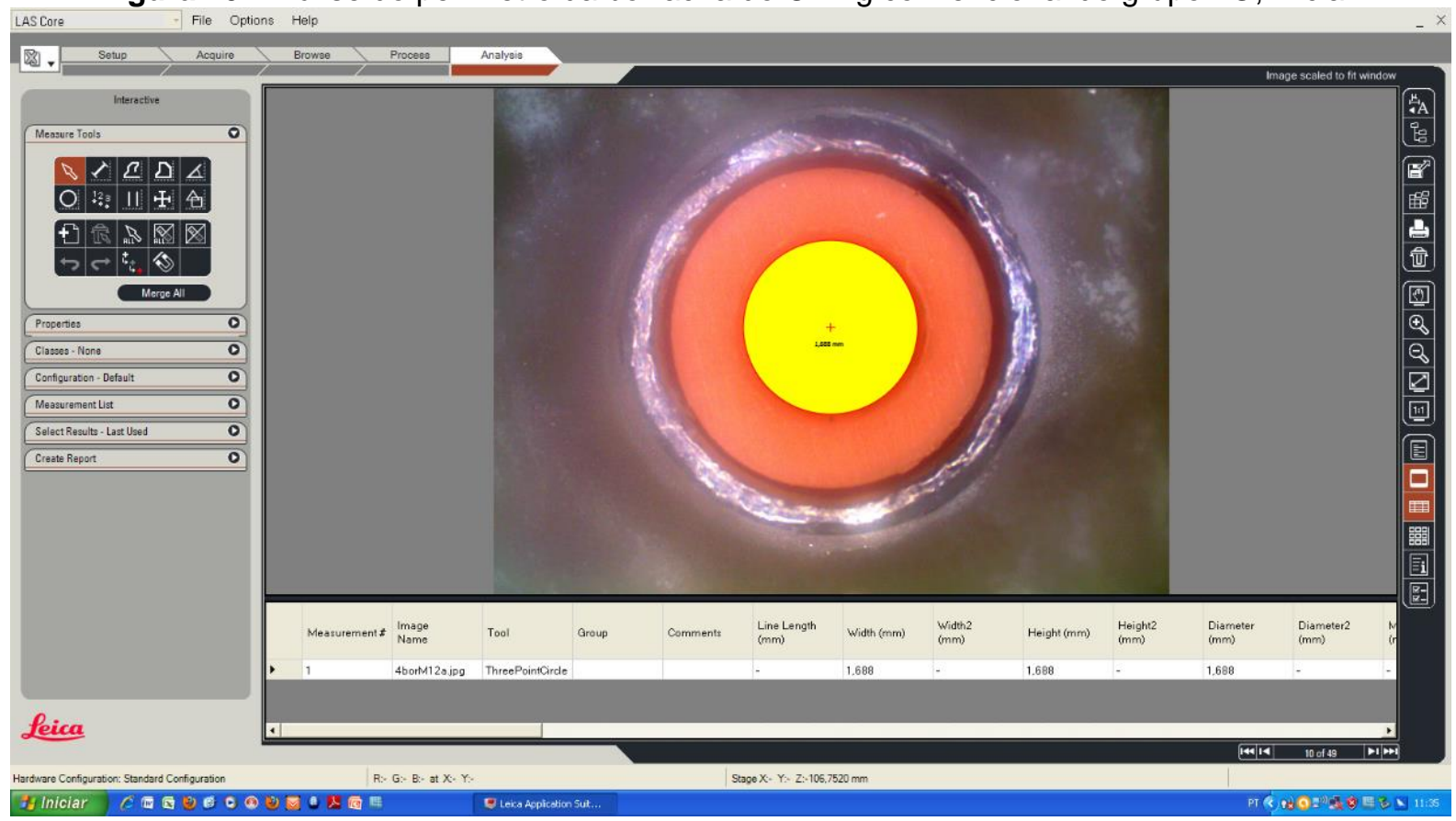

Figura 41. Análise do perímetro da borracha do O'ring convencional do grupo 4O, após $380 \mathrm{~N}$.

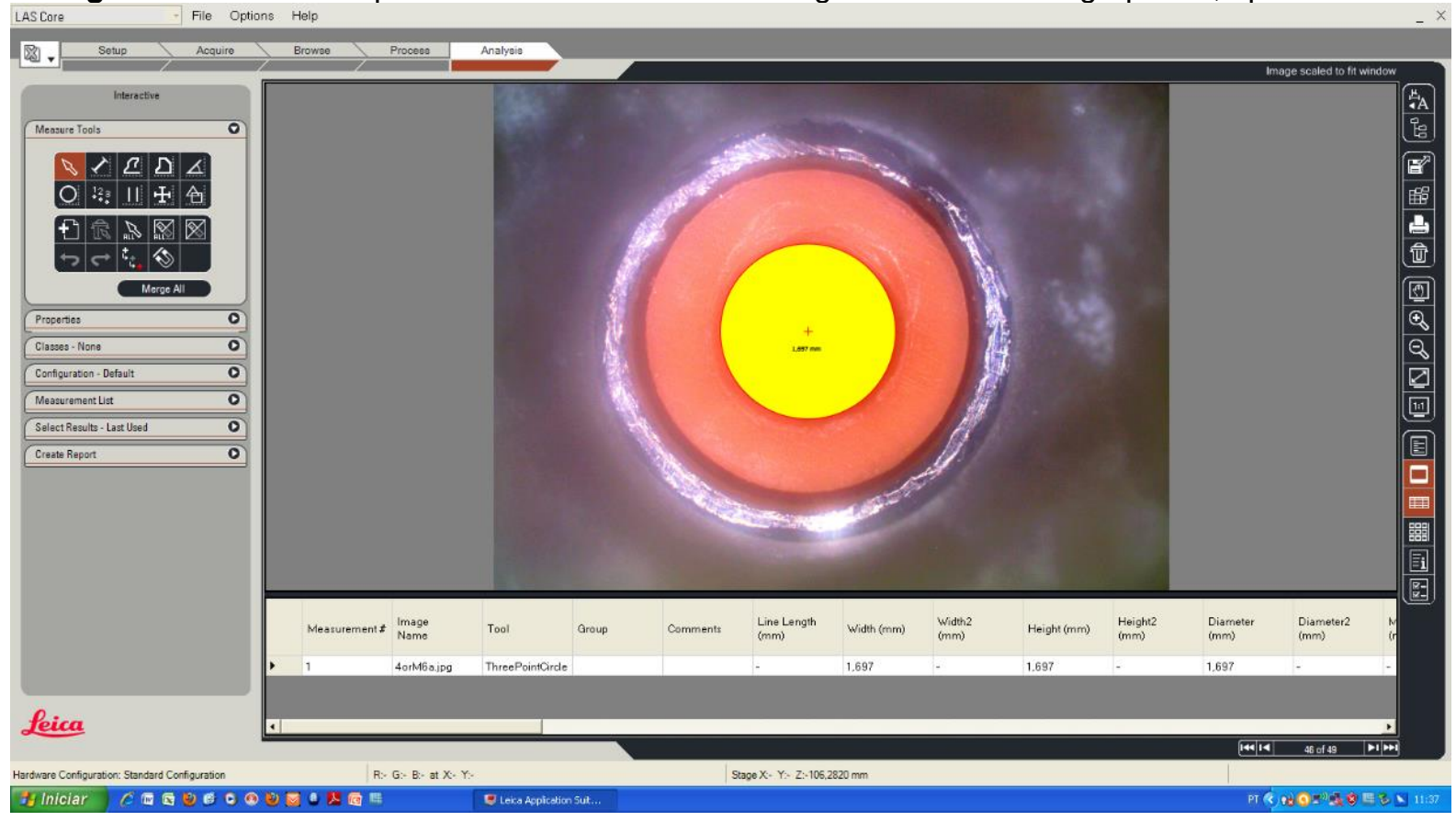


Figura 42. Análise da distância entre as paredes em 3 pontos do clipe no grupo 1B, inicial.

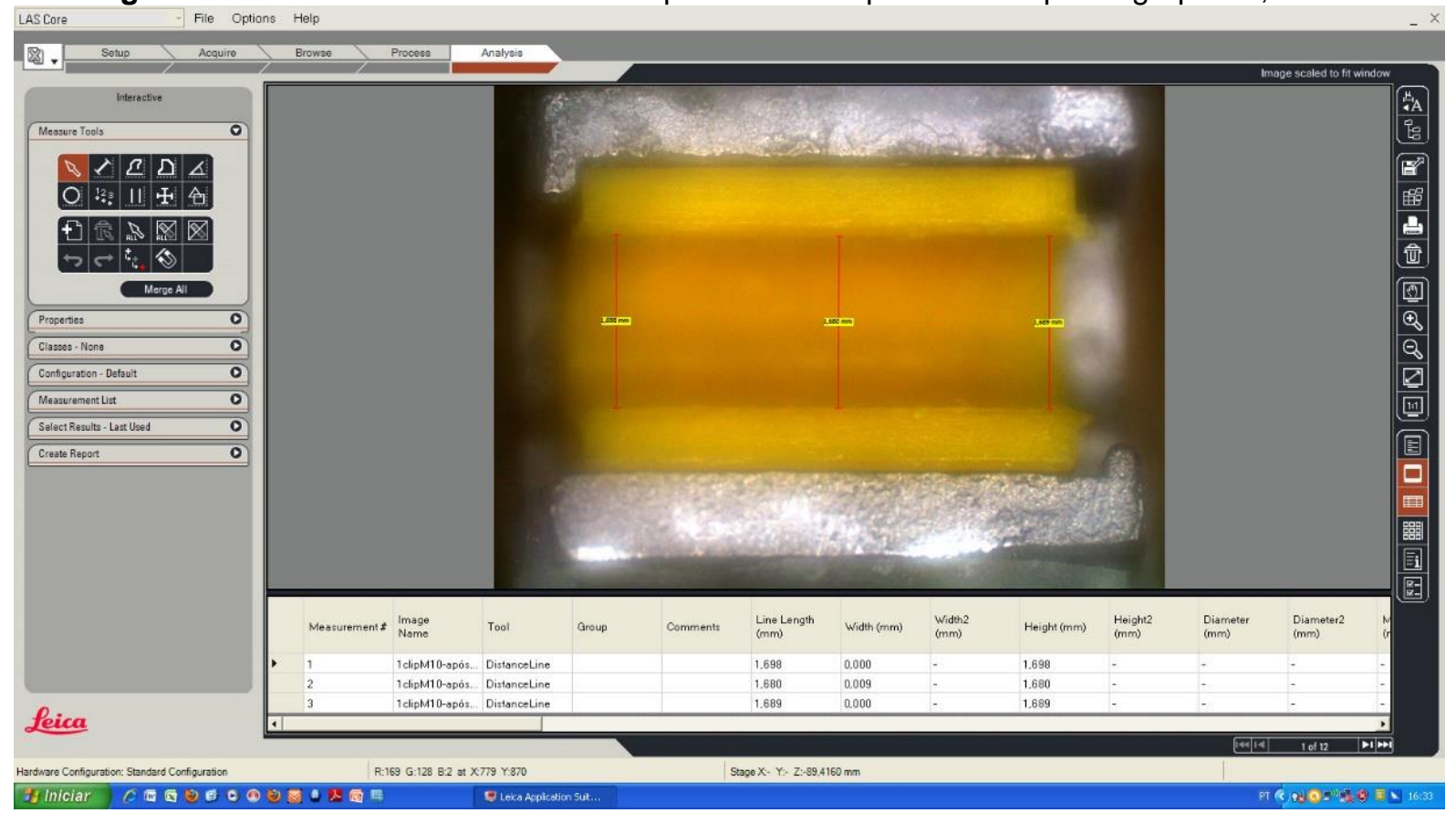

Figura 43. Análise da distância entre as paredes em 3 pontos do clipe no grupo 1B, após $380 \mathrm{~N}$.

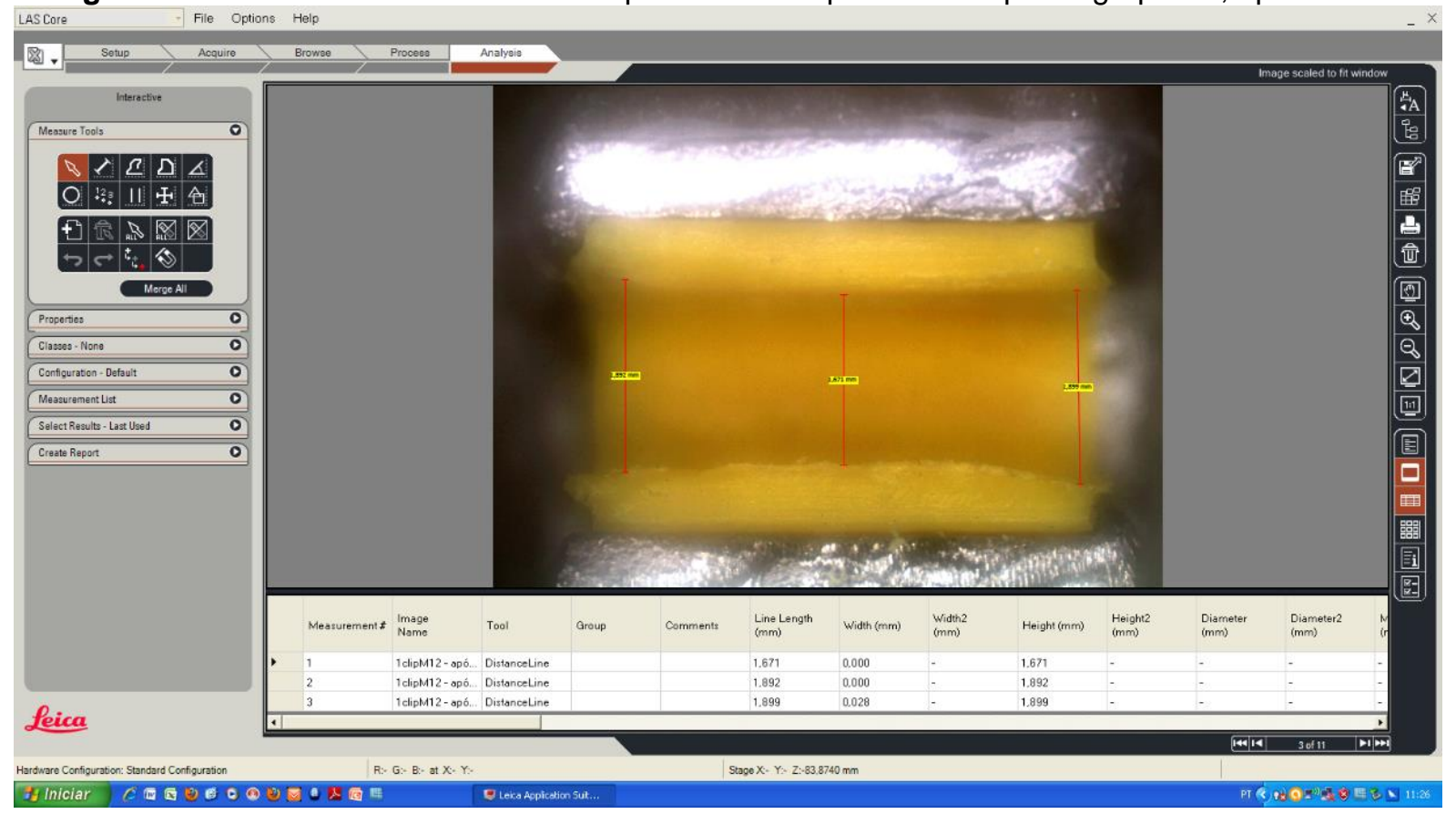


Figura 44. Análise da distância entre as paredes em 3 pontos do clipe no grupo 1B2O, inicial.

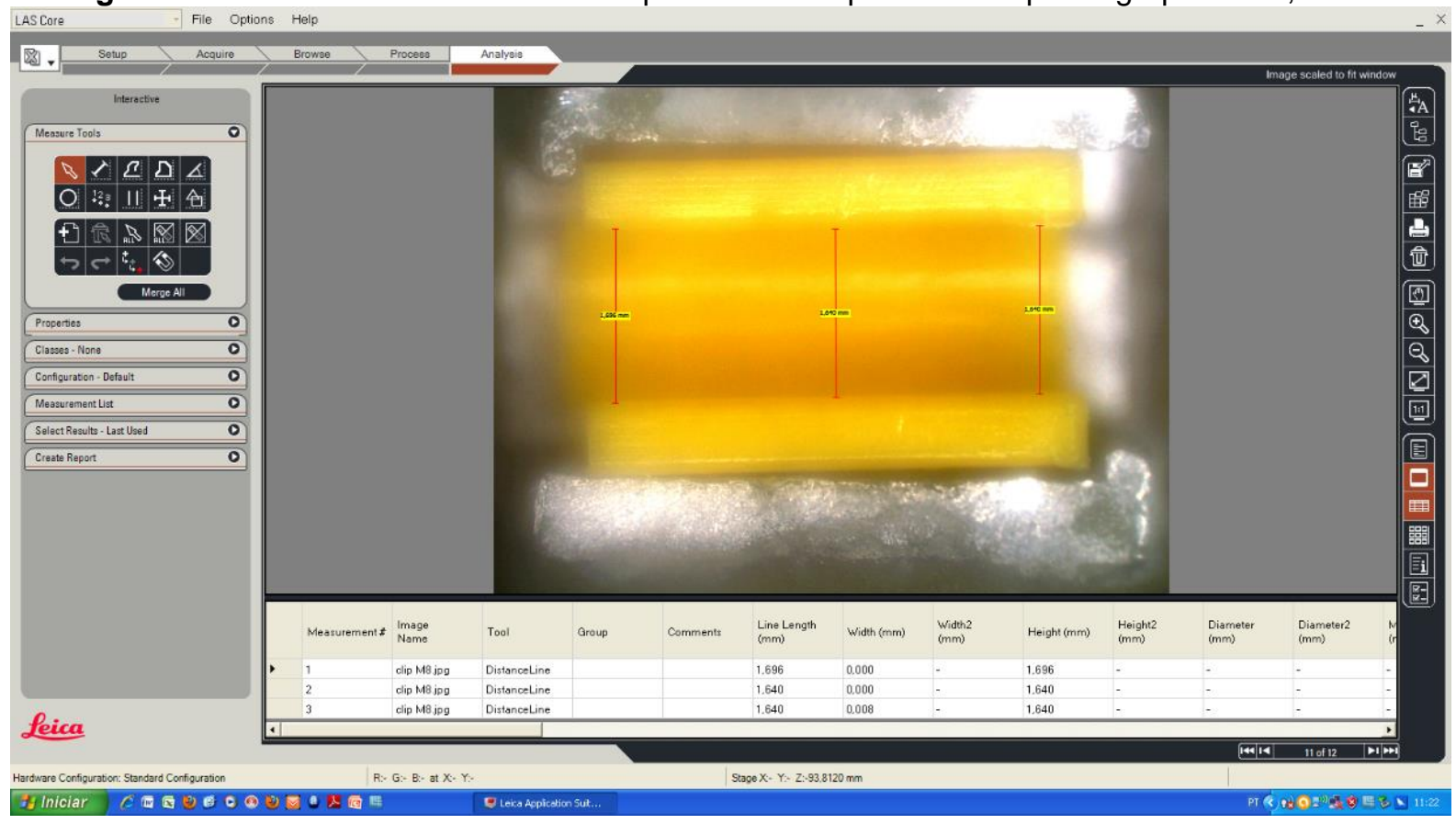

Figura 45. Análise da distância entre as paredes em 3 pontos do clipe no grupo 1B2O, após $380 \mathrm{~N}$.

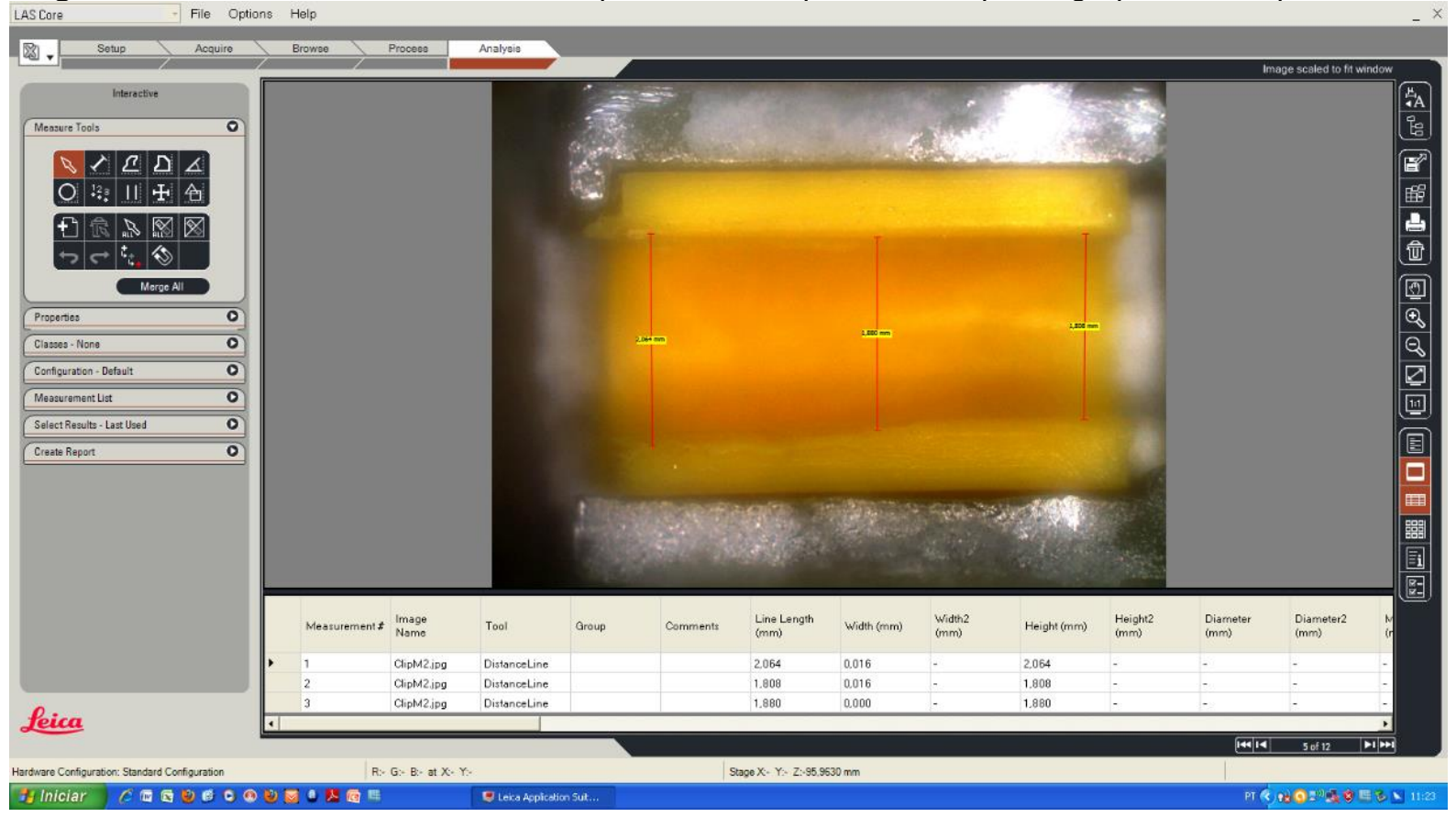


Figura 46. Análise do perímetro da borracha do O'ring mini-implante do grupo 1B2O, inicial.

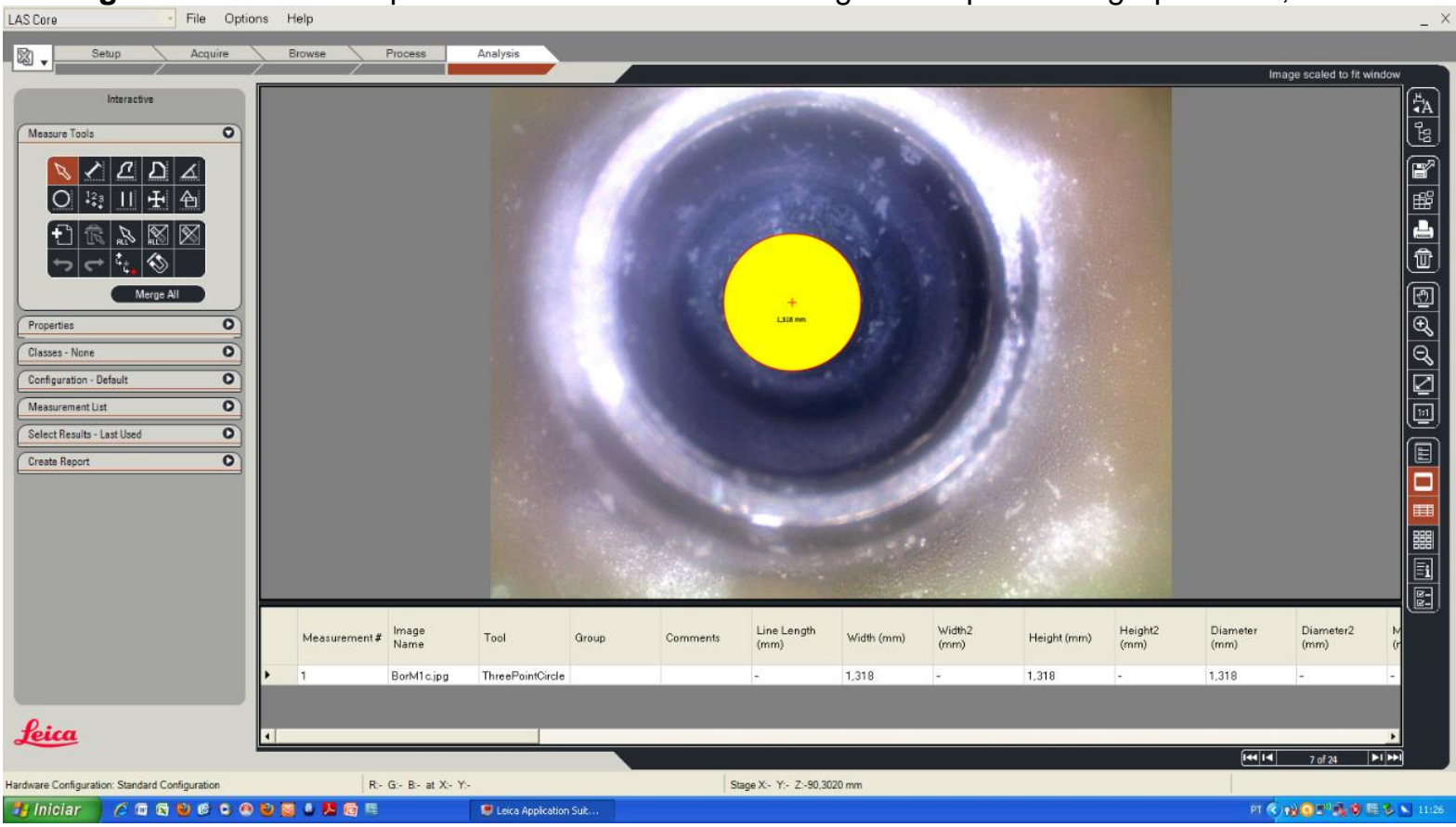

Figura 47. Análise do perímetro da borracha do O'ring mini-implante do grupo 1B2O, após $380 \mathrm{~N}$.

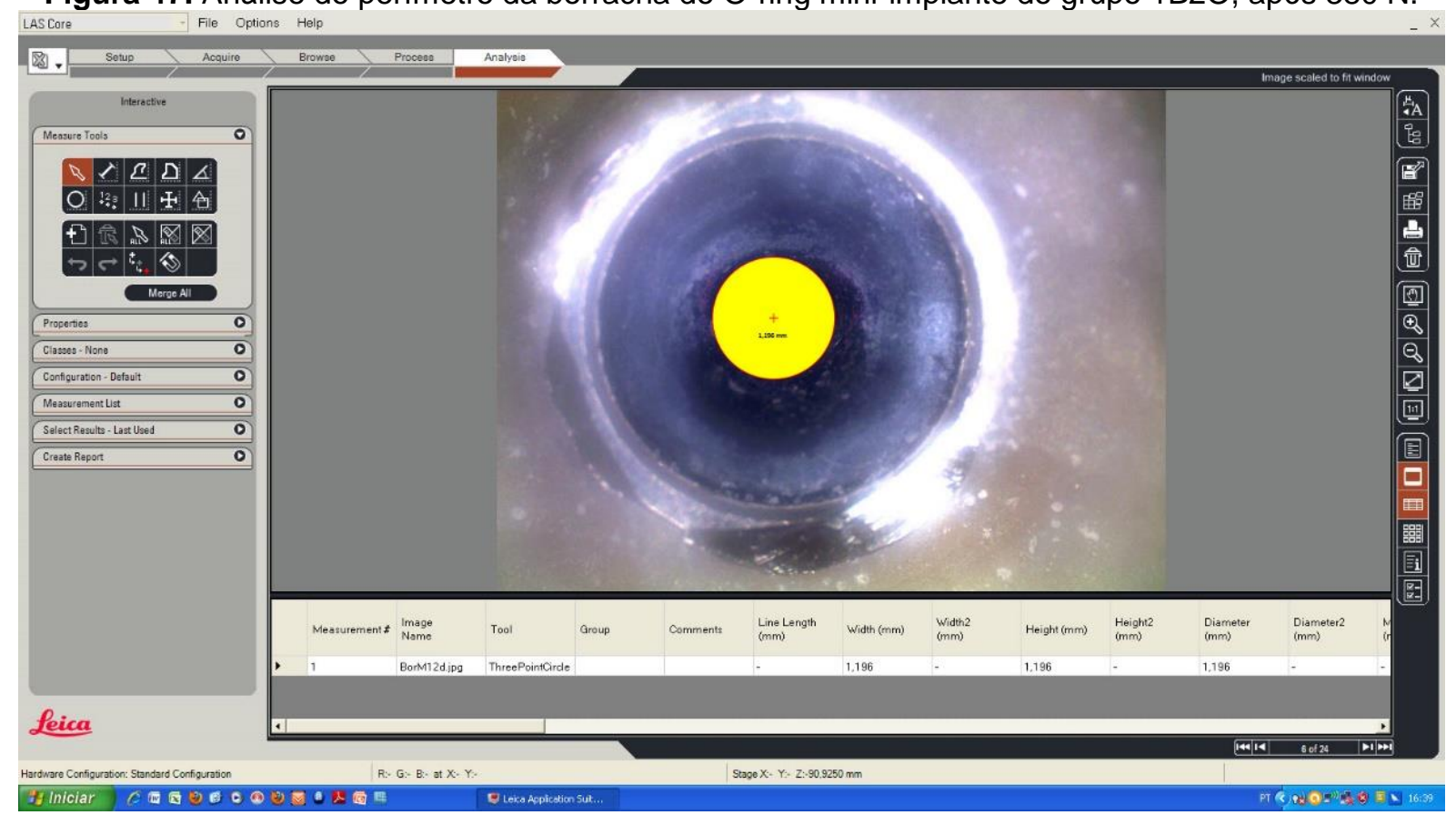


5. DISCUSSÃO 



\section{DISCUSSÃO}

Este estudo avaliou a retenção, durabilidade e transmissão de tensões de dois sistemas de attachments, barra/clipe ou bola/O'ring, em overdentures convencionais comparando a overdentures associadas a mini-implantes na região posterior da mandíbula. Alguns princípios biomecânicos e características de materiais podem interferir na distribuição de tensão aos tecidos ósseo e mucoso, quando cargas são aplicadas sob próteses implantossuportadas e dentossuportadas e, se não estabelecer distribuição adequada da carga oclusal, pode ocorrer fraturas e deformações estruturais, por exceder o limiar fisiológico do tecido ósseo (Glantz, Nilder, 2000; Beumer, Lewis,1990; Sahin, Cehreli, Yalçin, 2002; de Souza Batista et al., 2017).

Os mini-implantes posteriores têm sido utilizados para retenção de overdentures mandibulares, na região anterior, de forma bem-sucedida, como alternativa para casos com rebordo reduzido como revela alguns estudos (Jofré et al., 2010a; Jofré, Cendoya, Munoz, 2010b; Bidra e Almas, 2013, Šćepanović et al., 2015), por isso notou-se relevante realizar estudo que analise a retenção e distribuição de tensão em overdentures, utilizando mini-implantes na região posterior, buscando diminuir a alavanca ocasionada pelas próteses.

A colocação deste implante com diâmetro reduzido (Davarpanah et al., 2000; Quek, Tan, Nicholls, 2006; Bidra, Almas, 2013), foi proposto com os mesmos fins vantajosos relatados por Bulard e Vance (2005); Toth et al. (2017), no aspecto da necessidade de menor espessura óssea para instalação, pois são significativamente mais estreitos. Fortin et al. (2006) relata que as incisões e rebatimento de retalho geralmente não são necessários para a instalação, o que favorece o reparo tecidual e minimiza a reabsorção óssea durante a osseointegração e os autores Griffiths, Collins CP, Collins (2005); Della Vecchia (2015) descrevem ser uma intervenção com custo reduzido quando se compara a tratamento com implantes convencionais. A utilização de mini-implantes é uma opção eletiva para grande parte dos pacientes que possuem dificuldades na retenção e estabilidade de suas próteses totais convencionais.

As análises qualitativas das tensões dos modelos experimentais deste estudo foram realizadas pelo método da correlação de imagens digitais (CID) (Amodio et al., 2003). Com este método avaliou-se o deslocamento dos pontos da 
superfície dos modelos sob carga pré-determinada, ou seja, os modelos apresentavam pontos pretos em sua superfície vestibular e, sob aplicação de cargas pontual $(250 \mathrm{~N})$ e oclusal $(300 \mathrm{~N})$, foram registradas imagens subsequentes (frequência de $1,00 \mathrm{~Hz}$ ) e posteriormente foi realizada a análise do deslocamento dos pontos da área escolhida (Gustafson, Siegmund, Cripton, 2016; Palanca, Tozzi, Cristofolini, 2016; Hu et al., 2016). O método de correlação de imagens proporciona análise da superfície do modelo de forma mais ampla, abrangendo um campo completo e detalhado das tensões geradas, em vez de avaliar a média dos valores de uma pequena superfície, quando comparada ao uso de extensômetros (Tiossi, 2010).

No presente estudo, os modelos foram avaliados frontalmente, na região que se encontrava os implantes cone Morse anteriores convencionais e também, lateralmente, região que apresentava os mini-implantes nos modelos correspondentes, ou apenas o rebordo posterior para as overdentures convencionais.

Avaliando os resultados da carga oclusal na vista frontal, observou-se que todos os modelos apresentaram tensões de tração na parte central anterior do modelo e compressão perto dos implantes convencionais. A presença de tensões nas overdentures convencionais na região onde encontra-se os implantes osseointegrados, vai de encontro com estudo de Celik e Uludag (2007), no qual avaliaram o estresse gerado sobre overdentures retidas por bola/O'ring, Locator, barra/clipe e barra/clipe com sistema bola/O'ring sobre 3 implantes anteriores. Observaram níveis de estresses em todos os sistemas de fixação, porém o sistema bola/O'ring produziu o nível mais baixo de tensão. No estudo de Chen et al. (2015) também observaram estresses gerado na região dos implantes sob overdentures convencionais. Correlacionaram os resultados de análise de tensão pelo método de elementos finitos de overdenture e próteses totais convencionais, com análises clínicas realizadas por tomografias computadorizadas de pacientes que utilizavam estes tipos de próteses. Concluíram que, apesar da melhora na função e estabilidade das próteses totais anexas a implantes anteriores, as regiões que envolviam os implantes apresentaram tensões evidentes, principalmente na região posterior aos implantes, causado pelo efeito do cantiléver da overdenture comparada a prótese total convencional, apontando maior reabsorção óssea posterior. 
$\mathrm{Na}$ vista lateral com carregamento oclusal, a região posterior dos modelos 1B e 1B2O apresentaram semelhanças na distribuição de tensões, notando tensões compressivas na parte posterior aos implantes e coexistência de tensão de tração e áreas neutras na região do molar, constatando que a colocação de mini-implantes posteriores nestas overdentures não altera significativamente a distribuição de tensão. No entanto, quando se analisa os grupos 20 e 40 na região posterior, observa-se tensão de tração muito intensa na região posterior aos implantes no grupo 20 , enquanto no grupo 40 houve tensão de compressão e com intensidade mais amena, concluindo que a colocação de mini-implantes posteriores em overdenture com bola/O'rings anteriores favorece muito a distribuição de tensões por todo rebordo, diminuindo a alavanca ocorrida pela extensão distal da prótese implanto-mucosuportada.

A concentração de tensão na região posterior dos implantes deste estudo não está de acordo com o estudo de Dashti et al. (2013), no qual compararam dois sistemas de retenção (barra/clipe e bola/O'ring) para overdenture, retidas por 2 implantes anteriores. Um modelo básico foi produzido a partir dos dados fornecidos por tomografia computadorizada da mandíbula do paciente, modelos diagnósticos básicos de elementos finitos e overdenture existentes. Foram avaliadas as tensões resultantes de carga vertical $(35 \mathrm{~N})$ geradas no rebordo residual posterior mandibular, por meio da análise de elemento finito. Concluíram que o sistema bola/O'ring apresentou menor estresse ao rebordo mandibular posterior comparado ao sistema barra/clipe. No presente estudo notou-se resposta contrária, pois o grupo 20 apresentou maior concentração de tensão na região posterior aos implantes. Estes resultados podem ser devido a diferença de material do sistema O'ring, uma vez que neste estudo citado foi utilizado retentores de nylon e no presente estudo foi utilizado cápsula metálica com borracha (polímero). O tipo e a magnitude da carga exercida também são fatores relevantes para esta diferença, já que no estudo citado aplicou-se carga de $35 \mathrm{~N}$ na região do primeiro molar, e no presente estudo utilizouse carregamento oclusal de $300 \mathrm{~N}$. Esta diferença é dada pela metodologia aplicada, já que o modelo utilizado na correlação de imagens digitais apresenta maior rigidez do material (poliuretano), e para obter resultados coerentes do deslocamento e geração de tensões na superfície do modelo, necessita-se de carga elevadas.

A vantagem da colocação de mini-implantes posteriores em relação a distribuição de tensões vai de encontro com alguns estudos (de Freitas et al.' 2012; 
Hegazy et al., 2013; Gonçalves, Campos, Garcia, 2014) que avaliaram princípios biomecânicos e clínicos quando colocaram implantes posteriores na extensão distal de prótese parcial removível (PPR) classe I ou II de Kennedy. Tinham o intuito de avaliar as ocorrências na rotação posterior deste tipo de prótese e as tensões geradas ao suporte ósseo e tecidual, pela ocorrência de alavanca, ou seja, mecanismo biomecânico semelhante ao que ocorre em próteses overdentures, porém a prótese está anexada a implantes anteriores, e não a dentes naturais. Concluíram que existem vantagens em todos os aspectos analisados quando comparado a prótese parcial removíveis convencionais, por proporcionar melhor distribuição das cargas mastigatórias aos pilares, dentes e implantes, melhorando 0 conforto por causa do menor movimento de rotação.

No presente estudo, quando avaliou-se os modelos lateralmente com carga pontual, todos os grupos (1B, 1B2O, $2 \mathrm{O}$ e 4O) apresentaram tensão de compressão na região do primeiro molar, local que a carga estava sendo aplicada e, tensão de tração na região posterior aos implantes convencionais anteriores, principalmente nos grupos $2 \mathrm{O}$ e 40 , porém comparando estes dois grupos o grupo 40 a distribuição da tensão apresentava-se menos concentrada, certificando-se que os mini-implantes posteriores mais uma vez contribuiram na estabilidade da prótese e, fizeram com que a força aplicada fosse melhor distribuída por todo rebordo no grupo dos O'rings. Essa diferença, entre a distribuição de tensão dos modelos com barra/clipe e bola/O'ring, não vai de encontro com o estudo de Mazaro et al. (2011), no qual avaliaram padrões de tensões, pela metodologia de fotoelasticidade, comparando prótese parcial fixa a overdentures com quatro implantes anteriores, por sistemas de barra/clipe, barra/clipe com O'ring posteriores e bola/O'ring, com aplicação de carga pontual de $100 \mathrm{~N}$ nas regiões anterior e posterior dos modelos. Concluíram que o sistema barra/clipe apresentaram tensão imediata e de grande magnitude nos implantes ipsilateriais e o sistema bola/O'ring transferiram mínimo estresse aos implantes.

Celik e Uludag (2014) avaliaram tensões geradas em modelos fotoelásticos quando aplicada carga pontual no molar em próteses overdentures retidas por diferentes sistemas de retenção. Os modelos com componente ERA apresentaram menor estresse em torno dos implantes, porém utilizaram um sistema diferente de encaixe do sistema bola/O'ring utilizado neste estudo e, nos modelos com barra/clipe eles utilizaram em suas extremidades sistema adicional de encaixe, como 
sistema bola ou Easy Slot. Além disso, com o método de avaliação utilizado, fotoelasticidade, não é possível diferenciar as tensões em tração ou compressão, como é proporcionado no método CID utilizado neste estudo.

No modelo 1B2O houve a concentração de compressão na região anterior oposta a aplicação da carga, devido a diminuição de rotação do clipe somado a parada do movimento com os mini-implantes posteriores. O clipe é um componente menos resiliente e a barra tem um formato em $U$, limitando o movimento de rotação ântero-posterior. Desta forma, a pouca liberdade de movimentação, devido as paredes paralelas da barra e delimitação rotacional por parte dos mini-implantes com sistema bola/O'ring, fizeram com que ocorresse tensão de compressão da barra/clipe aos implantes e tecidos adjacentes e tracionamento da região posterior. $\mathrm{Na}$ situação que se aplicou carga pontual, os mini-implantes posteriores exerceram diferença positiva na distribuição de tensão, principalmente nos grupos com O'rings anteriores.

O presente estudo também avaliou a durabilidade e retenção dos componentes, pelo efeito do ensaio de fadiga acelerada progressiva na máquina de ciclagem termomecânica com valores de cargas compatíveis com a força de mordida sobre próteses removíveis (<150 N) (Koc, Dogan, Bek, 2010; Miyaura et al., 2000; Ferrario et al., 2004), chegando a valores maiores relatados na literatura (DeLong e Douglas, 1983; Rekow e Thompson, 2005). A carga cíclica é um teste de fadiga in vitro que simula o carregamento mecânico presente na cavidade oral em ambiente úmido ou seco, para investigar o efeito da força de degradação de um material dental (Gratton, Aquilino, Stanford, 1995; Binon e McHugh, 1996; Khraisat et al., 2006). A durabilidade dos componentes de implante é fortemente influenciada pela carga cíclica durante os ciclos mastigatórios (Wilding e Lewin, 1994; Richter, 1995). Para este estudo a taxa de sobrevivência das overdentures foi de 97,92\%, em razão de ocorrer falha em uma prótese do grupo 1B, após a ciclagem termomecânica com carga de $80 \mathrm{~N}$. Porém, presume-se que esta fratura ocorreu devido a pouca espessura de resina na região lingual onde se encontrava o clipe, e não por falha devido a carga estabelecida. Mesmo utilizando o ensaio de fadiga acelerada progressiva com diferentes cargas, pode-se relatar sucesso com a alta taxa de sobrevivência das overdentures e componentes, independentemente do sistema analisado. 
A perda de retenção do componente da prótese overdenture é a complicação mais comum para este tipo de prótese (Hemmings, Schmitt, Zarb, 1994). A comparação entre os grupos nos tempos estabelecidos revelou não haver diferença significativa na retenção de seus componentes entre os grupos 1B e 1B2O em todos os tempos analisados. Todavia, comparando os demais grupos, as diferenças foram significativas. Analisando as comparações entre os grupos 1B com 20 e 1B2O com 4O, os grupos com sistema barra/clipe obtiveram maior retenção que os grupos com O'ring, porém com queda de retenção ao longo do aumento da carga cíclica. O que está de acordo com os resultados encontrados em outro estudo (Shastry et al., 2016) no qual, compararam a força de retenção de três sistemas (bola/O'ring, barra/clipe, Locator), e concluíram que o sistema Locator apresentou a menor retenção entre os sistemas e a barra/clipe a maior força média retentiva no final do estudo. Em relação à retenção dos grupos dos O'rings, observa-se que o grupo com 4 O'rings apresentou maior força retentiva durante todo o ensaio. Verificando que para o grupo com O'rings, a presença dos mini-implantes posteriores aumentou a capacidade retentiva da prótese.

$\mathrm{Na}$ análise do comportamento dos componentes do mesmo grupo ao longo do tempo e frente a diferentes cargas, observou não haver diferença significativa na retenção para os grupos com O'rings, mostrando que a ciclagem não afetou a capacidade retentiva destes componentes. As borrachas são mais flexível e possuem maior resiliência comparados ao material do clipe, por isso ao aplicar força ela se comprime, ou se estende, com facilidade. Isso porque suas moléculas não estão em arranjo rígido, apresentando certo grau de mobilidade (Heckmann et al., 2001; Daas et al., 2008), ou seja, o ensaio da fadiga acelerada progressiva direciona a carga no sentindo vertical de oclusão sobre os attachments bola (esfera) ocasionando maior liberdade de recuperação da deformação tensional.

A força de retenção de três tipos de attachments foi analisada no estudo de Aroso et al. (2016), após ensaio de inserção e remoção, revelou haver diferenças significativas no valor médio da força de inserção ao longo do tempo, porém este valor aumentou significativamente, indicando haver um achatamento da parte interna do Teflon, o que leva à necessidade de maior força de inserção. Em relação a força de remoção não observaram diferenças significativas no valor médio ao longo do tempo, porém obtiveram diferenças significativas para diferentes angulações e attachment analisados. Consequentemente as diferenças encontradas neste estudo 
citado com o estudo presente são resultantes da utilização de modelos com implantes em diferentes angulações e tipos diferentes de sistema retentivo O'ring. Esta diferença de material do sistema retentivo é evidenciada também no estudo in vitro de Branchi et al. (2010), no qual avaliaram a força de retenção e resistência de quatro tipos diferentes retentores do sistema bola. Utilizaram Teflon na cápsula de metal, retentor de titânio, retentor de metal nobre e retentor O'ring utilizando um mesmo sistema bola $(2,20 \mathrm{~mm}$ de diâmetro e $4 \mathrm{~mm}$ de altura), usados em overdentures. Diante dos resultados os autores concluíram que diferentes retentores para o mesmo tipo de sistema bola, proporcionam diferentes valores retentivos. Os retentores de teflon e ouro mostraram maior retenção sem perda da mesma após três anos de uso e os retentores de titânio e O'ring, apresentaram contínua perda da retenção durante o uso.

Neste estudo, os grupos 1B e 1B2O, apresentaram diferenças significativas, no grupo 1B houve diferença significativa quando comparou o grupo nos tempos 2 e 3, com queda na capacidade retentiva, o mesmo acontecendo para o grupo 1B2O nos tempos 1 e 3. Contrariamente aos resultados de Botega et al. (2004), no qual avaliaram a força retentiva e a resistência à fadiga de dois sistemas de attachments (tipo barra-clipe e bola/O'ring) para overdentures de empresas diferentes. As amostras foram submetidas à fadiga mecânica, perfazendo 5.500 ciclos de inserção e remoção ( $f=0,8 \mathrm{~Hz}$ ) imersos em saliva artificial, sendo feitas aferições da força retentiva (Inicial, após 3000 e após 5500 ciclos). Contudo, comparando-se o mesmo tipo de attachment (barra e O'ring), entre empresas diferentes, constatou-se que ambos os sistemas apresentaram diferenças estatísticas significantes ao comparar os valores da força retentiva. Notou-se que o sistema barra/clipe da Conexão apresentou um acréscimo nos valores retentivos durantes os testes. A diferença de resultados com os dados deste estudo, pode ser devido a diferença do sistema clipe, pois para este estudo o clipe era de plástico e acoplado a uma cápsula metálica, obtendo maior liberdade de movimentação e por consequência, maior deformação ao longo do tempo. Porém, no estudo descrito acima, o clipe é retido diretamente na prótese com resina acrílica, proporcionando menor liberdade de flexão.

Deve-se considerar que nos estudos in vitro a tração é realizada sempre em posição ideal. O paciente nem sempre insere e remove a prótese no eixo correto, podendo causar deformação dos componentes. Esta consideração é semelhante a colocação de Setz, Lee, Engel (1998), que avaliou forças de retenção de diferentes 
attachments, utilizando o teste de fadiga (15000 ciclos), revelando que a maioria dos attachments mostraram pouca perda de retenção em comparação com as forças de retenção iniciais, porém sugere que os testes convencionais de fadiga com aplicação de cargas axiais não simulam adequadamente a fadiga clínica. E a maioria dos modelos mandibulares encontrados na literatura usa condições de contorno simplificadas. Por exemplo, fixar um ponto sobre a overdenture na direção vertical para simular a presença de um alimento é muito restritivo em comparação com a situação verdadeira (Menicucci et al., 1998). Para completar as avaliações referentes as retenções, foi realizado análise dos componentes por microscopia óptica, para verificar o perímetro circunferencial interno das borrachas e distância das paredes dos clipes, observando se houveram alterações estruturais desses componentes ao longo da ciclagem. Comparando os componentes do mesmo grupo nos tempos determinados, observa não haver diferença significativa na estrutura interna dos O'rings dos mini-implantes do grupo 1B2O, porém houve diferença significativa do clipe no grupo 1B2O. E no grupo 1B, ocorreu também significativa diferença na deformação do seu clipe, mostrando que o clipe sofre deformação estrutural, independente se tem ou não de mini-implantes posteriores.

Na comparação microscópica dos componentes entre os grupos, 1B e 1B2O nota-se haver diferença significativa na distância entre as paredes dos clipes em todos os tempos analisados, mostrando que a presença de mini-implantes posteriores não atua como diferencial e de forma positiva para estrutura interna dos clipes, ou seja, há deformação estrutural em todos os tempos analisados.

Comparando o perímetro das borrachas no mesmo grupo, observou não haver diferença significativa nem no grupo 20 e nem no grupo 40. Comparando os dois grupos, observou também não haver diferença na deformação estrutural entre os componentes anteriores em nenhum dos tempos estabelecidos. Supostamente, a não deformação dos componentes, mesmo com cargas elevadas, é devido ao tipo e formato de material dos O'rings. Notando, que para esta avaliação microscópica a colocação de mini-implantes posteriores não altera a estrutura interna borrachóide, devido a sua flexibilidade. Nos grupos com clipe, 1B e 1B2O, houve deformação estrutural dos clipes, deste modo os mini-implantes não minimizaram as injúrias causadas no clipe no grupo 1B2O. Em relação a estrutura das borrachas dos O'rings dos mini-implantes deste mesmo grupo, não foi registrado diferença significante da sua estrutura. Esta diferença deve-se ao tipo de attachment, o sistema bola possui 
resiliência universal e seu formato esférico faz com que os movimentos sejam mais livres em qualquer direção, já o formato da barra Dolder tem resiliência limitada, e há limitação na movimentação ântero-posterior e ocluso-cervical.

A influência das estruturas dos componentes é também descrita por Choi et al. (2016), no qual declara que a capacidade de retenção do O'ring é influenciada pela elasticidade do anel de borracha, pela conformação de altura do retentor e pela resistência de fricção entre eles, e assim, independentemente da angulação do implante, a retenção tende a diminuir gradualmente durante os ciclos de carga e inserção/remoção. O desgaste, a deformação e a degeneração podem resultar na perda da força de retenção, e além deste estudo citado, mais estudos mostram que quanto maior o aumento do desgaste no diâmetro do anel, maior é a perda de retenção (Rodrigues et al., 2009; Nagaoka et al., 1980). Além disso, a afirmação de Ortegón et al. (2009) sobre componentes, como clipe, vai de encontro com os resultados deste estudo, no qual revela que limitações na rotação durante os movimentos, causam desgastes desiguais, sendo um fator relevante na ocorrência da falta de adaptação correta e completa da prótese ao rebordo, no desgaste prematuro e perda de retenção. Analisando todos os dados e ensaios, pode-se dizer que a colocação de mini-implantes posteriores, quando se utiliza sistema bola/O'ring anterior, apresentaram resultados positivos tanto na distribuição das tensões, quanto na retenção ao longo do tempo analisado, e ainda se nota menos danos estruturais quando avaliados microscopicamente. Porém, nos grupos com sistema barra/clipe, a colocação ou não de mini-implantes posteriores, não alterou as condições biomecânicas das próteses, e notou-se que há alterações nas estruturas das paredes dos clipes nos dois grupos (1B e 1B2O). Possivelmente essas considerações estão relacionadas ao tipo e formato do material dos componentes avaliados, são materiais com características diferentes, ou seja, com resiliências diferentes.

Além dos fatores já citados, deve-se ressaltar a existência de algumas limitações deste estudo in vitro. Quando se realizou a simulação da mastigação pelo ensaio de ciclagem termomecânica, trabalhou-se com imersão em água e não em saliva. A saliva, assim como outros alimentos pode levar a alterações na estrutura da borracha e no clipe. Botega et al. (2004) também relatada que o ambiente oral, a composição da saliva e a temperatura poderia influenciar os resultados de um estudo in vitro. 
Analisando os resultados deste estudo, pode-se sugerir que a qualidade de vida de pacientes usuários de prótese total pode melhorar, com a colocação de implantes anteriores retidos a sistemas bola/O'ring e mini-implantes posteriores, já que este tipo de implante tem relatos científicos de ter resultados promissores na ancoragem óssea e resistência a cargas elevadas. Tornaria uma situação clínica favorável a estabilidade e retenção da prótese, e contribuiria para melhor distribuição das cargas mastigatórias pelo rebordo. A estimulação óssea e a não concentração de tensão em determinadas áreas, favoreceria a diminuição de reabsorção óssea. É um tratamento no qual grande parcela da população teria acesso, por não ser um tratamento dispendioso e invasivo, apresentando boa relação de custo-benefício. Até o momento a literatura apresenta a utilização de mini-implantes apenas para região anterior, e não havia estudos com a colocação dos mesmos na região posterior, por isso nota-se a necessidade de outros ensaios biomecânicos e clínicos que complementem as análises realizadas neste estudo. 
6. CONCLUSÃO 



\section{CONCLUSÃO}

Baseado na metodologia empregada e considerando as limitações deste estudo, conclui-se que:

1. Em relação à distribuição de tensões, nos grupos com barra/clipe as tensões com ou sem mini-implante foram semelhantes. Nos grupos com O'rings houve melhora na distribuição de tensão nas overdentures com mini-implantes posteriores;

2. No ensaio de fadiga acelerada progressiva, a taxa de sobrevivência das overdentures foi de 97,92\%;

3. A força de retenção do grupo barra/clipe foi maior quando comparada aos grupos com O'rings. A colocação de mini-implantes posteriores no grupo 40 elevou a força retentiva em todos os tempos analisados;

4. As imagens revelam que não há alteração dos componentes O'rings, no entanto, há deformação estrutural no clipe. 

REFERÊNCIAS 



\section{REFERÊNCIAS}

Adell R, Lekholm U, Rockler B, Branemark PI. A 15-year study of osseointegrated implants in the treatment of the edentulous jaw. Int J Oral Surg. 1981; 10(6):387-416.

Allen PF, McMilan AS. A longitudinal study of quality of life outcomes in older adults requesting implant prostheses and complete removable dentures. Clin. Oral Implants Res. 2003; 14:173-9.

Alsabeeha NH, Payne AG, Swain MV. Attachment systems for mandibular twoimplant overdentures: a review of in vitro investigations on retention and wear features.Int J Prosthodont. 2009; 22(5):429-40.

Amodio D, Broggiato G, Campana F, Newaz G. Digital speckle correlation for strain measurement by image analysis. Experimental Mechanics. 2003; 43(4):396-402.

Andersen E.; Saxegaard E.; Knutsen BM; Haanaes HR. A prospective clinical study evaluating the safety and effectiveness of narrow-diameter threaded implants in the anterior region of the maxilla. International J Oral and Maxillofac Implant. 2001; 16(2): 217-24.

Aroso C, Silva AS, Ustrell R, Mendes JM, Braga AC, Berastegui E, Escuin T. Effect of abutment angulation in the retetion and durability of three overdenture attchament systems: Na in vitro study. J Adv Prosthodont. 2016; 8(1):21-9.

Assunção WG, Barão VA, Tabata LF, Gomes EA, Delben JA, dos Santos PH. Biomechanics studies in dentistry: bioengineering applied in oral implantology. $J$ Craniofac Surg. 2009; 20(4):1173-7.

Aunmeungtong $W$, Kumchai $T$, Strietzel FP, Reichart PA, Khongkhunthian P . Comparative Clinical Study of Conventional Dental Implants and Mini Dental Implants for Mandibular Overdentures: A Randomized Clinical Trial. Clin Implant Dent Relat Res. 2017; 19(2):328-40.

Barão VA, Assunção WG, Tabata LF, Delben JA, Gomes EA, de Sousa EA, Rocha EP. Finite element analysis to compare complete denture and implant-retained overdentures with different attachment systems. J Craniofac Surg. 2009; 20(4):106671.

Barbier L, Schepers E. Adaptive bone remodeling around oral implants under axial and non-axial loading conditions in the dog mandible. Int $\mathrm{J}$ Oral Maxillofac Implants. 1997; 12:215-23.

Batenburg $\mathrm{RH}$, Meijer HJ, Raghoebar GM, Vissink A. Treatment concept for mandibular overdentures supported by endosseous implants: a literature review. Int J Oral Maxillofac Surg. 1998; 13:539-45.

Behneke A, Behneke N, d'Hoedt B. A 5-year longitudinal study of the clinical effectiveness of ITI solid-screw implants in the treatment of mandibular edentulism. Int J Oral Maxillofac Implants. 2002; 17(6):799-810. 
Ben-Ur Z, Aviv I, Maharshak B. Factors affecting displacement of free-end saddle removable partial dentures. Quintessence Int. 1991; 22(1):23-7.

Beumer J, Lewis SG. The Brånemark implant system: clinical and laboratory procedures. St Louis: Ishiyaku Euro America Inc. 1990; p.111.

Bidra AS, Almas K. Mini implants for definitive prosthodontic treatment: a systematic review. J Prost Dent. 2013; 109:156-64.

Bilhan $\mathrm{H}$, Mumcu $\mathrm{E}$, Arat $\mathrm{S}$. The comparison of marginal bone loss around mandibular overdenture-supporting implants with two different attachment types in a loading period of 36 months. Gerodontology. 2011; 28(1):49-57.

Binon PP, McHugh MJ. The effect of eliminating implant/abutment rotational misfit on screw joint stability. Int J Prosthodont. 1996; 9:511-9.

Botega DM, Mesquita MF, Henriques GEP, Vaz ELG. Retention force and fatigue strength of overdenture attachment systems. J Oral Rehabil. 2004; 31(9):884-9.

Branchi R, Vangi D, Virga A, Guertin G, Fazi G. Resistance to wear of four matrices with ball attachments for implant overdentures: A fadigue study. J Prosthodont. 2010; 19(8):614-9.

Bulard RA, Vance JB. Multi-clinic evaluation using mini-dental implants for long-term denture stabilization: a preliminary biometric evaluation. Compend Contin Educ Dent. 2005; 26:892-7.

Cardoso RG, Melo LA, Barbosa GA, Calderon PD, Germano AR, Mestriner W Junior, Carreiro AD. Impact of mandibular conventional denture and overdenture on quality of life and masticatory efficiency. Braz Oral Res. 2016; 30(1):102.

Celik G, Uludag B. Photoelastic stress analysis of various retention mechanisms on 3-implant-retained mandibular overdentures. J Prosthet Dent. 2007; 97:229-35.

Celik G1, Uludag B. Effect of the number of supporting implants on mandibular photoelastic models with different implant-retained overdenture designs. J Prosthodont. 2014; 23(5):374-80.

Chen J, Ahmad R, Suenaga H, Li W, Swain M, Li Q. A comparative study on complete and implant retained denture treatments: a biomechanics perspective. J Biomech. 2015; 48(3):512-9.

Chen KW, Lin TM, Liu PR, Ramp LC, Lin HJ, Wu CT, Pan YH. An analysis of the implant-supported overdenture in the edentulous mandible. J Oral Rehabil. 2013; 40:43-50.

Chiapasco M, Zaniboni M, Boisco M. Augmentation procedures for the rehabilitation of deficient edentulous ridges with oral implants. Clin Oral Implants Res. 2006; $17(2): 136-59$. 
Choi JW, Bae JH, Jeong CM, Huh JB. Retention and wear behaviors of two implant overdenture stud-type attachments at differentimplant angulations. J Prosthet Dent. 2016, Nov 15 [Epub ahead of print].

Cordaro L, Torsello F, Mirisola Di Torresanto V. Retrospective evaluation of mandibular incisor replacement with narrow neck implants. Clinical Oral Implants Res. 2006; 17(6):730-35.

Cune $M$, Burgers $M$, van Kampen $F$, de Putter $C$, van der Bilt A. Mandibular overdentures retained by two implants: 10-year results from a crossover clinical trial comparing ball-socket and bar-clip attachments. Int J Prosthodont. 2010; 23(4):3107.

Daas M, Dubois G, Bonnet AS, Lipinski P, Rignon-Bret C. A complete finite element model of a mandibular implant-retained overdenture with two implants: comparison between rigid and resilient attachment configurations. Med Eng Phys. 2008; $30(2): 218-25$.

das Neves FD, Fones D, Bernardes SR, do Prado CJ, Neto AJ. Short implants an analysis of longitudinal studies. Int J Oral Maxillofac Implants. 2006; 21(1):86-93.

Dashti MH, Atashrazm P, Emadi MI, Mishaeel S, Banava S. The effects of two attachment types on the stresses introduced to the mandibular residual ridge: a 3D finite element analysis. Quintessence Int. 2013; 44(8):585-90.

Davarpanah M.; Martinez H; Tecucianu JF, Celletti R; Lazzara R. Small-diameter implants: indications and contraindications. J Esthet Dent. 2000; 12(4):186-94.

de Freitas RF, de Carvalho Dias K, da Fonte Porto Carreiro A, Barbosa GA, Ferreira MA. Mandibular implant-supported removable partial denture with distal extension: a systematic review. J Oral Rehabil. 2012; 39:791-8.

de Kok IJ, Chang KH, Lu TS, Cooper LF. Comparison of three-implant-supported fixed dentures and two-implant-retained overdentures in the edentulous mandible: a pilot study of treatment efficacy and patient satisfaction. Int $\mathrm{J}$ Oral Maxillofac Implants. 2011; 26(2):415-26.

de Souza Batista VE, Verri FR, Almeida DA, Santiago Junior JF, Lemos CA, Pellizzer EP. Finite element analysis of implant-supported prosthesis with pontic and cantilever in the posterior maxilla. Comput Methods Biomech Biomed Engin. 2017; 20(6):66370.

de Souza RF, Ribeiro AB, Della Vecchia MP, Costa L, Cunha TR, Reis AC, Albuquerque RF Jr. Mini vs. Standard Implants for Mandibular Overdentures: A Randomized Trial. J Dent Res. 2015; 94(10):1376-84.

Della Vecchia MP. Ensaio clínico randomizado de overdentures mandibulares retidas por mini-implantes ou implantes convencionais: análise de parâmetros clínicos e custo. (Tese). Ribeirão Preto: Universidade de São Paulo, Faculdade de Odontologia de Ribeirão Preto; 2015. 
DeLong R, Douglas WH. Development of an artificial oral environment for the testing of dental restoratives: bi-axial force and movement control. J Dent Res. 1983; $62(1): 32-6$.

Diggle PJ, Liang KY, Seger SL. Analysis of Longitudinal Data. New York, NK: Oxford University Press.1995.

Dudic A, Mericske-Stern R. Retention mechanisms and prosthetic complications of implant-supported mandibular overdentures: long-term results. Clin Implant Dent Relat Res. 2002; 4(4):212-9.

Eisenman E. Implant retained suprastructures passivated to a stress free fit through spark erosion. Quintessenz Zahntechnik Implantologie. 1997; 2:1440.

Feine JS, Carlsson GE, Awad MA, Chehade A, Duncan WJ, Gizani S, et al. The McGill consensus statement on overdentures. Mandibular two-implant overdentures as first choice standard of care for edentulous patients. Gerodontology. 2002; 19:3-4.

Ferrario VF, Sforza C, Zanotti G, Tartaglia GM. Maximal bite forces in healthy young adults as predicted by surface electromyography. J Dent. 2004; 32(6):451-7.

Fortin T, Bosson JL, Isidori M, Blanchet E. Effect of flapless surgery on pain experienced in implant placement using an image-guided system. Int $\mathrm{J}$ Oral Maxillofac Implants. 2006; 21:298-304.

Geertman ME, van Waas MA, van't Hof MA, Kalk W. Denture satisfaction in a comparative study of implant-retained mandibular overdentures: a randomized clinical trial. Int J Oral Maxillofac Implants. 1996; 11:194-200.

Glantz PO, Nilder K. Biomechanical aspects of prosthetic implant-borne reconstructions. J Periodontol. 2000; 17(1):119-24.

Gonçalves TM, Campos CH, Garcia RC. Implant retention and support for distal extension partial removable dental prostheses: satisfaction outcomes. J Prosthet Dent. 2014; 112(2)334-9.

Gotfredsen K, Holm B. Implant-supported mandibular overdentures retained with ball or bar attachments: a randomized prospective 5-year study. Int J Prosthodont. 2000; 13(2):125-30.

Gratton DG, Aquilino SA, Stanford CM. Micromotion and dynamic fatigue properties of the dental implant-abutment interface. J Prosthet Dent. 1995; 85:47-52.

Griffiths TM, Collins CP, Collins PC. Mini dental implants: an adjunct for retention, stability, and comfort for the edentulous patient. Oral Surg Oral Med Oral Pathol Oral Radiol Endod. 2005; 100(5):81.

Gustafson H, Siegmund G, Cripton P. Comparison of Strain Rosettes and Digital Image Correlation for Measuring Vertebral Body Strain. J Biomech Eng. 2016; 138(5):054501. 
Hagi D, Deporter DA, Pilliar RM, Arenovich T. A targeted review of study outcomes with short $(<$ or $=7 \mathrm{~mm}$ ) endosseous dental implants placed in partially edentulous patients. J Periodontol. 2004; 75(6):798-804.

Harder S, Wolfart S, Egert C, Kern M. Three-year clinical outcome of single implantretained mandibular overdentures--results of preliminary prospective study. J Dent. 2011; 39(10):656-61.

Heckmann, SM, Winter, W, Meyer, M, Weber, HP, Wichmann, M.G. Overdenture attachment selection and the loading of implant and denture-bearing area. Part 2: A methodical study using five types of attachment. Clinical Oral Implants Research, $2001 ; 12(6): 640-7$.

Hegazy SA, Elshahawi IM, Elmotayam H. Stresses induced by mesially and distally placed implants to retain a mandibular distal-extension removable partialoverdenture: a comparative study. Int J Oral Maxillofac Implants. 2013; 28(2):403-7.

Hemmings KW, Schmitt A, Zarb GA. Complications and maintenance requirements for fixed prostheses and overdentures in the edentulous mandible: a 5-year report. Int J Oral Maxillofac Implants, 1994; 9:191-6.

Hong HR, Pae A, Kim Y, Paek J, Kim HS, Kwon KR. Effect of implant position, angulation, and attachment height on peri-implant bone stress associated with mandibular two-implant overdentures: a finite element analysis. Int J Oral Maxillofac Implants. 2012; 27:69-76.

Hu, X., Maiti, R., Liu, X., Gerhardt, L-C., Lee, Z.S., Byers, R., Franklin, S.E., Lewis, R., Matcher, S.J., Carré, M.J. Skin Surface and sub-surface strain and deformation imaging using optical coherence tomography and digital image correlation. In: Proceedings of the International Society for Optics and Photonics, SPIE San Francisco, 2016; 13-8.

Ichikawa $T$, Horiuchi $M$, Wigianto $R$, Matsumoto $N$. In vitro study of mandibular implant-retained overdentures: the influence of stud attachments on load transfer to the implant and soft tissue. Int J Prosthodont. 1996; 9:394-9.

Jofré J, Cendoya P, Munoz P. Effect of splinting mini-implants on marginal bone loss: a biomechanical model and clinical randomized study with mandibular overdentures. Int J Oral Maxillofac Implants. 2010b; 25(6):1137-44.

Jofré J, Hamada T, Nishimura M, Klattenhoff. The effect of maximum bite force on marginal bone loss of mini-implants supporting a mandibular overdenture: a randomized controlled trial. Clin Oral Impl Res. 2010a; 21:243-9.

Karbach J, Hartmann S, Jahn-Eimermacher A, Wagner W. Oral Health-Related Quality of Life in Edentulous Patients with Two- vs Four-Locator-Retained Mandibular Overdentures: A Prospective, Randomized, Crossover Study. Int J Oral Maxillofac Implants. 2015; 30(5):1143-8.

Karl M, Graef F, Heckmann S, Taylor T. A methodology to study the effects of prosthesis misfit over time: an in vivo model. Int J Oral Maxillofac Implants. 2009; 24(4):689-94. 
Kayumi S, Takayama Y, Yokoyama A, Ueda N. Effect of bite force on occlusal adjustment of dental implants in occlusal pressure distribution: comparison of three bite forces in occlusal adjustment. Int J Implante Dent. 2015; 1(1):14.

Kenney R, Richards MW. Photoelastic stress patterns produced by implant-retained overdentures. J Prosthet Dent. 1998; 80:559-64.

Khraisat A, Baqain ZH, Smadi L, Nomura S, Miyakawa O, Elnasser Z. Abutment rotational displacement of external hexagon implant system under lateral cyclic loading. Clin Implant Dent Relat Res. 2006; 8:95-9.

Khuder T, Yunus N, Sulaiman E, Ibrahim N, Khalid T, Masood M. Association between occlusal force distribution in implant overdenture prostheses and residual ridge resorption. J Oral Rehabil. 2017; 44(5):398-404.

Koc D, Dogan A, Bek B. Bite force and influential factors on bite force measurements: a literature review. Eur J Dent. 2010; 4(2):223-32.

Kordatzis K, Wright PS, Meijer HJ. Posterior mandibular residual ridge resorption in patients with conventional dentures and implant overdentures. Int J Oral Maxillofac Implants. 2003; 18:447-52.

Kotsovilis S, Fourmousis I, Karoussis IK, Bamia C. A systematic review and metaanalysis on the effect of implant length on the survival of rough-surface dental implants. J Periodontol. 2009; 80(11):1700-18.

Kronstrom M, Davis B, Loney R, Gerrow J, Hollender L. Satisfaction and Clinical Outcomes Among Patients with Immediately Loaded Mandibular Overdentures Supported by One or Two Dental Implants: Results of a 5-Year Prospective Randomized Clinical Trial. Int J Oral Maxillofac Implants. 2017; 32(1):128-36.

Lachmann S, Kimmerle-Müller E, Gehring K, Axmann D, Gomez-Roman G, Watzek $\mathrm{G}$, Weber $\mathrm{H}$. A comparison of implant-supported, bar- or ball-retained mandibular overdentures: a retrospective clinical, microbiologic, and immunologic study of 10 edentulous patients attending a recall visit. Int J Prosthodont. 2007; 20(1):37-42.

Li J, Fok AS, Satterthwaite J, Watts DC. Measurement of the full-field polymerization shrinkage and depth of cure of dental composites using digital image correlation. Dent Mater. 2009; 25:582-8.

Liddelow L, Henry P. The immediately loaded single implant-retained mandibular overdenture: a 36-month prospective study. Int J Prosthodont. 2010; 23(1):13-21.

Maiti R, Gerhardt LC, Lee ZS, Byers RA, Woods D, Sanz-Herrera JA, Franklin SE, Lewis R, Matcher SJ, Carré MJ. In vivo measurement of skin surface strain and sub-surface layer deformation induced by natural tissue stretching. J Mech Behav Biomed Mater. 2016; 62:556-69.

Maló P.; Nobre MA. Implants (3.3 mm diameter) for the rehabilitation of edentulous posterior regions: a retrospective clinical study with up to 11 Years of follow-up. Clin Implant Dent Relat Res. 2011; 13(2):95-103. 
Mazaro JV, Filho HG, Vedovatto E, Pellizzer EP, Rezende MC, Zavanelli AC. Evaluation of stress patterns produced by implant-retained overdentures and implantretained fixed partial denture. J Craniofac Surg. 2011; 22(6):2153-7.

McCullagh P and Nelder J. Generalized Linear Models. Chapman and Hall, London, 2ed, 1989.

Menani LR. Análise fotoelástica das tensões geradas por diferentes planejamentos de próteses parciais fixas cimentadas sobre implantes cone morse (Tese). Ribeirão Preto (SP): Universidade de São Paulo, Faculdade de Odontologia de Ribeirão Preto; 2009.

Menicucci G, Lorenzetti M, Pera P, Preti G. Mandibular implant-retained overdenture: finite element analysis of two anchorage systems. Int $\mathrm{J}$ Oral Maxillofac Implants, 1998; 13:369-76.

Miyaura K, Morita M, Matsuka Y, Yamashita A, Watanabe T. Rehabilitation of biting abilities in patients with different types of dental prostheses. J Oral Rehabil. 2000; 27(12):1073-6.

Müller F, Hernandez M, Grütter L, Aracil-Kessler L, Weingart D, Schimmel M. Masseter muscle thickness, chewing efficiency and bite force in edentulous patients with fixed and removable implant-supported prostheses: a cross-sectional multicenter study. Clin Oral Implants Res. 2012; 23:144-50.

Mumcu E, Bilhan $\mathrm{H}$, Geckili O. The influence of healing type on marginal bone levels of implants supporting mandibular overdentures: a randomized clinical study. Indian J Dent Res. 2012; 23(4):514-8.

Naert I, Alsaadi G, van Steenberghe D, Quirynen M. A 10-year randomized clinical trial on the influence of splinted and unsplinted oral implants retaining mandibular overdentures: Peri-implant outcome. Int J Oral Maxillofac Implants. 2004; 19(5):695702.

Naert I, Quirynen M, Theuniers G, van Steenberghe D. Prosthetic aspects of osseointegrated fixtures supporting overdentures: a 4-year report. J Prosthet Dent. $1991 ; 65: 671-80$.

Nagaoka E, Nagayasu Y, Yamashita H, Matsushiro H, Okuno Y. Study of retention in attachments for overdenture. (II) O-ring attachment. J Osaka Univ Dent Sch. 1980; 20:215-26.

Ochiai KT, Williams BH, Hojo S, Nishimura R, Caputo AA. Photoelastic analysis of the effect of palatal support on various implant-supported overdenture designs. J Prosthet Dent. 2004; 91:421-7.

Ohkubo C, Kobayashi M, Suzuki Y, Hosoi T. Effect of implant support on distalextension removable partial dentures: in vivo assessment. Int $\mathrm{J}$ Oral Maxillofac Implants. 2008; 23(6):1095-101. 
Ortegón SM, Thompson GA, Agar JR, Taylor TD, Perdikis D. Retention forces of spherical attachments as a function of implant and matrix angulation in mandibular overdentures: an in vitro study. J Prosthet Dent. 2009; 101(4):231-8.

Palanca M, Tozzi G, Cristofolini L. The use of digital image correlation in the biomechanical area: a review. Int. Biomech. 2016; 3(1):1-21.

Paranhos HFO, Muglia VA, da Silva CHL, de Souza RF. Manual Laboratorial de Prótese Total. Universidade de São Paulo, Faculdade de Odontologia de Ribeirão Preto - Departamento de Materiais Dentários e Prótese. Ribeirão Preto, 2006.

Payant L, Williams JE, Zwemer JD. Survey of dental implant practice. J Oral Implantol. 1994; 20:50-8.

Peixoto RF, Macedo AP, Martinelli J, Faria AC, Tiossi R, Ribeiro RF, de Mattos MD. A Digital Image Correlation Analysis of Strain Generated by 3-Unit Implant-Supported Fixed Dental Prosthesis: An In Vitro Study. Implant Dent. 2017; Apr 5. [Epub ahead of print]

Pistilli R, Felice P, Cannizzaro G, Piatelli M, Corvino V, Barausse C, Buti J, Soardi E, Esposito M. Posterior atrophic jaws rehabilitated with prostheses supported by 6 $\mathrm{mm}$ long $4 \mathrm{~mm}$ wide implants or by longer implants in augmented bone. One-year post-loading results from a pilot randomised controlled trial. Eur $\mathrm{J}$ Oral Implantol. 2013; 6(4):359-72.

Prakash V, D'Souza M, Adhikari R. A comparison of stress distribution and flexion among various designs of bar attachments for implant overdentures: a three dimensional finite element analysis. Indian J Dent Res. 2009; 20(1):31-6.

Provenza F. Desenhista de Máquinas, Engenharia. Ed Pro Tec Escola, 1986.

Quek CE, Tan KB, Nicholls JI. Load fatigue performance of a single-tooth implant abutment system: effect of diameter. International J Oral Maxillofac Implants. 2006; 21(6):929-36.

Rached RN, de Souza EM, Dyer SR, Ferracane JL. Dynamic and static strength of an implant-supported overdenture model reinforced with metal and nonmetal strengtheners. J Prosthet Dent. 2011; 106(5):297-304.

Rekow D, Thompson VP. Near-surface damage--a persistent problem in crowns obtained by computer-aided design and manufacturing. Proc Inst Mech Eng H. 2005; 219(4):233-43.

Richter EJ. In vivo vertical forces on implants. Int J Oral Maxillofac Implants. 1995; 10:99-108.

Rocchietal I, Fontana F, Simion M. Clinical outcomes of vertical bone augmentation to enable dental implant placement: A systematic review. J Clin Periodontol. 2008; 35(8):203-15. 
Rodrigues RC, Faria AC, Macedo AP, Sartori IA, deMattosMda G, Ribeiro RF. An in vitro study of non-axial forces upon the retention of an O-ring attachment. Clin Oral Implants Res. 2009; 20(12):1314-9.

Rutkunas $\mathrm{V}$, Mizutani $\mathrm{H}$, Takahashi $\mathrm{H}$. Influence of attachment wear on retention of mandibular overdenture. J Oral Rehabil. 2007; 34:41-51.

Sahin S, Cehreli MC, Yalçin E. The influence of functional forces on the biomechanics of implant-supported prostheses - a review. J Dent. 2002; 30(7-8): 271-82.

SAS Institute Inc., SAS/STAT® User's Guide, Version 6, Fourth Edition, Volume 1, Cary, NC: SAS Institute Inc., 1989. 943 pp.

Šćepanović $M$, Todorović A, Marković A, Patrnogić $V$, Miličić $B$, Moufti AM, Mišić T. Immediately loaded mini dental implants as overdenture retainers: 1-Year cohort study of implant stability and peri-implant marginal bone level. Ann Anat. 2015; 199:85-91.

Schall R. Estimation in generalized linear models with random effects. Biometrika. 1991; 78(4):719-27.

Setz I, Lee SH, Engel E. Retention of prefabricated attachments for implant stabilized overdentures in the edentulous mandible: an in vitro study. J Prosthet Dent, 1998; 80:323-29.

Shastry T, Anupama NM, Shetty S, Nalinakshamma M. An in vitro comparative study to evaluate the retention of different attachment systems used in implant-retained overdentures. J Indian Prosthodont Soc. 2016; 16(2):159-66.

Stellingsma C, Vissink A, Raghebar GM. Surgical dilemmas. Choice os treatment in cases of extremely atrophic mandibles. Ned Tijdschr Tandheelkd. 2008; 115(12): 655-60.

Sutton MA, Orteu JJ, Schreier HW. Image correlation for shape, motion and deformation meaasurements. New York: Springer Science, 2009.

Suzuki Y, Kono K, Shimpo H, Sato Y, Ohkubo C. Clinical evaluation of implantsupported removable partial dentures with a stress-breaking attachment. Implant Dent. 2017; Apr 3. [Epub ahead of print]

Thomason JM, Feine J, Exley C, Moynihan P, Muller F, Naert I, et al. Mandibular two implant-supported overdenture as the first choice standart of care for edentulous patients- the York Consensus Statement. Br Dent J. 2009; 22; 207(4):185-6.

Thomason JM, Kelly SA, Bendkowski A, Ellis JS. Two implant retained overdenturea review of the literature supporting the McGill and York Consensus Statement. J Dent. 2012; 40(1):22-34.

Tiossi R, de Torres EM, Rodrigues RC, Conrad HJ, de Mattos Mda G, Fok AS, Ribeiro RF. Comparison of the correlation of photoelasticity and digital imaging to 
characterize the load transfer of implant-supported restorations. J Prosthet Dent. $2014 ; 112(2): 276-84$.

Tiossi R, Lin L, Rodrigues RC, Heo YC, Conrad HJ, de Mattos Mda G, et al. Digital image correlation analysis of the load transfer by implant-supported restorations. $J$ Biomech. 2011; 44(6):1008-13.

Tiossi R. Efeitos do uso de próteses múltiplas implantossuportadas, unidas e isoladas, nas tensões geradas em áreas posteriores da mandíbula. Ribeirão Preto, (Tese). Ribeirão Preto: Universidade de São Paulo, Faculdade de Odontologia de Ribeirão Preto, 2010.

Toth A, Hasan I, Bourauel C, Mundt T, Biffar R, Heinemann F. The influence of implant body and thread design of mini dental implants on the loading of surrounding bone: a finite element analysis. Biomed Tech (Berl). 2017; Mar 30. [Epub ahead of print]

van Steenberghe D. A retrospective multicenter evaluation of the survival rate of osseointegrated fixtures supporting fixed partial prostheses in the treatment of partial edentulism. J Prosthet Dent. 1989; 61:217-23.

Weinberg LA. The biomechanics of force distribution in implant-supported prostheses. Int J Oral Maxillofac Implants. 1993; 8(1):19-31.

Wilding RJ, Lewin A. The determination of optimal human jaw movements based on their association with chewing performance. Archives Oral Biology. 1994; 39:333-43.

Wiskott HWA, Belser UC. Lack of osseointegration of smooth titanium surfaces: a working hypothesis based on strains generated in the surrounding bone. Clin Oral Implants Res. 1999; 10:429-44.

Wright PS, Glantz PO, Randow K, Watson RM. The effects of fixed and removable implant-stabilised prostheses on posterior mandibular residual ridge resorption. Clin Oral Implants Res. 2002; 13(2):169-74.

Yamaguto OT, Vasconcelos MHF. Determinação das medidas dentárias mésiodistais em indivíduos brasileiros leucodermas com oclusão normal. R Dental Press Ortodon Ortop Facial, 2005; 10(5):99-107.

Zeger SL, Liang KY. Longitudinal data analysis using generalized linear models. Biometrica. 1986; 73:13-22. 
APÊNDICES 

Apêndice 1. Dados originais da resistência de retenção $(\mathrm{N})$ em relação aos grupos e aos tempos no ensaio de tração.

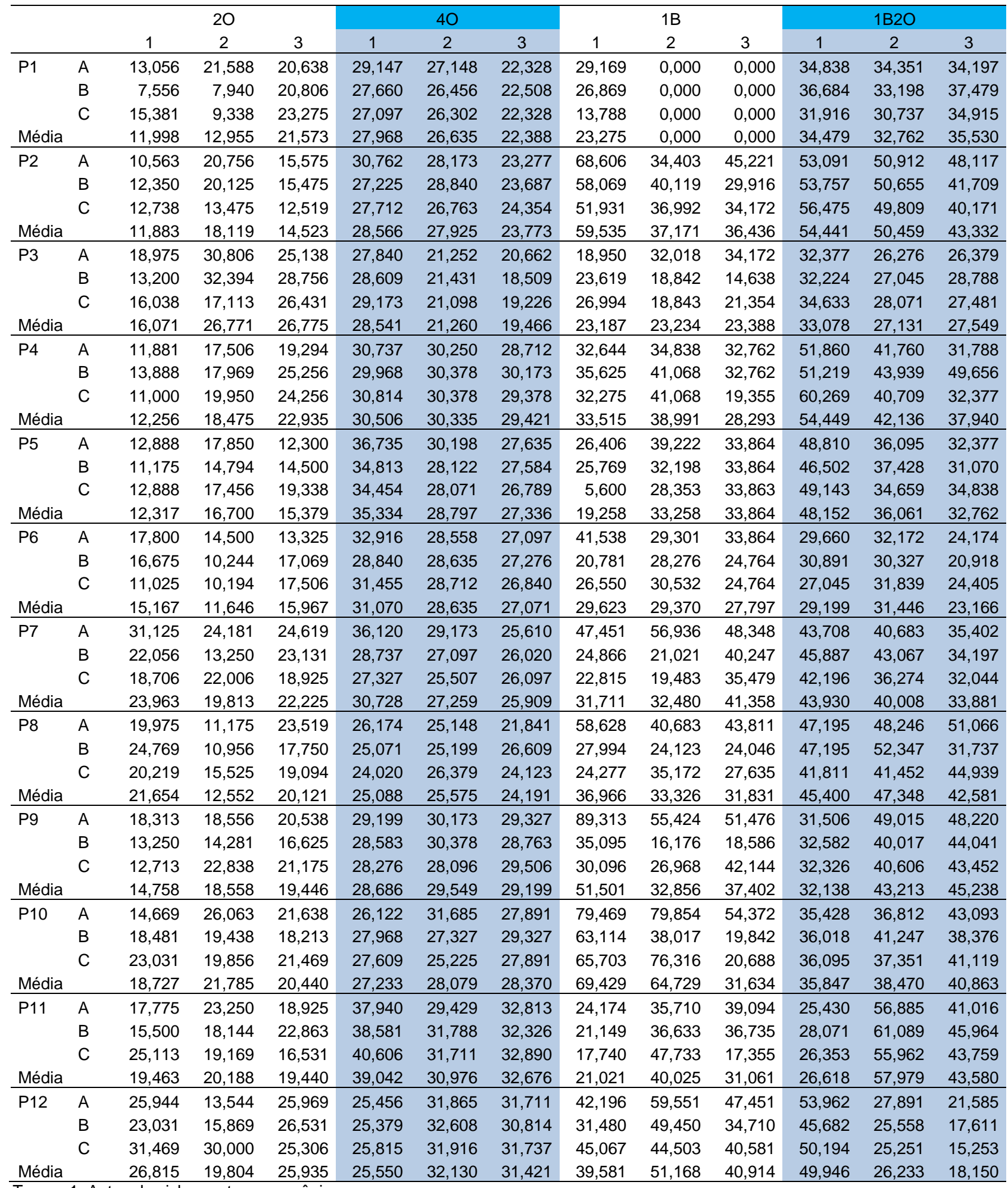

Tempo 1. Antes da ciclagem termomecânica

Tempo 2. Após $200 \mathrm{~N}$

Tempo 3. Após $380 \mathrm{~N}$

O'rings. A, B, C, D

P. Corpos de prova 
Apêndice 2. Dados originais do perímetro do O'ring ( $\mathrm{mm})$ e distância entre as paredes do clipe (mm) em relação aos grupos e aos tempos na análise de microscopia óptica.

\begin{tabular}{|c|c|c|c|c|c|c|c|c|c|c|c|c|c|c|c|c|c|c|}
\hline & & & & 20 & & & & & & & & 4 & 0 & & & & & \\
\hline & 1 & & & 2 & & & & 1 & & & & 2 & 2 & & & 3 & & \\
\hline & A & B & A & B & A & B & A & B & C & D & A & B & C & D & A & B & C & D \\
\hline P1 & 5,050 & 5,223 & 5,308 & 5,225 & 5,476 & 5,239 & 5,033 & 5,173 & 3,914 & 3,754 & 5,236 & 5,321 & 4,622 & 3,826 & 5,307 & 5,131 & 4,534 & 3,859 \\
\hline P2 & 5,353 & 5,226 & 5,231 & 5,305 & 5,255 & 5,295 & 5,314 & 5,346 & 3,845 & 3,799 & 5,353 & 5,422 & 3,853 & 3,937 & 5,319 & 5,506 & 3,880 & 4,022 \\
\hline P3 & 5,364 & 5,300 & 5,350 & 5,166 & 5,504 & 5,464 & 5,273 & 5,083 & 3,847 & 4,083 & 5,389 & 5,063 & 3,735 & 4,078 & 5,389 & 5,063 & 3,747 & 4,108 \\
\hline P4 & 5,308 & 5,223 & 5,215 & 5,266 & 5,077 & 5,266 & 5,340 & 5,409 & 4,236 & 4,124 & 5,397 & 5,300 & 3,720 & 3,855 & 5,456 & 5,508 & 3,830 & 3,941 \\
\hline P5 & 5,495 & 5,537 & 5,171 & 5,064 & 5,170 & 5,411 & 5,229 & 5,193 & 4,126 & 4,328 & 5,211 & 5,235 & 4,470 & 4,220 & 5,296 & 5,058 & 4,800 & 4,272 \\
\hline P6 & 5,274 & 5,356 & 5,259 & 5,311 & 5,286 & 5,380 & 5,328 & 5,304 & 4,140 & 3,768 & 5,340 & 5,369 & 3,919 & 3,850 & 5,332 & 5,287 & 4,015 & 3,910 \\
\hline P7 & 5,194 & 5,285 & 4,065 & 4,067 & 5,204 & 5,131 & 5,073 & 5,125 & 3,493 & 3,908 & 5,139 & 5,231 & 3,579 & 3,986 & 5,198 & 4,920 & 3,969 & 3,668 \\
\hline P8 & 5,324 & 5,348 & 5,214 & 5,273 & 5,321 & 5,359 & 5,360 & 5,328 & 3,746 & 3,963 & 5,262 & 5,323 & 3,972 & 4,020 & 5,325 & 5,342 & 4,094 & 3,736 \\
\hline P9 & 5,452 & 5,230 & 5,449 & 5,235 & 5,300 & 5,290 & 5,369 & 5,144 & 3,790 & 4,080 & 5,276 & 5,141 & 4,532 & 4,190 & 5,266 & 5,207 & 4,035 & 4,218 \\
\hline P10 & 5,373 & 5,335 & 5,097 & 5,245 & 4,902 & 5,126 & 5,375 & 5,424 & 3,694 & 3,821 & 5,439 & 5,092 & 3,814 & 3,920 & 5,414 & 5,154 & 3,830 & 3,815 \\
\hline P11 & 5,226 & 5,245 & 5,095 & 5,559 & 4,943 & 5,220 & 5,311 & 5,312 & 4,195 & 4,280 & 5,289 & 5,244 & 4,114 & 4,185 & 5,300 & 5,185 & 4,155 & 4,173 \\
\hline $\mathrm{P} 12$ & 5,339 & 5,215 & 5,323 & 5,333 & 5,193 & 5,152 & 5,302 & 5,353 & 3,816 & 3,798 & 5,276 & 5,207 & 4,055 & 4,096 & 5,327 & 5,322 & 4,275 & 4,073 \\
\hline Média & 5,313 & 5,294 & 5,148 & 5,171 & 5,219 & 5,278 & 5,276 & 5,266 & 3,904 & 3,976 & 5,301 & 5,246 & 4,032 & 4,014 & 5,327 & 5,224 & 4,097 & 3,983 \\
\hline DP & 0,118 & 0,093 & 0,356 & 0,366 & 0,183 & 0,111 & 0,112 & 0,116 & 0,227 & 0,201 & 0,086 & 0,109 & 0,342 & 0,140 & 0,068 & 0,178 & 0,310 & 0,193 \\
\hline $\begin{array}{l}\text { Tempo } 2 \\
\text { Tempo } 3 \\
\text { O'rings. } \\
\text { P. Corpo }\end{array}$ & A, Apó & $\begin{array}{l}\text { a cicla } \\
30 \mathrm{~N} \\
30 \mathrm{~N} \\
0\end{array}$ & & & & & & & & & & & & & & & & \\
\hline
\end{tabular}




\begin{tabular}{|c|c|c|c|c|c|c|c|c|c|c|c|c|c|c|c|c|c|c|c|c|c|c|c|c|}
\hline & \multicolumn{9}{|c|}{ 1B } & \multicolumn{15}{|c|}{ 1B2O } \\
\hline & \multicolumn{3}{|c|}{1} & \multicolumn{3}{|c|}{2} & \multicolumn{3}{|c|}{3} & \multicolumn{5}{|c|}{1} & \multicolumn{5}{|c|}{2} & \multicolumn{5}{|c|}{3} \\
\hline & Clipe & Clipe & Clipe & Clipe & Clipe & Clipe & Clipe & Clipe & Clipe & C & D & Clipe & Clipe & Clipe & C & D & Clipe & Clipe & Clipe & C & D & Clipe & Clipe & Clipe \\
\hline P1 & 1,781 & 1,833 & 1,869 & 0,000 & 0,000 & 0,000 & 0,000 & 0,000 & 0,000 & 4,140 & 3,723 & 1,728 & 1,753 & 1,728 & 3,995 & 6,747 & 1,810 & 1,790 & 1,750 & 6,584 & 4,397 & 2,064 & 1,808 & 1,880 \\
\hline P2 & 1,777 & 1,751 & 1,751 & 1,920 & 1,856 & 1,877 & 1,963 & 1,849 & 1,799 & 4,162 & 3,837 & 1,976 & 1,728 & 1,848 & 3,900 & 3,666 & 1,929 & 1,749 & 1,910 & 3,478 & 3,805 & 2,064 & 1,808 & 1,880 \\
\hline P3 & 1,742 & 1,724 & 1,777 & 1,806 & 1,842 & 1,785 & 1,856 & 1,906 & 1,806 & 3,849 & 3,822 & 1,768 & 1,768 & 1,720 & 3,957 & 3,943 & 1,690 & 1,740 & 1,650 & 4,030 & 3,639 & 1,856 & 2,048 & 1,856 \\
\hline P4 & 1,715 & 1,697 & 1,688 & 1,840 & 1,805 & 1,796 & 1,799 & 1,749 & 1,764 & 3,635 & 4,119 & 1,816 & 1,808 & 1,752 & 4,230 & 4,078 & 1,890 & 1,850 & 1,830 & 4,124 & 3,893 & 1,848 & 1,990 & 1,872 \\
\hline P5 & 1,751 & 1,733 & 1,742 & 1,724 & 1,787 & 1,751 & 1,778 & 1,764 & 1,756 & 3,850 & 3,859 & 1,792 & 1,960 & 1,792 & 3,893 & 3,879 & 1,900 & 1,890 & 1,810 & 3,728 & 3,790 & 1,944 & 1,992 & 1,832 \\
\hline P6 & 1,715 & 1,760 & 1,706 & 1,893 & 1,831 & 1,813 & 1,863 & 1,870 & 1,806 & 3,816 & 3,811 & 1,880 & 1,832 & 1,768 & 3,735 & 3,761 & 1,900 & 1,970 & 1,820 & 4,055 & 4,414 & 1,992 & 1,968 & 1,824 \\
\hline P7 & 1,742 & 1,680 & 1,698 & 1,734 & 1,671 & 1,689 & 1,906 & 1,721 & 1,771 & 4,022 & 3,699 & 1,672 & 1,584 & 1,616 & 2,479 & 3,740 & 1,816 & 1,792 & 1,768 & 3,981 & 3,544 & 1,936 & 2,056 & 1,808 \\
\hline P8 & 1,633 & 1,636 & 1,662 & 1,760 & 1,716 & 1,769 & 1,799 & 1,813 & 1,714 & 4,096 & 3,920 & 1,696 & 1,640 & 1,640 & 4,033 & 4,031 & 1,760 & 1,792 & 1,736 & 3,945 & 3,729 & 1,832 & 1,832 & 1,800 \\
\hline P9 & 1,618 & 1,618 & 1,609 & 1,609 & 1,636 & 1,582 & 1,778 & 1,785 & 1,735 & 3,940 & 3,925 & 1,728 & 1,752 & 1,728 & 4,251 & 3,631 & 1,928 & 2,080 & 1,904 & 3,631 & 4,248 & 1,776 & 1,816 & 1,744 \\
\hline P10 & 1,615 & 1,545 & 1,641 & 1,698 & 1,680 & 1,689 & 1,733 & 1,778 & 1,742 & 3,626 & 4,329 & 1,712 & 1,712 & 1,736 & 3,811 & 4,647 & 1,752 & 1,848 & 1,744 & 3,822 & 3,673 & 1,944 & 2,096 & 1,904 \\
\hline P11 & 1,676 & 1,606 & 1,606 & 1,733 & 1,733 & 1,751 & 1,664 & 1,671 & 1,742 & 3,900 & 3,845 & 1,736 & 1,720 & 1,696 & 3,662 & 3,792 & 1,912 & 1,816 & 1,872 & 3,815 & 3,579 & 1,832 & 1,848 & 1,832 \\
\hline $\mathrm{P} 12$ & 1,580 & 1,545 & 1,563 & 1,689 & 1,621 & 1,856 & 1,671 & 1,892 & 1,899 & 3,913 & 3,759 & 1,704 & 1,712 & 1,688 & 4,585 & 4,752 & 2,017 & 1,776 & 1,841 & 4,324 & 3,432 & 1,792 & 1,856 & 1,768 \\
\hline Média & 1,695 & 1,677 & 1,693 & 1,764 & 1,598 & 1,613 & 1,651 & 1,650 & 1,628 & 3,912 & 3,887 & 1,767 & 1,747 & 1,726 & 3,878 & 4,222 & 1,859 & 1,841 & 1,803 & 4,126 & 3,845 & 1,907 & 1,927 & 1,833 \\
\hline DP & 0,069 & 0,089 & 0,085 & 0,093 & 0,510 & 0,514 & 0,527 & 0,524 & 0,515 & 0,175 & 0,177 & 0,088 & 0,095 & 0,063 & 0,508 & 0,873 & 0,093 & 0,099 & 0,076 & 0,807 & 0,332 & 0,099 & 0,109 & 0,048 \\
\hline
\end{tabular}

